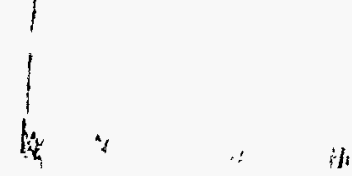

DOE/mc/32260 - -3

DE-FC21-95MC32260--3

\title{
Pegasus International, Inc. Coating Removal Systems
}

\author{
Topical Report \\ February 1998
}

Work Performed Under Contract No.: DE-FC21-95MC32260

For

U.S. Department of Energy

Office of Environmental Management Office of Technology Development 1000 Independence Avenue Washington, DC 20585
U.S. Department of Energy Office of Fossil Energy Federal Energy Technology Center P.O. Box 880

Morgantown, West Virginia 26507-0880

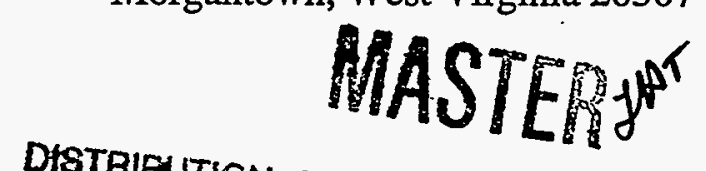

Dts

Operating Engineers National HAZMAT Program

1293 Airport Road

Beaver, West Virginia 25813 


\section{Disclaimer}

This report was prepared as an account of work sponsored by an agency of the United States Government. Neither the United States Government nor any agency thereof, nor any of their employees, makes any warranty, express or implied, or assumes any legal liability or responsibility for the accuracy, completeness, or usefulness of any information, apparatus, product, or process disclosed, or represents that its use would not infringe privately owed rights. Reference herein to any specific commercial product, process, or service by trade name, trademark, manufacturer, or otherwise does not necessarily constitute or imply its endorsement, recommendation, or favoring by the United States Government or any agency thereof. The views and opinions of authors expressed herein do not necessarily state or reflect those of the United States Government or any agency thereof. 


\section{DISCLAIMER}

Portions of this document may be illegible electronic image products. Images are produced from the best available original document. 


\section{PEREIVED SEP 031998 \\ PEGASUS INTERNATIONAL, INC. COATING REMOVAL SYSTEM (PCRS) (CONCRETE FLOOR) TABLE OF CONTENTS}

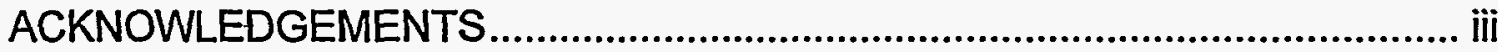

EXECUTIVE SUMMARY ................................................................................ iv

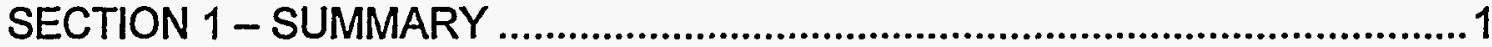

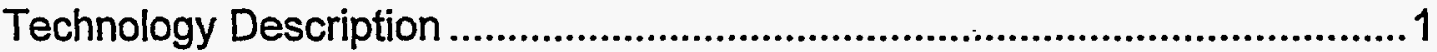

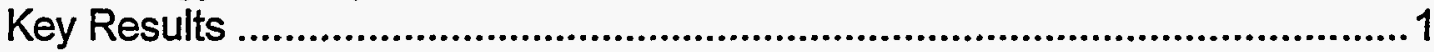

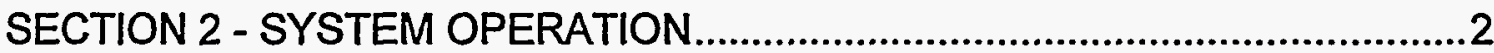

SECTION 3 - HEALTH AND SAFETY EVALUATION .......................................2

General Health and Safety Concerns ......................................................2

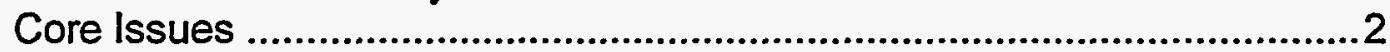

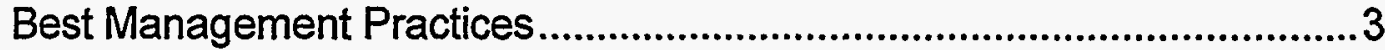

Industrial Hygiene Monitoring ...................................................................... 3

Human Factors Interface ....................................................................

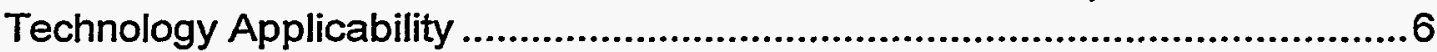

SECTION 4 - EMERGENCY RESPONSE/PREPAREDNESS .........................6

SECTION 5 - REGULATORY POLICY ISSUES..............................................6

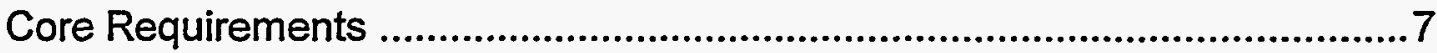

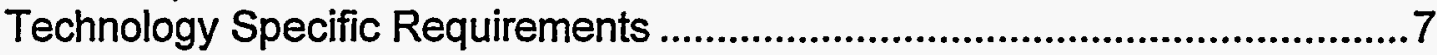

Best Management Practices.....................................................................8

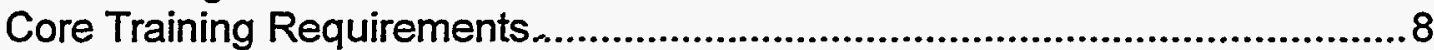

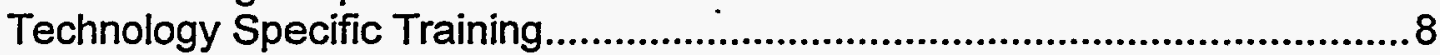

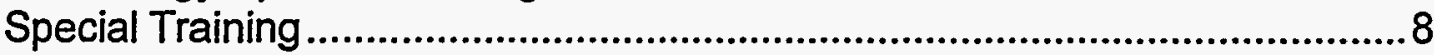

Best Management Practice Training .........................................................

SECTION 6 - OPERATIONAL CONSIDERATIONS AND

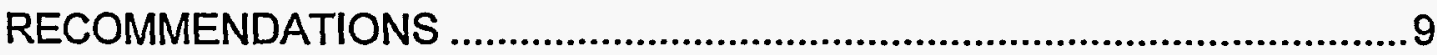

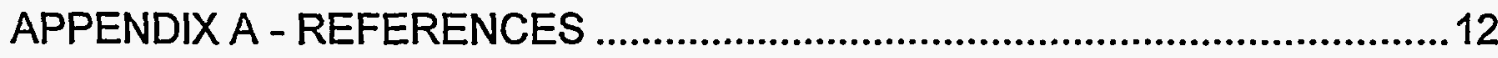

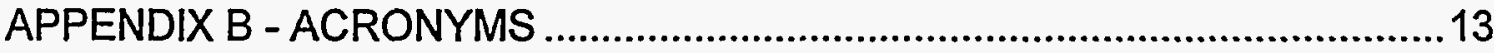




\section{ACKNOWLEDGEMENTS}

The human factors assessment of Pegasus International, Inc., Coating Removal System (Concrete Floor), was conducted under support of the U.S. Department of Energy's Federal Energy Technology Center, under cooperative agreement DE-FC2195MC32260 with the Operating Engineers National Hazmat Program. The Operating Engineers National Hazmat Program would like to thank the following people for their participation on the "research action team" and the professional expertise they provided for this assessment:

Barbara McCabe Ralph Pascarella Daniel Timmerman
Operating Engineers National Hazmat Program Operating Engineers Local Union 30

Operating Engineers National Hazmat Program 


\section{EXECUTIVE SUMMARY}

The Pegasus Coating Removal System (PCRS) was demonstrated at Florida International University (FIU) where it was being evaluated for efficiency and cost. In conjunction with the FIU testing demonstration, a human factors assessment was conducted to assess the hazards and associated safety and health issues of concern for workers utilizing this technology.

The PCRS is a chemical paste that is applied to the surface using a brush, roller, or airless sprayer. Two types of PCRS are available. PCRS-5/7 is an organic solvent mixture primarily used for chemically resistant coatings and PCRS-ST1 and PCRS-1, which is an alkaline mixture of calcium hydroxide, magnesium hydroxide, and sodium hydroxide. PCRS-ST1 and PCRS-1 are primarily used for alkyd/latex coating removal. The type of PCRS used depends on the type and thickness of the coating, and the type of substrate material. In order to determine the type of PCRS for the job, the required thickness of the paste, and the dwell time, a test area of approximately one square foot is used. Based on the performance of the system over this one square foot area, the operational parameters can be determined. Dwell time, which is the time required for the chemical to have its desired effect, can range from several hours to 24 hours. After the type of PCRS, thickness, and dwell time have been determined, a laminated backed material is placed on top of the chemical paste to slow down the drying process and to provide a mechanism to strip-off the chemical. After the dwell time is reached, the chemical substrate can be removed. Scrapers may be used to break-loose the layers as necessary or to break-loose the layers that are not removed when the laminated paper is picked up. Residue may also be cleaned off of the surface with a damp sponge with an agitating motion, absorbent sponges, or a vacuum, as needed. The paint and removal agent is then placed in drums for disposal at a later time.

During the human factors assessment of the PCRS, the PCRS- $5 / 7$ was used for the removal of the concrete slab coating.

During the assessment sampling was conducted for organic vapors and general observational techniques were conducted for ergonomics. General observational techniques for ergonomics showed the potential for some ergonomic problems during application and removal of the chemical. The chemical was applied to the concrete slab by two methods: (1) long-handled squeegee-type applicators and (2) spatulas. Using the long-handled applicator required both workers to constantly bend over because the handles were straight and slightly short for them. This constant bending, although slight, has the potential to cause lower back sprain/strain. An adjustable ergonomically designed handle would help alleviate this stress on the back. Using the spatula to apply the chemical requires the worker to either kneel or stoop. This has the potential to cause strain/sprain to the knees, ankles, lower/upper legs, and back. Removal of the 
chemical presents the same types of ergonomic stressors because removal requires the use of either a shovel and/or a paint scraper.

The organic vapor readings during application and removal of the PCRS ranged from 0.0 to $6.0 \mathrm{ppm}$. These measurements indicate that organic vapors are present during application and removal of the PCRS. Monitoring for the specific ingredients needs to be considered on a job-by-job site-by-site basis. The low levels of organic vapor have the potential to cause headache, skin irritation, and respiratory tract irritation. Therefore, workers may need to utilize appropriate PPE when applying and removing the PCRS regardless of the ppm levels recorded.

Recommendations for improved worker safety and health during application and removal of the PCRS include: 1 . work practices that reflect avoidance of exposure or reducing the risk of exposure; 2 . assuring all PPE and equipment are compatible with the chemicals being used; 3 . work practices that reduce the worker's need to walk on the slippery surface caused by the chemical or the use of special anti-slip soles; 4 . careful control of overspray (if a spray application is used); and 5. the use of ergonomically designed long-handled tools to apply and remove the chemical (to alleviate some of the ergonomic concerns). 


\section{PEGASUS INTERNATIONAL, INC. COATING REMOVAL SYSTEM (PCRS) (CONCRETE FLOOR) \\ Human Factors Assessment}

\section{SECTION 1 - SUMMARY}

\section{TECHNOLOGY DESCRIPTION}

The Pegasus Coating Removal System (PCRS) technology was tested and is being evaluated at Florida International University (FIU) as a baseline technology. In conjunction with FIU's evaluation of efficiency and cost, this report covers the hazard analysis and safety evaluation. PCRS is a commercially available technology and has been used for various projects at locations throughout the country.

The PCRS is a chemical paste that is applied to the surface using a brush, roller, or airless sprayer. The type of PCRS used depends on the type and thickness of the coating, the age of the coating, and the type of substrate material. A laminated backed material is placed on top of the chemical paste to slow down the drying process and to provide a mechanism to strip-off the material. In order to determine the type of PCRS, the required thickness of the paste, and the dwell time, a test area of approximately one square foot is used. Based on the performance of the chemical over this one square foot area, the operational parameters can be determined. Dwell time can range from several hours to 24 hours.

\section{KEY RESULTS}

The safety and health evaluation during the testing demonstration focused on two main areas: exposure to the organic chemicals and ergonomics. Air sampling with a photo ionization detector (PID) showed low exposure values but there is concern for skin exposures. Further testing for the individual ingredients of the organic based solvent is recommended. In addition, it is recommended that sampling be conducted in an enclosed environment. The outdoor environment where the testing demonstration took place may cause the results to be inapplicable to enclosed operating environments, where it is feasible that the exposure levels would be greater. Ergonomic stressors are potentially significant. Other safety and health issues found were heat stress, slipping/fall hazards, and environmental concerns from accidentally spreading the chemical to areas outside the immediate exclusion zone. 


\section{SECTION 2 - SYSTEM OPERATION}

The PCRS is a chemical paste that is applied to the surface using a brush, roller, or airless sprayer. Two types of PCRS are available. PCRS-5/7 is an organic solvent mixture primarily used for chemically resistant coatings and PCRS-ST1 and PCRS-1, which are alkaline mixtures of calcium hydroxide, magnesium hydroxide, and sodium hydroxide. PCRS-ST1 and PCRS-1 are primarily used for alkyd/latex coating removal. The type of PCRS used depends on the type and thickness of the coating and the type of substrate material. In order to determine the type of PCRS for the job, the required thickness of the paste, and the dwell time, a test area of approximately one square foot is used. Based on the performance of the chemical over this one square foot area, the operational parameters can be determined. Dwell time, which is the time required for the chemical to have its desired effect, can range from several hours to 24 hours. After the type of PCRS, thickness, and dwell time have been determined, a laminated backed material is placed on top of the chemical paste to slow down the drying process and to provide a mechanism to strip-off the material. After the dwell time is reached, the chemical substrate can be removed. Scrapers may be used to break-loose the layers as necessary or to break-loose the layers that are not removed when the laminated paper is picked up. Residue may also be cleaned off of the surface with a damp sponge with an agitating motion, absorbent sponges, or a vacuum, as needed. The paint and removal agent is then placed in drums for disposal at a later time.

During the human factors assessment of the PCRS, the PCRS- $5 / 7$ was used for the removal of the concrete floor coating.

\section{SECTION 3 - HEALTH AND SAFETY EVALUATION}

\section{GENERAL SAFETY AND HEALTH CONCERNS}

Personnel where the PCRS is being used need to be concerned with safety and health issues. Issues that personnel need to be cognizant of may be divided into two categories. Core issues are those that are based on current safety and health regulatory requirements. Best management practices are related to issues that are not based on current safety and health regulations, but are key elements in preventing worker injury and illness on the job.

Safety and health issues of concern with PCRS included:

\section{Core lssues:}

- Work Practices (housekeeping) - The process of applying the chemical is difficult to accomplish without the worker coming in contact with it. Training workers to 
apply good work practices would assist in alleviating this concern. In addition, the need for stringent housekeeping must be addressed.

- Personal Protective Equipment (PPE) - The PPE utilized during the application of the PCRS needs to be compatible with the chemicals being used.

- Hazard Communication - The material safety data sheet (MSDS) for the chemical being used must be available in accordance with 29 CFR 1910.1200 . In addition, workers must be trained on its specific hazards.

- Exposure to Chemical - There is potential for the worker to be exposed to the chemical being used for coating removal. Exposure may occur during application and removal, from the chemical splashing during application, or by the worker coming in direct contact with the chemical. This will be discussed in greater detail in the Industrial Hygiene section of this report.

\section{Best management practices:}

- Ergonomics - There are ergonomic stressors that have the potential to cause stress/strain to the lower and upper back, shoulders, arms, and knees due to the bending, stooping, $k$ kneeling postures required for application and removal of the PCRS.

- Slipping Hazards - The chemical applied to the concrete pad made the surface extremely slippery. The workers almost fell several times during both application and removal of the chemical.

- Heat Stress - Workers are subjected to an increase in heat stress due to the need to utilize chemical protective PPE during the application and removal of the PCRS. The user will need to develop a heat stress program for the environment in which the chemical removal system is being used, taking into consideration any PPE that may need to be utilized, ambient temperatures, etc.

\section{INDUSTRIAL HYGIENE MONITORING}

During the testing demonstration with the PCRS, sampling was conducted for organic vapors. In addition, the wet-bulb globe temperature was monitored to evaluate heat stress. Observational evaluation was conducted for ergonomics. 
Through general observational techniques the potential for ergonomic problems was evaluated during the testing demonstration. The chemical was applied to the concrete

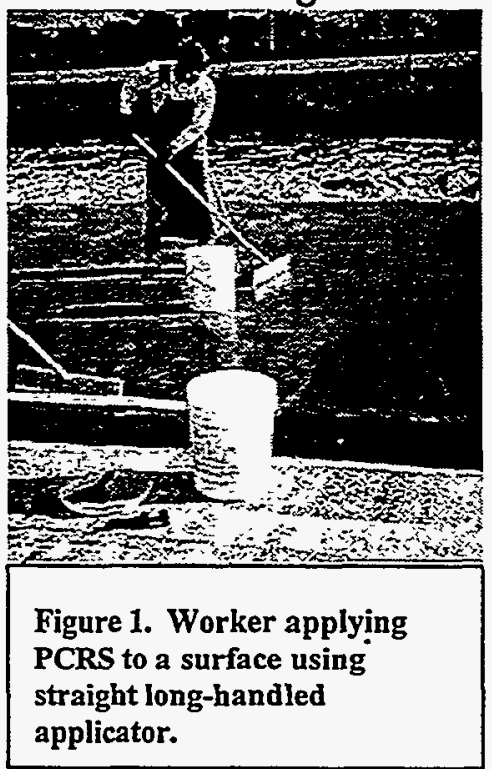
slab by two methods: (1) longhandled squeegee-type applicators and (2) spatulas. Using the long-handled applicator required both workers to constantly bend over because the handles were straight and slightly short for them. This constant bending, although slight, has the potential to cause lower back sprain/strain. An adjustable ergonomically designed handle would help alleviate this stress on the

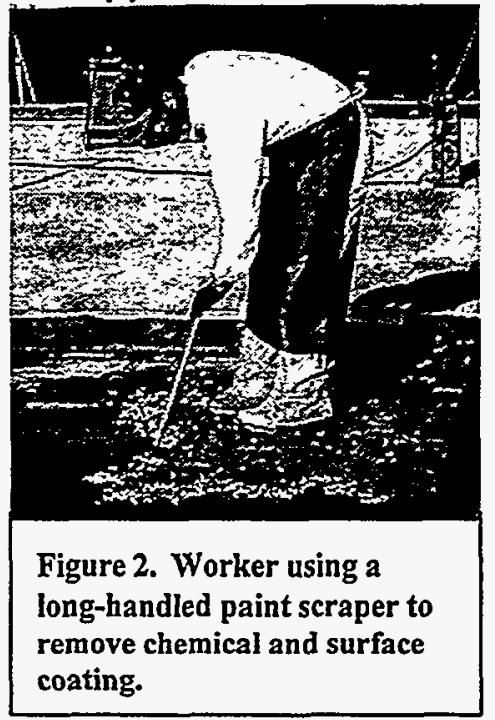
back. Using the spatula to apply the chemical requires the worker to either kneel or stoop. This has the potential to cause strain/sprain to the knees, ankles, lower/upper legs, and back. Removal of the chemical presents the same types of ergonomic stressors because removal requires the use of either a shovel and/or a paint scraper.

Heat stress parameters were monitored using a Quest QuestTemp ${ }^{\circ} 15$ Heat Stress Monitor. The wet-bulb globe temperature was used to determine the work/rest regimen in accordance with the American Conference of Governmental Industrial Hygienist (ACGIH) recommendations. In accordance with ACGIH guidelines, the wet-bulb globe temperature was adjusted for the type of clothing, including PPE, that the worker was wearing. While heat stress will be increased when wearing PPE, the overall heat stress response will vary from worker to worker. Each situation in which the current technology is used will need to be evaluated for the heat stress potential, taking into consideration the wet-bulb globe temperature, PPE in use, physical condition of the worker, and amount of worker acclimatization.

The PCRS applied to the concrete slab for coating removal was the PCRS-5/7, the organic solvent mixture. According to the MSDS supplied by Pegasus Inc., the mixture contains 10-25\% Dibasic Ether, 20-50\% N-Methyl-2-Pyrrolidone, 20-40\% Aluminum Silicate, $1-5 \%$ Nonylphenol Ethoxylate, and $10-30 \%$ Non-hazardous ingredients. The dibasic ether has a manufacturer's recommended exposure limit of $10 \mathrm{mg} / \mathrm{m}^{3}$ and the aluminum silicate has an OSHA permissible exposure limit (PEL) of $15 \mathrm{mg} / \mathrm{m}^{3}$ and an ACGIH threshold limit value (TLV) of $10 \mathrm{mg} / \mathrm{m}^{3}$, as total dust. Dust was not a concern during the application and removal of the PCRS since it was a wet process. Therefore, organic vapor monitoring was conducted during application and removal. Monitoring 
was conducted using an MSA Passport Photo lonization Detector (PID). The Passport is a real-time monitor that measures organic vapors in parts per million (ppm). The PID does not identify the specific organic vapor but identifies the presence of any organic vapor.

The organic vapor readings during application and removal of the PCRS ranged from 0.0 to $6.0 \mathrm{ppm}$. Since it cannot be determined if these levels present the potential for overexposure, sampling for the individual ingredients in the PCRS-5/7 needs to be conducted. It does, however, indicate that organic vapors are present. Even at low levels, the organic vapor odor could be detected, especially when down wind of the concrete pad. These low levels have the potential to cause headache, skin irritation, and respiratory tract irritation. Therefore, workers may need to utilize the appropriate PPE when applying and removing the PCRS regardless of the ppm levels recorded.

Environmental conditions such as temperature, radiant heat load, and ventilation in the area can affect how rapidly the organic solvent mixture vaporizes and therefore, the exposure level at a given time. The exposure level (vapor build-up) will also be affected by the size of the area where it is being used. The PCRS was applied and removed in an open outdoor environment during the testing demonstration. There is the potential for the organic vapor levels to be significantly higher in an enclosed environment. A monitoring plan will need to be developed for the specific site and job where the chemical is being used.

\section{HUMAN FACTORS INTERFACE}

The MSDS for PCRS- $5 / 7$ recommends the following PPE be used when applying or removing it: chemical goggles, butyl rubber gloves, impervious apron, and boots. It states that respiratory protection is not normally needed, but for spray applications or where exposures may be excessive, a National Institute of Occupational Safety and Health (NIOSH) approved organic vapor respirator may be used.

Depending on the application and removal methods used, a greater level of PPE may be required. (This was evident during the testing demonstration when the tyvek suit being worn under the impervious apron was soaked with the chemical.) This may include a chemically impervious suit instead of only an apron and a full face air purifying respirator. This has the potential to cause a decrease in visibility, mobility, and tactile sensation for the workers, as well as an increase in heat stress. Additionally, because of the extremely slippery surface condition, boots with special anti-slip soles need to be used. 


\section{TECHNOLOGY APPLICABILITY}

After the coating has been removed from the surface by the chemical, it will need to be assured that the surface is "clean" of both PCRS residue and whatever contaminant was originally present on the surface.

Consideration will also need to be given to the wastes that are generated. Wastes may include different combinations: the PCRS itself and the PCRS combined with the surface coating being removed and its contaminants.

\section{SECTION 4 - EMERGENCY RESPONSE/PREPAREDNESS}

The use of the PCRS technology would not be applicable for use in an emergency response situation.

Emergency response/preparedness must be part of every hazardous waste site safety and health plan. In addition to credible site emergencies, site personnel must plan for credible emergencies in connection with the PCRS.

All precautions used when responding to an emergency situation at the site will apply. The PCRS- $5 / 7$ is flammable and is $85 \%$ volatile by volume. Its products of decomposition may include carbon dioxide, carbon monoxide, and oxides of nitrogen. In accordance with the MSDS a fire involving the PCRS- $5 / 7$ should be extinguished with water spray or fog, foam, carbon dioxide, or dry chemical. This information needs to be conveyed to both on-site and off-site emergency response personnel before a situation occurs that involves the PCRS.

\section{SECTION 5 - REGULATORYIPOLICY ISSUES}

The site safety and health personnel where the PCRS technology is being used need to be concerned with safety and health regulations applicable to the issues discussed above. Regulations that apply may be divided into four categories. Core requirements are those regulations that would apply to any hazardous waste work site, regardless of the type of job. Technology specific requirements are those regulations that apply due to the specific technology being used. Special requirements are standards and policies that are specific to the technology itself and are required by reference in a regulation. Best management practices are not required, but are recommended by organizations such as the American National Standards Institute (ANSI), NIOSH, Department of Energy (DOE), National Fire Protection Association (NFPA), etc. These regulations/standards may include but not be limited to the following: 
Core requirements:

$\checkmark \quad$ OSHA 29 CFR 1926.25 Housekeeping

OSHA 29 CFR 1910.141 Sanitation (1910.141(a)(3) covers housekeeping)

- OSHA 29 CFR 1926 Subpart Z Toxic and Hazardous Substances

- OSHA 29 CFR 1910 Subpart Z Toxic and Hazardous Substances

$-\quad$ OSHA 29 CFR 1926.59 Hazard Communication

- OSHA 29 CFR 1910.1200 Hazard Communication

$-\quad$ OSHA 29 CFR 1926.64 Process Safety Management of Highly Hazardous Chemicals

$-\quad$ OSHA 29 CFR 1910.119 Process Safety Management of Highly Hazardous Chemicals

- OSHA 29 CFR 1926.65 Hazardous Waste Operations and Emergency $\therefore$ Response

- OSHA 29 CFR 1910.120 Hazardous Waste Operations and Emergency Response

- Occupational Safety and Health Act 1970(5)(a)(1) General Duty Clause Technology Specific Requirements:

- OSHA 29 CFR 1926.103-Respiratory Protection

- OSHA 29 CFR 1910.134 Respiratory Protection

OSHA 29 CFR 1926.102 Eye and Face Protection

- OSHA 29 CFR 1910.133 Eye and Face Protection

- OSHA 29 CFR 1926.28 Personal Protective Equipment

- OSHA 29 CFR 1910.132 General Requirements (Personal Protective Equipment) 
- OSHA 29 CFR 1926.23 First Aid and Medical Attention

- OSHA 29 CFR 1910.151 Medical Services and First Aid

\section{Best Management Practices:}

- ACGIH Threshold Limit Values for Chemical Substances and Physical Agents and Biological Exposure Indices

In addition to the above regulations and policies, it is imperative that all workers have appropriate and adequate training for the task and associated safety and health hazards. Training that would be required may be divided into four categories. Core training is that which is required for anyone entering a hazardous waste site to perform work, regardless of the type of job. Technology specific training is that training which is specific to the technology and required by safety and health standards. Special training is that which is specific to the technology to assure the worker is adequately trained for the task, but is not necessarily required by safety and health standards. Best management practices are trainings that while not mandated by health and safety standards, provide information and knowledge to the worker that will allow the worker to perform his/her job safely. Training to be applied may include but not be limited to:

\section{Core Training Requirements:}

$\checkmark \quad$ HAZWOPER

$-\quad$ HAZCOM

Technology Specific Training:

- Respiratory Protection

- Personal Protective Equipment

\section{Special training:}

Job specific training for chemical application and removal

\section{Best Management Practice training:}

- Ergonomics (proper lifting, bending, stooping, kneeling, safe shoveling techniques) 
Heat stress (learning to recognize signs and symptoms)

CPR/First Aid/Emergency Response/Blood-borne Pathogens

Construction Safety (OSHA 500) and or General Industry Safety (OSHA 501)

\section{SECTION 6 - \\ OPERATIONAL CONSIDERATIONS \& RECOMMENDATIONS}

Recommendations made here for improved worker safety and health take into consideration the use of the PCRS-5/7. Specific recommendations include:

Work practices are of critical importance for worker exposure to the chemical being applied to and removed from the coated surface. Application and removal is a difficult process to accomplish without the worker coming in contact with the chemical. Training the worker to use the best work practices possible will help to alleviate some of these concerns. Examples of the types of work practices that are of concern include:

1. Close all containers, both storage and waste, when not in use. This will keep the chemical from adding to the vapor load in the area where the work is being conducted.

2. Assure all PPE chosen is compatible with the chemical. An impervious apron (as recommended by the MSDS) is of no use if the material it is made of is incompatible with the chemical being used. Additional consideration needs to be given to the PPE used under the apron. If the chemical comes in contact with the garment under the apron and it is not compatible with the chemical, it is of no use.

3. All workers need to be trained in the specific hazards associated with the chemical and work practices should reflect avoidance of exposure or reducing the risk of exposure. For example, the organic solvent mixture is an eye irritant. Workers wearing goggles should never touch or remove the goggles while in the work area, nor should they touch or remove the goggles until their gloves that are contaminated with chemical are removed and their hands have been decontaminated. Additionally, touching the goggles with contaminated gloves increases the likelihood of getting the chemical on the face and head. 
4. The chemical made the surface extremely slippery. Training workers to apply and remove the chemical to eliminate the need to walk on the area where chemical has been applied would reduce the risk of slipping and falling. Additionally, the waste containers should be placed in a location where workers do not have to walk on the slippery surface to get to them. This would also reduce the potential to have the chemical tracked onto "clean" areas. Workers should never move from the work area (exclusion zone) to the clean area (support zone) without proper decontamination of the worker taking place.

PPE must be chosen that is compatible with the hazards and the job.

Chemically impervious suits, aprons, gloves, and boots will be useless if the material they are made from is not compatible with the chemical. Consideration must also be given to special hazards that may be encountered. For example, normal chemical protective boots are inadequate during PCRS application and removal because of the extremely slippery surface conditions it creates. Special anti-slip soles need to be considered.

- Due to the open outdoor environment in which the testing demonstration took place and therefore, the organic vapor monitoring, it is recommended that additional monitoring be conducted when the PCRS is applied and removed in an enclosed environment similar to environments in which it would be used at a hazardous waste clean-up site. Additionally, monitoring needs to be conducted, as appropriate, for the individual ingredients of the organic solvent mixture.

- Using the spatulas to apply and paint scrapers to remove the chemical caused

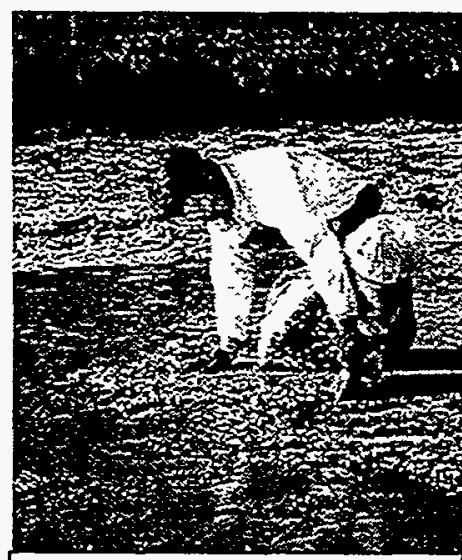

Figure 3. Worker kneeling on surface using a shorthandled paint scraper to remove chemical and surface coating. the workers to come into direct contact with the chemical that was on the surface either by kneeling on the surface or by stooping and balancing with a hand on the surface. This increases the workers potential for exposure as well as increases the ergonomic stressors placed on the worker. It is recommended that application and removal only be done with longhandled (ergonomically designed) tools and standard operating procedures (SOP's) be developed that do not permit the worker to come into direct contact with the surface where the chemical has been applied.

In addition, using the spatulas and paint scrapers which had short handles cause the chemical to come 
up over the tool and handle onto the worker's gloves. This increases the potential for exposure and would be eliminated by the use of long-handled tools.

- There is concern with the ergonomic stressors placed on the worker during both application and removal of the chemical. The chemical was applied to the concrete slab by two methods: (1) long-handled squeegee-type applicators; and (2) spatulas. Using the long-handled applicator required both workers to constantly bend over because the handles were straight and slightly short for them. This constant bending, although slight, has the potential to cause lower back sprain/strain. Using the spatula to apply the chemical requires the worker to either kneel or stoop. This has the potential to cause strain/sprain to the knees, ankles, and lower/upper legs. Removal of the chemical presents the same types of ergonomic stressors because removal requires the use of a shovel and/or a paint scraper. Using only long-handled ergonomically designed tools would help alleviate these stressors. 


\section{APPENDIX A \\ REFERENCES}

Occupational Safety and Health Standards for General Industry, 29 CFR Part 1910, Occupational Safety and Health Administration United States Department of Labor

Occupational Safety and Health Standards for the Construction Industry, 29 CFR Part 1926, Occupational Safety and Health Administration United States Department of Labor

Threshold Limit Values (TLV's) for Chemical Substances and Physical Agents and Biological Exposure Indices (BEl's), American Conference of Governmental Industrial Hygienists, 1995-1996.

ANSI 1986, Guide for the Measurement and Evaluation of Human Exposure to Vibration Transmitted to the Hand, New York, NY: American National Standards Institute, ANSI S3.34.

U.S. Department of Health and Human Services, Manual for the Revised NIOSH Lifting Equation, January 1994.

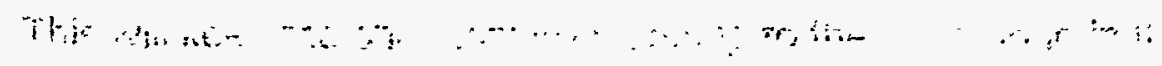




\section{APPENDIX B ACRONYMS}

$\begin{array}{lcl}\text { ACGH } & - & \text { American Conference of Governmental Industrial Hygienists } \\ \text { ANSI } & - & \text { American National Standards Institute } \\ \text { CFR } & - & \text { Code of Federal Regulations } \\ \text { DOE } & - & \text { Department of Energy } \\ \text { FIU } & - & \text { Florida International University } \\ \text { HAZCOM } & - & \text { Hazard Communication } \\ \text { HAZWOPER - } & \text { Hazardous Waste Operations } \\ \text { MSA } & - & \text { Mine Safety Appliances } \\ \text { MSDS } & - & \text { Material Safety Data Sheet } \\ \text { NFPA } & - & \text { National Fire Protection Association } \\ \text { NIOSH } & - & \text { National Institute of Occupational Safety and Health } \\ \text { OSHA } & - & \text { Occupational Safety and Health Administration } \\ \text { PCRS } & - & \text { Pegasus Chemical Removal System } \\ \text { PEL } & - & \text { permissible exposure limit } \\ \text { PID } & - & \text { photo ionization detector } \\ \text { PPE } & - & \text { personal protective equipment } \\ \text { PPM } & - & \text { parts per million } \\ \text { SOP's } & - & \text { standard operating procedures } \\ \text { TLV } & - & \text { threshold limit value }\end{array}$




\section{PEGASUS INTERNATIONAL, INC. COATING REMOVAL SYSTEM (METAL) TABLE OF CONTENTS}

ACKNOWLEDGEMENTS iii

EXECUTIVE SUMMARY iv

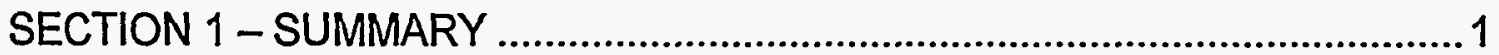

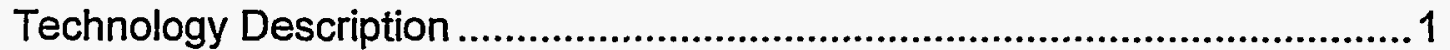

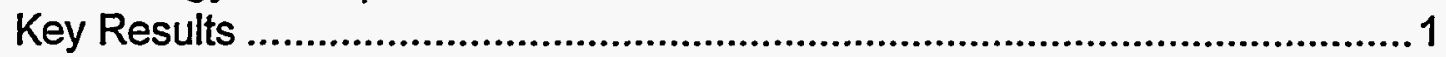

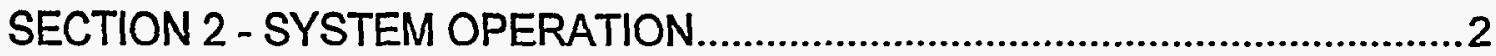

SECTION 3 - HEALTH AND SAFETY EVALUATION

General Health and Safety Concerns ..........................................................2

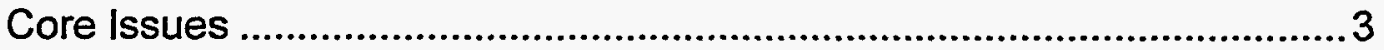

Best Management Practices.....................................................................

Industrial Hygiene Monitoring .................................................................. 3

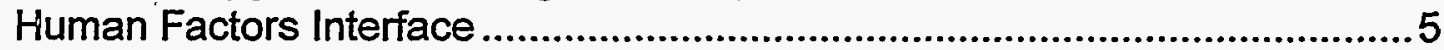

Technology Applicability ................................................................................

SECTION 4 - EMERGENCY RESPONSE/PREPAREDNESS ..........................6

SECTION 5 - REGULATORY POLICY ISSUES ..............................................6

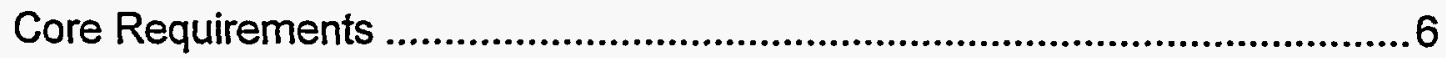

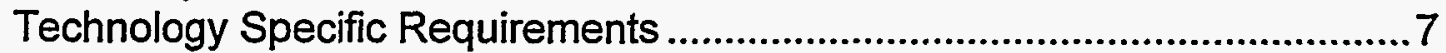

Best Management Practices..........................................................................

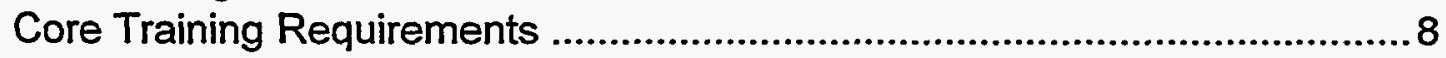

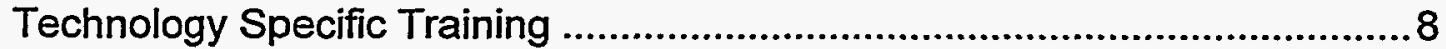

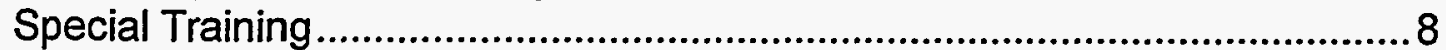

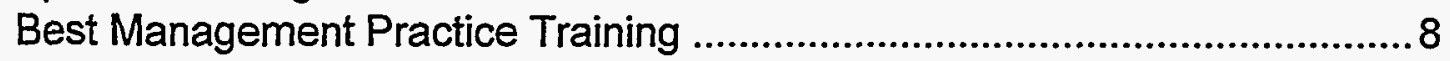

SECTION 6 - OPERATIONAL CONSIDERATIONS AND

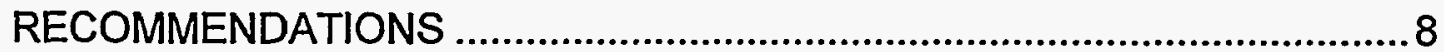




\section{TABLE OF CONTENTS (Continued)}

APPENDIX A - REFERENCES .11

APPENDIX B - ACRONYMS . 


\section{ACKNOWLEDGEMENTS}

The human factors assessment of Pegasus International, Inc., Coating Removal System (Concrete Floor), was conducted under support of the U.S. Department of Energy's Federal Energy Technology Center, under cooperative agreement DE-FC21-95MC32260 with the Operating Engineers National Hazmat Program. The Operating Engineers National Hazmat Program would like to thank the following people for their participation on the "research action team" and the professional expertise they provided for this assessment:

Barbara McCabe

Ralph Pascarella

Daniel Timmerman
Operating Engineers National Hazmat Program

Operating Engineers Local Union 30

Operating Engineers National Hazmat Program 


\section{EXECUTIVE SUMMARY}

The Pegasus Coating Removal System (PCRS) was demonstrated at Florida International University (FIU) where it was being evaluated for efficiency and cost. In conjunction with the FIU testing demonstration, a human factors assessment was conducted to assess the hazards and associated safety and health issues of concern for workers utilizing this technology.

The PCRS is a chemical paste that is applied to the surface using a brush, roller, or airless sprayer. Two types of PCRS are available. PCRS- $5 / 7$ is an organic solvent mixture primarily used for chemically resistant coatings and PCRS-ST1 and PCRS-1, which is an alkaline mixture of calcium hydroxide, magnesium hydroxide, and sodium hydroxide. PCRS-ST1 and PCRS-1 are primarily used for alkyd/latex coating removal. The type of PCRS used depends on the type and thickness of the coating and the type of substrate material. In order to determine the type of PCRS for the job, the required thickness of the paste, and the dwell time, a test area of approximately one square foot is used. Based on the performance of the chemical over this one square foot area, the operational parameters can be determined. Dwell time, which is the time required for the chemical to have its desired effect, can range from several hours to 24 hours. After the type of PCRS, thickness, and dwell time have been determined, a laminated backed material is placed on top of the chemical paste to slow down the drying process and to provide a mechanism to strip-off the chemical. After the dwell time is reached, the chemical substrate can be removed. Scrapers may be used to break-loose the layers as necessary or to break-loose the layers that are not removed when the laminated paper is picked up. Residue may also be cleaned off of the surface with a damp sponge with an agitating motion, absorbent sponges, or a vacuum, as needed. The paint and removal agent is then placed in drums for disposal at a later time.

During the human factors assessment of the PCRS, the PCRS-5/7 was used for the removal of the metal slab and l-beam coatings.

During the assessment sampling was conducted for organic vapors and general observational techniques were conducted for ergonomics. General observational techniques for ergonomics showed the potential for some ergonomic problems during application and removal of the chemical. The chemical was applied to the metal slabs and I-beams using spatulas. Using the spatula to apply the chemical requires workers to bend, kneel, or stoop to reach all sections of the metal plates and I-beams. This has the potential to cause strain/sprain to the back, knees, ankles, lower/upper legs, and back. Removal of the chemical presents the same types of ergonomic stressors because removal requires the use of a paint scraper. 
The organic vapor readings during application and removal of the PCRS ranged from 0.0 to $15.0 \mathrm{ppm}$, the higher readings being recorded in the enclosed work environment. These measurements indicate that organic vapors are present during application and removal of the PCRS. Monitoring for the specific ingredients needs to be considered on a job-by-job site-by-site basis. The low levels of organic vapor have the potential to cause headache, skin irritation, and respiratory tract irritation. Therefore, workers may need to utilize appropriate PPE when applying and removing the PCRS regardless of the ppm levels recorded.

Recommendations for improved worker safety and health during application and removal of the PCRS include: 1. work practices that reflect avoidance of exposure or reducing the risk of exposure; 2 . assuring all PPE and equipment are compatible with the chemicals being used; 3 . work practices that reduce the worker's need to walk on the slippery surface caused by the chemical or the use of special anti-slip soles; 4 . careful control of overspray (if a spray application is used); and 5. the use of ergonomically designed long-handled tools and adjustable work stations to apply and remove the chemical (to alleviate some of the ergonomic concerns). 


\section{PEGASUS INTERNATIONAL, INC. COATING REMOVAL SYSTEM (PCRS) \\ (METAL) \\ Human Factors Assessment}

\section{SECTION 1 - SUMMARY}

\section{TECHNOLOGY DESCRIPTION}

The Pegasus Coating Removal System (PCRS) technology was tested and is being evaluated at Florida International University (FIU) as a baseline technology. In conjunction with FIU's evaluation of efficiency and cost, this report covers the hazard analysis and safety evaluation. PCRS is a commercially available technology and has been used for various projects at locations throughout the country.

The PCRS is a chemical paste that is applied to the surface using a brush, roller, or airless sprayer. They type of PCRS used depends on the type and thickness of the coating, the age of the coating, and the type of substrate material. A laminated backed material is placed on top of the chemical paste to slow down the drying process and to provide a mechanism to strip-off the material. In order to determine the type of PCRS, the required thickness of the paste, and the dwell time, a test area of approximately one square foot is used. Based on the performance of the chemical over this one square foot area, the operational parameters can be determined. Dwell time can range from several hours to 24 hours.

\section{KEY RESULTS}

The safety and health evaluation during the testing demonstration focused on two main areas: exposure to the organic chemicals and ergonomics. Air sampling with a photo ionization detector (PID) showed low exposure values but there is concern for skin exposures. Further testing for the individual ingredients of the organic based solvent is recommended. In addition, it is recommended that sampling be conducted in an enclosed environment. The outdoor environment where part of the testing demonstration took place may cause the results to be inapplicable to enclosed operating environments, where it is feasible that the exposure levels would be greater. Ergonomic stressors were potentially significant. Other safety and health issues found were heat stress, slipping/fall hazards, and environmental concerns from accidentally spreading the chemical to areas outside the immediate exclusion zone. 


\section{SECTION 2 - SYSTEM OPERATION}

The PCRS is a chemical paste that is applied to the surface using a brush, roller, or airless sprayer. Two types of PCRS are available. PCRS-5/7 is an organic solvent mixture primarily used for chemically resistant coatings and PCRS-ST1 and PCRS-1, which are alkaline mixtures of calcium hydroxide, magnesium hydroxide, and sodium hydroxide. PCRS-ST1 and PCRS-1 are primarily used for alkyd/latex coating removal. The type of PCRS used depends on the type and thickness of the coating and the type of substrate material. In order to determine the type of PCRS for the job, the required thickness of the paste, and the dwell time, a test area of approximately one square foot is used. Based on the performance of the chemical over this one square foot area, the operational parameters can be determined. Dwell time, which is the time required for the chemical to have its desired effect, can range from several hours to 24 hours. After the type of PCRS, thickness, and dwell time have been determined, a laminated backed material is placed on top of the chemical paste to slow down the drying process and to provide a mechanism to strip-off the material. After the dwell time is reached, the chemical substrate can be removed. Scrapers may be used to break-loose the layers as necessary or to break-loose the layers that are not removed when the laminated paper is picked up. Residue may also be cleaned off of the surface with a damp sponge with an agitating motion, absorbent sponges, or a vacuum, as needed. The paint and removal agent is then placed in drums for disposal at a later time.

During the human factors assessment-of the PCRS, the PCRS- $5 / 7$ was used for the removal of the metal coating.

\section{SECTION 3 - HEALTH AND SAFETY EVALUATION}

\section{GENERAL SAFETY AND HEALTH CONCERNS}

Personnel where the PCRS is being used need to be concerned with safety and health issues. Issues that personnel need to be cognizant of may be divided into two categories. Core issues are those that are based on current safety and health regulatory requirements. Best management practices are related to issues that are not based on current safety and health regulations, but are key elements in preventing worker injury and illness on the job.

Safety and health issues of concern with PCRS included: 


\section{Core Issues:}

Work Practices (housekeeping) - The process of applying the chemical is difficult to accomplish without the worker coming in contact with it. Training the workers to apply good work practices would assist in alleviating this concern. In addition, the need for stringent housekeeping must be addressed.

- Personal Protective Equipment (PPE) - The PPE utilized during the application of the PCRS needs to be compatible with the chemicals being used.

- Hazard Communication - The material safety data sheet (MSDS) for the chemical being used must be available in accordance with 29 CFR 1910.1200. In addition, workers must be trained on its specific hazards.

- Exposure to Chemical - There is potential for the worker to be exposed to the chemical being used for coating removal. Exposure may occur during application and removal, from the chemical splashing during application, or by the worker coming in direct contact with the chemical. This will be discussed in greater detail in the Industrial Hygiene section of this report.

\section{Best Management Practices:}

- Ergonomics - There are ergonomic stressors that have the potential to cause stress/strain to the lower and upper back, shoulders, arms, and knees due to the bending, stooping, kneeling postures required for application and removal of the PCRS.

- Slipping Hazards - The chemical applied to the metal made the work/walking surface extremely slippery.

- Heat Stress - Workers are subjected to an increase in heat stress due to the need to utilize chemical protective PPE during the application and removal of the PCRS. The user will need to develop a heat stress program for the environment in which the chemical removal system is being used, taking into consideration any PPE that may need to be utilized, ambient temperature, etc.

\section{INDUSTRIAL HYGIENE MONITORING}

During the testing demonstration with the PCRS, sampling was conducted for organic vapors. In addition, the wet-bulb globe temperature was monitored to evaluate heat stress. Observational evaluation was conducted for ergonomics.

Through general observational techniques the potential for ergonomic problems was evaluated during the testing demonstration. The chemical was applied to the metal 
Through general observational techniques the potential for ergonomic problems was evaluated during the testing demonstration. The chemical was applied to the metal plates and l-beams using spatulas. Using the spatula to apply the chemical requires

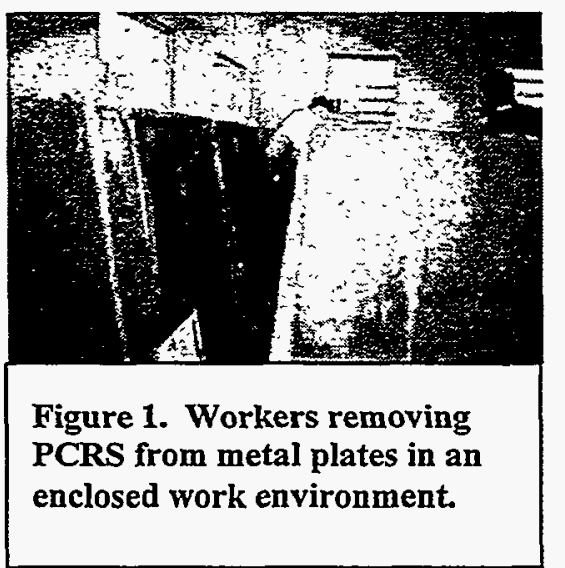
workers to bend, kneel, or stoop to reach all sections of the metal plates and I-beams. This has the potential to cause strain/sprain to the back, knees, ankles, lower/upper legs, and back. Removal of the chemical presents the same type of ergonomic stressors because removal was done using a paint scraper.

Heat stress parameters were monitored using a Quest QuestTemp ${ }^{\circ} 15$ Heat Stress Monitor. The wet-bulb globe temperature was used to determine the work/rest regimen in accordance with the American Conference of Governmental Industrial Hygienist (ACGIH)

recommendations. In accordance with $A C G I H$ guidelines, the wet-bulb globe temperature was adjusted for the type of clothing, including PPE, that the worker was wearing. While heat stress will be increased when wearing PPE, the overall heat stress response will vary from worker to worker. Each situation in which the current technology is used will need to be evaluated for the heat stress potential, taking into consideration the wet-bulb globe temperature, PPE in use, physical condition of the worker, and amount of worker acclimatization.

The PCRS applied to the metal for coating removal was the PCRS- $5 / 7$, the organic solvent mixture. According to the MSDS supplied by Pegasus Inc., the mixture contains 10-25\% Dibasic Ether, 20-50\% N-Methyl-2-Pyrrolidone, 20-40\% Aluminum Silicate, 1$5 \%$ Nonylphenol Ethoxylate, and 10-30\% Non-hazardous ingredients. The dibasic ether has a manufacturer's recommended exposure limit of $10 \mathrm{mg} / \mathrm{m}^{3}$ and the aluminum silicate has an Occupational Safety and Health Administration permissible exposure limit (PEL) of $15 \mathrm{mg} / \mathrm{m}^{3}$ and an ACGIH threshold limit value (TLV) of $10 \mathrm{mg} / \mathrm{m}^{3}$, as total dust. Dust was not a concern during the application and removal of the PCRS since it was a wet process. Therefore, organic vapor monitoring was conducted during application and removal. Monitoring was conducted using an MSA Passport Photo lonization Detector (PID). The Passport is a real-time monitor that measures organic vapors in parts per million (ppm). The PID does not identify the specific organic vapor but identifies the presence of any organic vapor.

The organic vapor readings during application and removal ranged from 0.0 to 15.0 $\mathrm{ppm}$, the higher readings being recorded in the enclosed work environment. Since it cannot be determined if these levels present the potential for overexposure, sampling for the individual ingredients in the PCRS-5/7 needs to be conducted. It does, however, indicate that organic vapors are present. Even at low levels, the organic vapor odor 


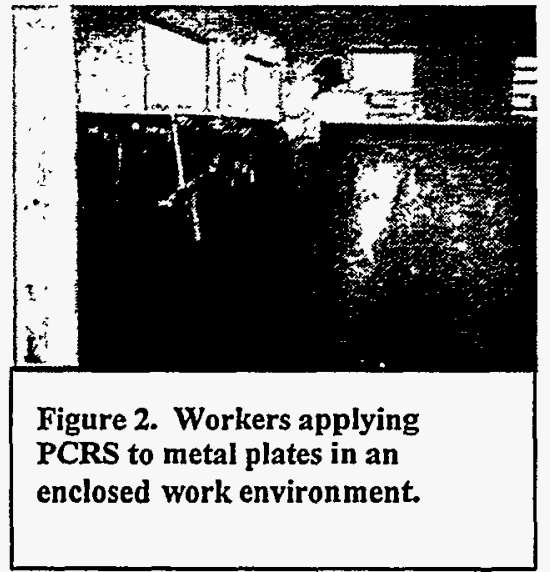

size or the area where it is being used.

The PCRS was applied and removed in an open outdoor environment during part of the testing demonstration. As previously noted, the lower organic vapors were measured at that time. There is the potential for the organic vapor levels to be significantly higher in an enclosed environment. A monitoring plan will need to be developed for the specific site and job where the chemical is being used.

\section{HUMAN FACTORS INTERFACE}

The MSDS for PCRS-5/7 recommends the following PPE be used when applying or removing it: chemical goggles, butyl rubber gloves, impervious apron, and boots. It states that respiratory protection is not normally needed, but for spray applications or where exposures may be excessive, a National Institute of Occupational Safety and Health (NIOSH) approved organic vapor respirator may be used.

Depending on the application and removal methods used, a greater level of PPE may be required. (This was evident during the testing demonstration when the tyvek suit being worn under the impervious apron was soaked with the chemical.) This may include a chemically impervious suit instead of only an apron and a full face air purifying respirator. This has the potential to cause a decrease in visibility, mobility, and tactile sensation for the workers, as well as an increase in heat stress. Additionally, because of the extremely slippery walking surface condition, boots with special anti-slip soles need to be used.

\section{TECHNOLOGY APPLICABILITY}

After the coating has been removed from the surface by the chemical, it will need to be assured that the surface is "clean" of both PCRS residue and whatever contaminant was originally present on the surface. 
Consideration will also need to be given to the wastes that are generated. Wastes may include different combinations: the PCRS itself and the PCRS combined with the surface coating being removed and its contaminants.

\section{SECTION 4 - EMERGENCY RESPONSE/PREPAREDNESS}

The use of the PCRS technology would not be applicable for use in an emergency response situation.

Emergency response/preparedness must be part of every hazardous waste site safety and health plan. In addition to credible site emergencies, site personnel must plan for credible emergencies in connection with the PCRS.

All precautions used when responding to an emergency situation at the site will apply. The PCRS $-5 / 7$ is flammable and is $85 \%$ volatile by volume. Its products of decomposition may include carbon dioxide, carbon monoxide, and oxides of nitrogen. In accordance with the MSDS a fire involving the PCRS-5/7 should be extinguished with water spray or fog, foam, carbon dioxide, or dry chemical. This information needs to be conveyed to both on-site and off-site emergency response personnel before a situation occurs that involves the PCRS.

\section{SECTION 5 - REGULATORYIPOLICY ISSUES}

The site safety and health personnel where the PCRS technology is being used need to be concerned with safety and health regulations applicable to the issues discussed above. Regulations that apply may be divided into four categories. Core requirements are those regulations that would apply to any hazardous waste work site, regardless of the type of job. Technology specific requirements are those regulations that apply due to the specific technology being used. Special requirements are standards and policies that are specific to the technology itself and are required by reference in a regulation. Best management practices are not required, but are recommended by organizations such as the American National Standards Institute (ANSI), NIOSH, Department of Energy (DOE), National Fire Protection Association (NFPA), etc. These regulations/standards may include but not be limited to the following:

Core requirements:

- OSHA 29 CFR 1926.25 Housekeeping

- OSHA 29 CFR 1910.141 Sanitation (1910.141(a)(3) covers housekeeping)

- OSHA 29 CFR 1926 Subpart Z Toxic and Hazardous Substances

OSHA 29 CFR 1910 Subpart Z Toxic and Hazardous Substances 
$\checkmark \quad$ OSHA 29 CFR 1926.59 Hazard Communication

OSHA 29 CFR 1910.1200 Hazard Communication

OSHA 29 CFR 1926.64 Process Safety Management of Highly Hazardous Chemicals

OSHA 29 CFR 1910.119 Process Safety Management of Highly Hazardous Chemicals

$\checkmark \quad$ OSHA 29 CFR 1926.65 Hazardous Waste Operations and Emergency Response

OSHA 29 CFR 1910.120 Hazardous Waste Operations and Emergency

Response

- Occupational Safety and Health Act 1970(5)(a)(1) General Duty Clause

Technology Specific Requirements:

$\checkmark \quad$ OSHA 29 CFR 1926.103 Respiratory Protection

- OSHA 29 CFR 1910.134 Respiratory Protection

OSHA 29 CFR 1926.102 Eye and Face Protection

- OSHA 29 CFR 1910.133 Eye and Face Protection

- OSHA 29 CFR 1926.28 Personal Protective Equipment

$\checkmark \quad$ OSHA 29 CFR 1910.132 General Requirements (Personal Protective Equipment)

OSHA 29 CFR 1926.23 First Aid and Medical Attention

OSHA 29 CFR 1910.151 Medical Services and First Aid

\section{Best Management Practices:}

- ACGIH Threshold Limit Values for Chemical Substances and Physical Agents and Biological Exposure Indices

In addition to the above regulations and policies, it is imperative that all workers have appropriate and adequate training for the task and associated safety and health hazards. Training that would be required may be divided into four categories. Core training is that which is required for anyone entering a hazardous waste site to perform 
work, regardless of the type of job. Technology specific training is that training that is specific to the technology and required by safety and health standards. Special training is that which is specific to the technology to assure the worker is adequately trained for the task, but is not necessarily required by safety and health standards. Best management practices are trainings that while not mandated by health and safety standards, provide information and knowledge to the worker that will allow the worker to perform his/her job safely. Training to be applied for the centrifugal shot blast technology may include but not be limited to:

\section{Core Training Requirements:}

$\checkmark$ HAZWOPER

- HAZCOM

Technology Specific Training:

- Respiratory Protection

- Personal Protective Equipment

\section{Special Training:}

- Job specific training for chemical application and removal

\section{Best Management Practice Training:}

- Ergonomics (proper lifting, bending, stooping, kneeling, safe shoveling techniques)

- Heat stress (learning to recognize signs and symptoms)

- CPR/First Aid/Emergency Response/Blood-borne Pathogens

- Construction Safety (OSHA 500) and or General Industry Safety (OSHA 501)

\section{SECTION 6 - \\ OPERATIONAL CONSIDERATIONS \& RECOMMENDATIONS}

Recommendations made here for improved worker safety and health take into consideration the use of the PCRS-5/7. Specific recommendations include:

- Work practices are of critical importance for worker exposure to the chemical being applied to and removed from the coated surface. Application and removal 
is a difficult process to accomplish without the worker coming in contact with the chemical. Training the worker to use the best work practices possible will help to alleviate some of these concerns. Examples of the types of work practices that are of concern include:

1. Close all containers, both storage and waste, when not in use. This will keep the chemical from adding to the vapor load in the area where the work is being conducted.

2. Assure all PPE chosen is compatible with the chemical. An

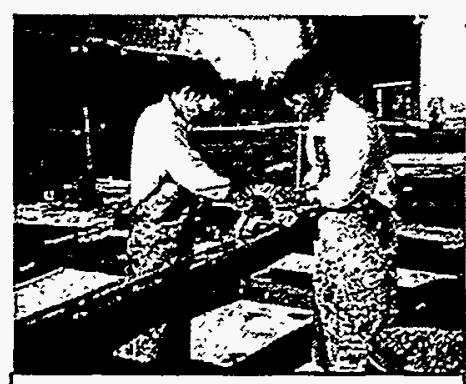
impervious apron (as recommended by the MSDS) is of no use if the material it is made of is incompatible with the chemical being used. Additional consideration needs to be given to the PPE used under the apron. If the chemical comes in contact with the garment under the apron and it is not compatible with the chemical, it is of no use.

Figure 3. Workers removing chemical, laminated paper and coating from I-beams.

3. All workers need to be trained in the specific hazards associated with the chemical and work practices should reflect avoidance of exposure or reducing the risk of exposure. For example, the organic solvent mixture is an eye irritant. Workers wearing goggles - should never touch or remove the goggles while in the work area, nor should they touch or remove the goggles until their gloves that are contaminated with chemical are removed and their hands have been decontaminated. Additionally, touching the goggles with contaminated gloves increases the likelihood of getting the chemical on the face and head.

4. The chemical being applied to the metal plates and I-beams dripped onto the walking surface. This made the walking surface

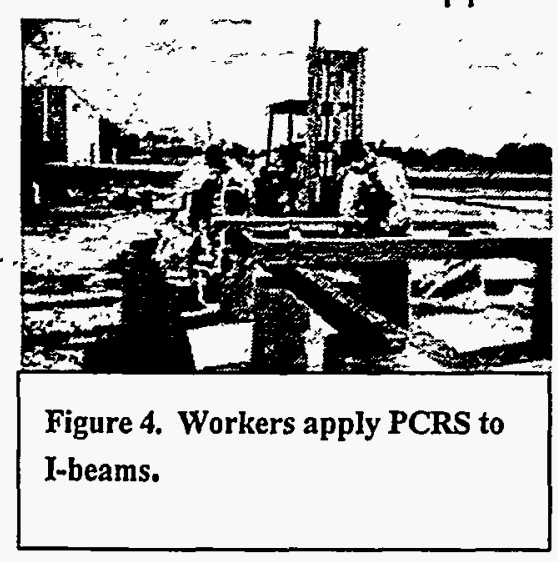
extremely slippery. Placing the plates and I-beams in a confined area or placing something under them, which could later be picked up, to catch the dripping would help keep the chemical off of the walking surface. Workers should also avoid walking where the chemical has dripped on the surface. This would also prevent the spread of the chemical to other areas of the work site. 
- PPE must be chosen that is compatible with the hazards and the job.

Chemically impervious suits, aprons, gloves, and boots will be useless if the material they are made from is not compatible with the chemical. Consideration must also be given to special hazards that may be encountered. For example, normal chemical protective boots are inadequate during PCRS application and removal because of the extremely slippery walking surface conditions it creates. Special anti-slip soles need to be considered.

- Due to the open outdoor environment in which part of the testing demonstration took place and therefore, the organic vapor monitoring, it is recommended that additional monitoring be conducted when the PCRS is applied and removed in an enclosed environment similar to environments in which it would be used at a hazardous waste clean-up site. Additionally, monitoring needs to be conducted, as appropriate, for the individual ingredients of the organic solvent mixture.

- Using the spatulas and paint scrapers which had short handles cause the chemical to come up over the tool and handle onto the worker's gloves. This increases the potential for exposure and would be eliminated by the use of longhandled tools and appropriate work practices.

- Through general observational techniques the potential for ergonomic problems was evaluated during the testing demonstration. The chemical was applied to the metal plates and I-beams using spatulas. Using the spatula to apply the chemical requires the workers to bend, kneel, or stoop to reach ail sections of the plates and I-beams. This has the potential to cause strain/sprain to the back, knees, ankles, and lower/upper legs. Removal of the chemical presents the same type of ergonomic stressors because removal was done using a paint scraper.

The use of long-handled applicators and tools for removal would allow the worker to reach all sections of the metal plates and l-beams without bending, kneeling, and stooping. Additionally, the metal pieces could be placed on an adjustable work surface that could be manipulated to the correct height and angle for the worker. 


\section{APPENDIX A \\ REFERENCES}

Occupational Safety and Health Standards for General Industry, 29 CFR Part 1910, Occupational Safety and Health Administration United States Department of Labor

Occupational Safety and Health Standards for the Construction Industry, 29 CFR Part 1926, Occupational Safety and Health Administration United States Department of Labor

Threshold Limit Values (TLV's) for Chemical Substances and Physical Agents and Biological Exposure Indices (BEl's), American Conference of Governmental Industrial Hygienists, 1995-1996

ANSI 1986, Guide for the Measurement and Evaluation of Human Exposure to Vibration Transmitted to the Hand, New York, NY: American National Standards Institute, ANSI S3.34

U.S. Department of Health and Human Services, Manual for the Revised NIOSH Lifting Equation, January 1994 


\section{APPENDIX B ACRONYMS}

$\begin{array}{lrl}\text { ACGIH } & - & \text { American Conference of Governmental Industrial Hygienists } \\ \text { ANSI } & - & \text { American National Standards Institute } \\ \text { CFR } & - & \text { Code of Federal Regulations } \\ \text { DOE } & - & \text { Department of Energy } \\ \text { FIU } & - & \text { Florida International University } \\ \text { HAZCOM } & - & \text { Hazard Communication } \\ \text { HAZWOPER - } & \text { Hazardous Waste Operations } \\ \text { MSA } & - & \text { Mine Safety Appliances } \\ \text { MSDS } & - & \text { Material Safety Data Sheet } \\ \text { NFPA } & - & \text { National Fire Protection Association } \\ \text { NIOSH } & - & \text { National Institute of Occupational Safety and Health } \\ \text { OSHA } & - & \text { Occupational Safety and Health Administration } \\ \text { PCRS } & - & \text { Pegasus Coating Removal System } \\ \text { PEL } & - & \text { permissible exposure limit } \\ \text { PID } & - & \text { photo ionization detector } \\ \text { PPE } & - & \text { personal protective equipment } \\ \text { PPM } & - & \text { parts per million } \\ \text { SOP's } & - & \text { standard operating procedures } \\ \text { TLV } & -\cdots & \text { threshold limit value }\end{array}$




\section{PEGASUS INTERNATIONAL, INC. COATING REMOVAL SYSTEM (PCRS) (WALL/CEILING) TABLE OF CONTENTS}

ACKNOWLEDGEMENTS iii

EXECUTIVE SUMMARY iv

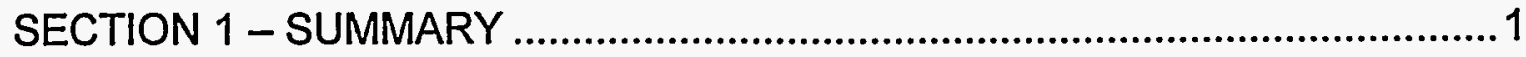

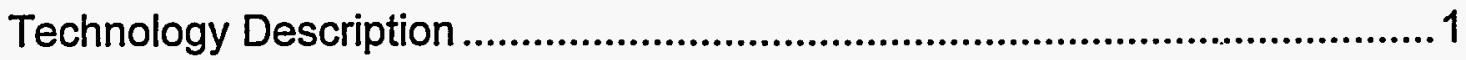

Key Results ................................................................................................. 1

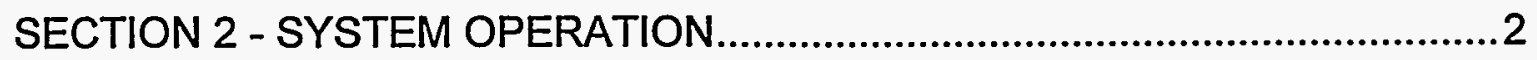

SECTION 3 - HEALTH AND SAFETY EVALUATION .......................................2

General Health and Safety Concerns .........................................................2

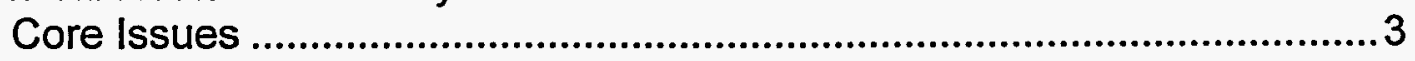

Best Management Practices.................................................................. 3

Industrial Hygiene Monitoring ..........................................................................4

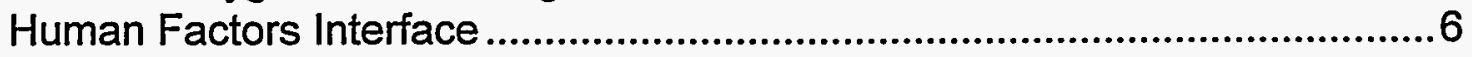

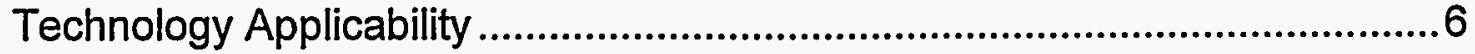

SECTION 4 - EMERGENCY RESPONSE/PREPAREDNESS ........................6

SECTION 5 - REGULATORY POLICY ISSUES .............................................

Core Requirements .............................................................................

Technology Specific Requirements .......................................................... 7

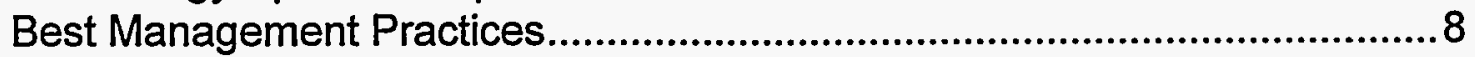

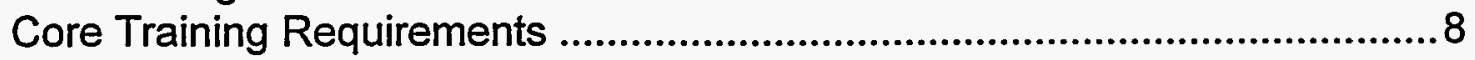

Technology Specific Training …................................................................

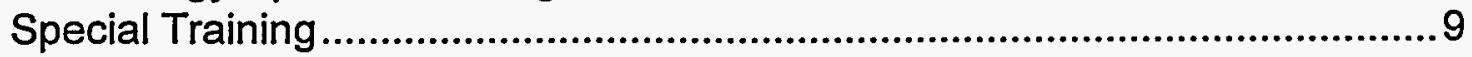

Best Management Practice Training .......................................................... 9

SECTION 6 - OPERATIONAL CONSIDERATIONS AND

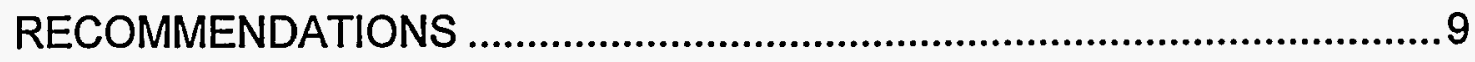

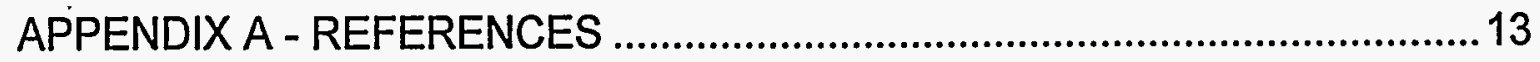

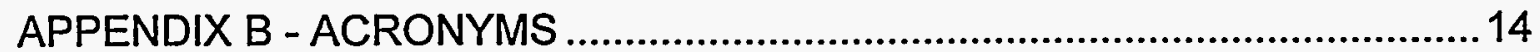




\section{ACKNOWLEDGEMENTS}

The human factors assessment of Pegasus International, Inc., Coating Removal System (Concrete Floor), was conducted under support of the U.S. Department of Energy's Federal Energy Technology Center, under cooperative agreement DE-FC2195MC32260 with the Operating Engineers National Hazmat Program. The Operating Engineers National Hazmat Program would like to thank the following people for their participation on the "research action team" and the professional expertise they provided for this assessment:

Barbara McCabe John Mason Bill Nelson
Operating Engineers National Hazmat Program

Operating Engineers Local Union 66

Operating Engineers Local Union 324 


\section{EXECUTIVE SUMMARY}

The Pegasus Coating Removal System (PCRS) was demonstrated at Florida International University (FIU) where it was being evaluated for efficiency and cost. In conjunction with the FIU testing demonstration, a human factors assessment was conducted to assess the hazards and associated safety and health issues of concern for workers utilizing this technology.

The PCRS is a chemical paste that is applied to the surface using a brush, roller, or airless sprayer. Two types of PCRS are available. PCRS- $5 / 7$ is an organic solvent mixture primarily used for chemically resistant coatings and PCRS-ST1 and PCRS-1, which is an alkaline mixture of calcium hydroxide, magnesium hydroxide, and sodium hydroxide. PCRS-ST1 and PCRS-1 are primarily used for alkyd/latex coating removal. The type of PCRS used depends on the type and thickness of the coating, and the type of substrate material. In order to determine the type of PCRS for the job, the required thickness of the paste, and the dwell time, a test area of approximately one square foot is used. Based on the performance of the system over this one square foot area, the operational parameters can be determined. Dwell time, which is the time required for the chemical to have its desired effect, can range from several hours to 24 hours. After the type of PCRS, thickness, and dwell time have been determined, a laminated backed material is placed on top of the chemical paste to slow down the drying process and to provide a mechanism to strip-off the chemical. After the dwell time is reached, the chemical substrate can be removed. Scrapers may be used to break-loose the layers as necessary or to break-loose the layers that are not removed when the laminated paper is picked up. Residue may also be cleaned off of the surface with a damp sponge with an agitating motion, absorbent sponges, or a vacuum, as needed. The paint and removal agent is then placed in drums for disposal at a later time.

During the human factors assessment of the PCRS, the PCRS-5/7 was used for the removal of the wall/ceiling coating.

During the assessment sampling was conducted for organic vapors and general observational techniques were conducted for ergonomics. General observational techniques for ergonomics showed the potential for some ergonomic problems during application and removal of the chemical. The chemical was applied to the wall and ceiling using a spatula and removed using a paint scraper for the locations where the removal with the laminated paper was not complete. To reach the lower portion of the wall personnel worked from ground level. To reach the upper portion of the wall, personnel worked from a ladder. There is the potential for sprain/strain to the back, shoulders, knees, and legs from the bending, kneeling, or stooping required to reach the lower section of the wall. When working from a ladder there is the potential for sprain/strain to the back, shoulders, and neck from reaching and from working with the arms extended above the head and neck for long periods of time. Removal of the 
chemical with a paint scraper presents the same type of ergonomic stressors as application using a spatula.

During removal of the chemical, the organic vapor readings ranged from 0.0 to 1.5 parts per million (ppm). During application with the paint sprayer (this was only done for approximately 5-10 minutes due to equipment malfunction), the readings ranged from 0.0 to $2.0 \mathrm{ppm}$ and during application using a spatula the readings ranged from 0.0 to $5.0 \mathrm{ppm}$. These measurements indicate that organic vapors are present during application and removal of the PCRS. Monitoring for the specific ingredients needs to be considered on a job-by-job site-by-site basis. The low levels of organic vapor have the potential to cause headache, skin irritation, and respiratory tract irritation. Therefore, workers may need to utilize appropriate PPE when applying and removing the PCRS regardless of the ppm levels recorded.

Recommendations for improved worker safety and health during application and removal of the PCRS include: 1. work practices that reflect avoidance of exposure or reducing the risk of exposure; 2 . assuring all PPE and equipment are compatible with the chemicals being used; 3 . work practices that reduce the worker's need to walk on the slippery surface caused by the chemical or the use of special anti-slip soles; 4 . careful control of overspray (if a spray application is used); 5 . the use of ergonomically designed long-handled tools to apply and remove the chemical (to alleviate some of the ergonomic concerns); and 6 . the use of scaffolding instead of a ladder to reach the upper portion of the wall and the ceiling for application and removal of the chemical. 


\section{PEGASUS INTERNATIONAL, INC. COATING REMOVAL SYSTEM (PCRS) (WALL/CEILING) \\ Human Factors Assessment}

\section{SECTION 1 - SUMMARY}

\section{TECHNOLOGY DESCRIPTION}

The Pegasus Coating Removal System (PCRS) technology was tested and is being evaluated at Florida International University (FIU) as a baseline technology. In conjunction with FIU's evaluation of efficiency and cost, this report covers the hazard analysis and safety evaluation. PCRS is a commercially available technology and has been used for various projects at locations throughout the country.

The PCRS is a chemical paste that is applied to the surface using a brush, roller, or airless sprayer. The type of PCRS used depends on the type and thickness of the coating, the age of the coating, and the type of substrate material. A laminated backed material is placed on top of the chemical paste to slow down the drying process and to provide a mechanism to strip-off the material. In order to determine the type of PCRS, the required thickness of the paste, and the dwell time, a test area of approximately one square foot is used. Based on the performance of the chemical over this one square foot area, the operational parameters can be determined. Dwell time can range from several hours to 24 hours.

\section{KEY RESULTS}

The safety and health evaluation during the testing demonstration focused on two main areas: exposure to the organic chemicals and ergonomics. Air sampling with a photo ionization detector (PID) showed low exposure values but there is concern for skin exposures. Further testing for the individual ingredients of the organic based solvent is recommended. In addition, it is recommended that sampling be conducted in an enclosed environment. The outdoor environment where the testing demonstration took place may cause the results to be inapplicable to enclosed operating environments, where it is feasible that the exposure levels would be greater. Ergonomic stressors were potentially significant. Other safety and health issues found were heat stress, slipping/fall hazards, and environmental concerns from accidentally spreading the chemical to areas outside of the immediate exclusion zone. 


\section{SECTION 2 - SYSTEM OPERATION}

The PCRS is a chemical paste that is applied to the surface using a brush, roller, or airless sprayer. Two types of PCRS are available. PCRS-5/7 is an organic solvent mixture primarily used for chemically resistant coatings and PCRS-ST1 and PCRS-1, which are alkaline mixtures of calcium hydroxide, magnesium hydroxide, and sodium hydroxide. PCRS-ST1 and PCRS-1 are primarily used for alkyd/latex coating removal. The type of PCRS used depends on the type and thickness of the coating, and the type of substrate material. In order to determine the type of PCRS for the job, the required thickness of the paste, and the dwell time, a test area of approximately one square foot is used. Based on the performance of the system over this one square foot area, the operational parameters can be determined. Dwell time, which is the time required for the chemical to have its desired effect, can range from several hours to 24 hours. After the type of PCRS, thickness, and dwell time have been determined, a laminated backed

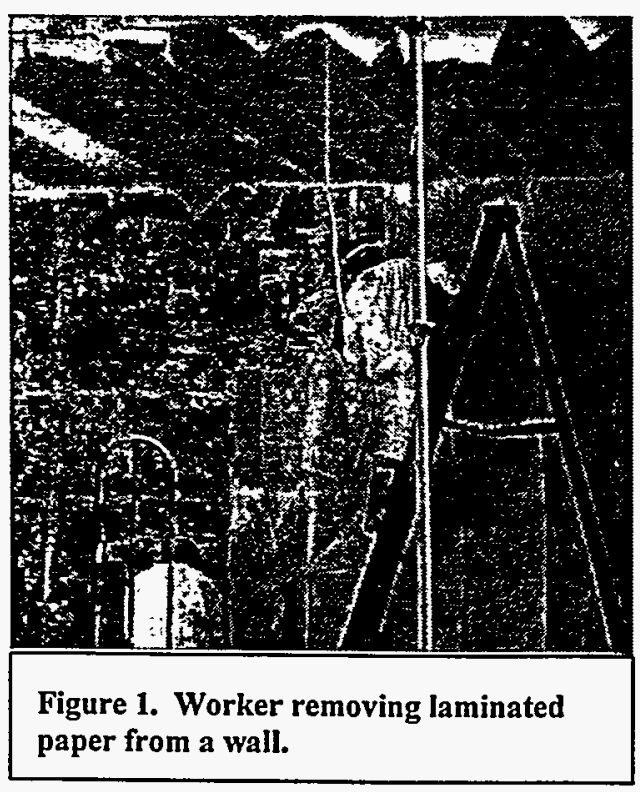
material is placed on top of the chemical paste to slow down the drying process and to provide a mechanism to strip-off the material. After the dwell time is reached, the chemical substrate can be removed. Scrapers may be used to break-loose the layers as necessary or to break-loose the layers that are not removed when the laminated paper is picked up. Residue may also be cleaned off of the surface with a damp sponge with an agitating motion, absorbent sponges, or a vacuum, as needed. The paint and removal agent is then placed in drums for disposal at a later time.

During the human factors assessment of the PCRS, the PCRS- $5 / 7$ was used for the removal of the wall/ceiling coating.

\section{SECTION 3 - HEALTH AND SAFETY EVALUATION}

\section{GENERAL SAFETY AND HEALTH CONCERNS}

Personnel where the Pegasus Coating Removal System is being used need to be concerned with safety and health issues. Issues that personnel need to be cognizant of may be divided into two categories. Core issues are those that are based on current safety and health regulatory requirements. Best management practices are related to issues that are not based on current safety and health regulations, but are key elements in preventing worker injury and illness on the job. 
Safety and health issues of concern with the PCRS included:

\section{Core Issues:}

Work Practices (housekeeping) - The process of applying the chemical is difficult to accomplish without the worker coming in contact with it. Training the workers to apply good work practices would assist in alleviating this concern. In addition, the need for stringent housekeeping must be addressed.

- Personal Protective Equipment - The personal protective equipment (PPE) utilized during the application of the PCRS needs to be compatible with the chemicals being used.

Hazard Communication - The material safety data sheet (MSDS) for the chemical being used must be available in accordance with 29 CFR 1910.1200. In addition, workers must be trained on its specific hazards.

- Exposure to Chemical - There is potential for the worker to be exposed to the chemical being used for coating removal. Exposure may occur during application and removal, from the chemical splashing during application, or by the worker coming in direct contact with the chemical. This will be discussed in greater detail in the Industrial Hygiene section of this report.

\section{Best Management Practices:}

Ergonomics - There are ergonomic stressors that have the potential to cause stress/strain to the lower and upper back, shoulders, arms, and knees due to the bending, stooping, kneeling postures required for application and removal of the PCRS.

Slipping Hazards - The chemical applied to the wall/ceiling made the walking surface extremely slippery. The workers almost fell several times during both application and removal of the chemical.

Heat Stress - Workers are subjected to an increase in heat stress due to the need to utilize chemical protective PPE during the application and removal of the PCRS. The user will need to develop a heat stress program for the environment in which the chemical removal system is being used, taking into consideration any PPE that may need to be utilized, ambient air temperatures, etc. 


\section{INDUSTRIAL HYGIENE MONITORING}

During the testing demonstration with the PCRS, sampling was conducted for organic vapors. In addition, the wet-bulb globe temperature was monitored to evaluate heat stress. Observational evaluation was conducted for ergonomics.

Through general observational techniques the potential for ergonomic problems was evaluated during the testing demonstration. The chemical was applied to the wall and ceiling using a spatula and removed using a paint scraper for the locations where the removal with the laminated paper was not complete. To reach the lower portion of the wall personnel worked from ground level. To reach the upper portion of the wall, personnel worked from a ladder. There is the potential for sprain/strain to the back, shoulders, knees, and legs from the bending, kneeling, or stooping required to reach the lower section of the wall. When working from a ladder there is the potential for sprain/strain to the back, shoulders, and neck from reaching and from working with the arms extended above the head and neck for long periods of time. Removal of the chemical with a paint scraper presents the same type of ergonomic stressors as application using a spatula.

Applying the chemical by spraying it onto the wall and ceiling had been accomplished previously but was not observed. The ergonomic stressors associated with this method of application needs to be assessed.

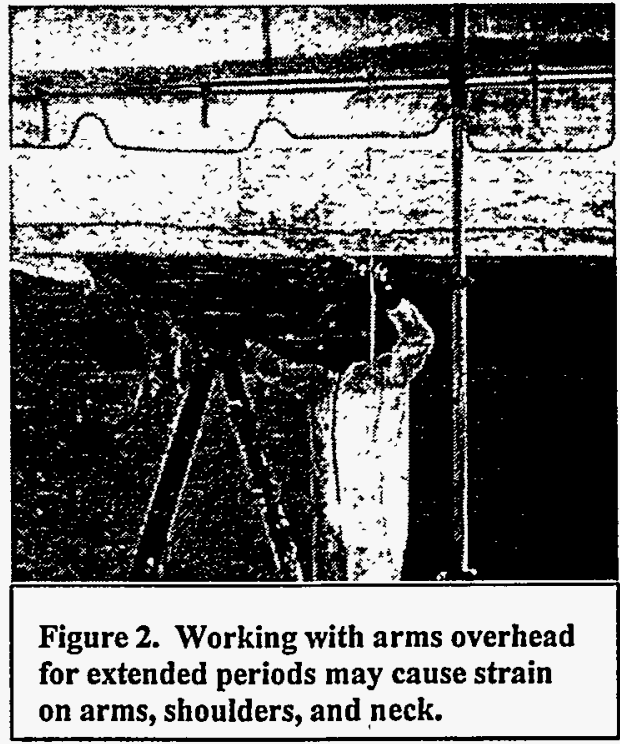

There are additional safety and health concerns with the use of a ladder for this type of job and these will be discussed in greater detail in a later section of this report.

Heat stress parameters were monitored using a Quest QuestTemp 15 Heat Stress Monitor. The wet-bulb globe temperature was used to determine the work/rest regimen in accordance with the American Conference of Governmental Industrial Hygienist (ACGIH) recommendations. In accordance with ACGIH guidelines, the wet-bulb globe temperature was adjusted for the type of clothing, including PPE, that the worker was wearing. While heat stress will be increased when wearing PPE, the overall heat stress response will vary from worker to worker. Each situation in which the current technology is used will need to be evaluated for the heat stress potential, taking into consideration the wet-bulb globe temperature, PPE in use, physical condition of the worker, and amount of worker acclimatization. 
The PCRS applied to the wall/ceiling for coating removal was the PCRS-5/7, the organic solvent mixture. According to the MSDS supplied by Pegasus Inc., the mixture contains 10-25\% Dibasic Ether, 20-50\% N-Methyl-2-Pyrrolidone, 20-40\% Aluminum Silicate, 1$5 \%$ Nonylphenol Ethoxylate, and $10-30 \%$ Non-hazardous ingredients. The dibasic ether has a manufacturer's recommended exposure limit of $10 \mathrm{mg} / \mathrm{m}^{3}$ and the aluminum silicate has an Occupational Safety and Health Administration (OSHA) permissible exposure limit (PEL) of $15 \mathrm{mg} / \mathrm{m}^{3}$ and an ACGIH threshold limit value (TLV) of 10 $\mathrm{mg} / \mathrm{m}^{3}$, as total dust. Dust is not a concern during the application and removal of the PCRS when the chemical remains wet, however, dust may become an exposure hazard if the chemical is allowed to dry before removal. This will need to be taken into consideration for each job where the PCRS is being used.

During the testing demonstration, organic vapor monitoring was conducted during application and removal. Monitoring was conducted using an MSA Passport Photo lonization Detector (PID). The Passport is a real-time monitor that measures organic vapors in parts per million (ppm). The PID does not identify the specific organic vapor but identifies the presence of any organic vapor.

During removal of the chemical, organic vapor readings ranged from 0.0 to $1.5 \mathrm{ppm}$. During application with the paint sprayer (this was only done for approximately 5-10 minutes due to equipment malfunction), the readings ranged from 0.0 to $2.0 \mathrm{ppm}$ and during application using a spatula the readings ranged from 0.0 to $5.0 \mathrm{ppm}$. Since it cannot be determined if these levels present the potential for overexposure, sampling for the individual ingredients in the PCRS-5/7 needs to be conducted. It does, however, indicate that organic vapors are present. Even at low levels, the organic vapor odor could be detected, especially when down wind of the work area. These low levels have the potential to cause headache, skin irritation, and respiratory tract irritation. Therefore, workers may need to utilize the appropriate PPE when applying and removing the PCRS regardless of the ppm levels recorded.

After the first application of the chemical (when it had been sprayed on), sections of the chemical had dried before removal. During removal in these areas (using a paint scraper), there was visible dust falling from the wall and ceiling. This creates a potential dust exposure and the potential for exposure to the constituents (as a dust) of the chemical and the coating that is being removed. Appropriate air sampling needs to be conducted under these conditions.

Environmental conditions such as temperature, radiant heat load, and ventilation in the area can affect how rapidly the organic solvent mixture vaporizes and therefore, the exposure level at a given time. The exposure level (vapor build-up) will also be affected by the size of the area where it is being used. The PCRS was applied and removed in an open outdoor environment during the testing demonstration. There is the potential for the organic vapor levels to be significantly higher in an enclosed environment. $A$ monitoring plan will need to be developed for the specific site and job where the chemical is being used. 


\section{HUMAN FACTORS INTERFACE}

The MSDS for PCRS-5/7 recommends the following PPE be used when applying or removing it: chemical goggles, butyl rubber gloves, impervious apron, and boots. It states that respiratory protection is not normally needed, but for spray applications or where exposures may be excessive, a National Institute of Occupational Safety and Health (NIOSH) approved organic vapor respirator may be used.

Depending on the application and removal methods used, a greater level of PPE may be required. (This was evident during the testing demonstration when the tyvek suits being worn under the impervious apron were soaked with the chemical.) This may include a chemically impervious suit instead of only an apron, and a full face air

purifying respirator. This has the potential to cause a decrease in visibility, mobility, and tactile sensation for the workers, as well as an increase in heat stress. Additionally, because of the extremely slippery work/walking surface condition, boots with special anti-slip soles need to be used.

\section{TECHNOLOGY APPLICABILITY}

After the coating has been removed from the surface by the chemical, it will need to be assured that the surface is "clean" of both PCRS residue and whatever contaminant was originally present on the surface.

Consideration will also need to be given to the wastes that are generated. Wastes may include different combinations: the PCRS itself and the PCRS combined with the surface coating being removed and its contaminants.

\section{SECTION 4 - EMERGENCY RESPONSE/PREPAREDNESS}

The use of the PCRS technology would not be applicable for use in an emergency response situation.

Emergency response/preparedness must be part of every hazardous waste site safety and health plan. In addition to credible site emergencies, site personnel must plan for credible emergencies in connection with the PCRS.

All precautions used when responding to an emergency situation at the site will apply. The PCRS- $5 / 7$ is flammable and is $85 \%$ volatile by volume. Its products of decomposition may include carbon dioxide, carbon monoxide, and oxides of nitrogen. In accordance with the MSDS, a fire involving the PCRS-5/7 should be extinguished with water spray or fog, foam, carbon dioxide, or dry chemical. This information needs to be conveyed to both on-site and off-site emergency response personnel before a situation occurs that involves the PCRS. 


\section{SECTION 5 - REGULATORY/POLICY ISSUES}

The site safety and health personnel where the PCRS technology is being used need to be concerned with safety and health regulations applicable to the issues discussed above. Regulations that apply may be divided into four categories. Core requirements are those regulations that would apply to any hazardous waste work site, regardless of the type of job. Technology specific requirements are those regulations that apply due to the specific technology being used. Special requirements are standards and policies that are specific to the technology itself and are required by reference in a regulation. Best management practices are not required, but are recommended by organizations such as the American National Standards Institute (ANSI), NIOSH, Department of Energy (DOE), National Fire Protection Association (NFPA), etc. These regulations/standards may include but not be limited to the following:

\section{Core requirements:}

- OSHA 29 CFR 1926.25 Housekeeping

- OSHA 29 CFR 1910.141 Sanitation (1910.141(a)(3) covers housekeeping)

OSHA 29 CFR 1926 Subpart Z Toxic and Hazardous Substances

OSHA 29 CFR 1910 Subpart Z Toxic and Hazardous Substances

$\checkmark \quad$ OSHA 29 CFR 1926.59 Hazard Communication

- OSHA 29 CFR 1910.1200 Hazard Communication

- OSHA 29 CFR 1926.64 Process Safety Management of Highly Hazardous Chemicals

- OSHA 29 CFR 1910.119 Process Safety Management of Highly Hazardous Chemicals

- OSHA 29 CFR 1926.65 Hazardous Waste Operations and Emergency Response

- OSHA 29 CFR 1910.120 Hazardous Waste Operations and Emergency Response

- Occupational Safety and Health Act 1970(5)(a)(1) General Duty Clause

Technology Specific Requirements:

- OSHA 29 CFR 1926 Subpart L Scaffolding 
- OSHA 29 CFR 1910.28 Safety Requirements for Scaffolding

- OSHA 29 CFR 1926 Subpart X Ladders

- OSHA 29 CFR 1910 Subpart D Ladders

$\checkmark \quad$ OSHA 29 CFR 1926.103 Respiratory Protection

$\checkmark \quad$ OSHA 29 CFR 1910.134 Respiratory Protection

$\checkmark \quad$ OSHA 29 CFR 1926.102 Eye and Face Protection

$\checkmark \quad$ OSHA 29 CFR 1910.133 Eye and Face Protection

$\checkmark \quad$ OSHA 29 CFR 1926.28 Personal Protective Equipment

- OSHA 29 CFR 1910.132 General Requirements (Personal Protective Equipment)

- OSHA 29 CFR 1926.23 First Aid and Medical Attention

- OSHA 29 CFR 1910.151 Medical Services and First Aid

\section{Best Management Practices:}

- ACGIH Threshold Limit Values for Chemical Substances and Physical Agents and Biological Exposure Indices

In addition to the above regulations and policies, it is imperative that all workers have appropriate and adequate training for the task and associated safety and health hazards. Training that would be required may be divided into four categories. Core training is that which is required for anyone entering a hazardous waste site to perform work, regardless of the type of job. Technology specific training is that training that is specific to the technology and required by safety and health standards. Special training is that which is specific to the technology to assure the worker is adequately trained for the task, but is not necessarily required by safety and health standards. Best management practices are trainings that while not mandated by health and safety standards, provide information and knowledge to the worker that will allow the worker to perform his/her job safely. Training to be applied for the centrifugal shot blast technology may include but not be limited to:

Core Training Requirements:

$\checkmark \quad$ HAZWOPER 
HAZCOM

Technology Specific Training:

$\checkmark \quad$ Ladder Safety

$\checkmark \quad$ Scaffolding Safety

- Respiratory Protection

Personal Protective Equipment

\section{Special training:}

- Job specific training for chemical application and removal

\section{Best Management Practice training:}

Ergonomics (proper lifting, bending, stooping, kneeling, safe shoveling techniques)

- Heat stress (learning to recognize signs and symptoms)

- CPR/First Aid/Emergency Response/Blood-borne Pathogens

- Construction Safety (OSHA 500) and or General Industry Safety (OSHA 501)

\section{SECTION 6 - \\ OPERATIONAL CONSIDERATIONS \& RECOMMENDATIONS}

Recommendations made here for improved worker safety and health take into consideration the use of the PCRS-5/7. Specific recommendations include:

- Work practices are of critical importance for worker exposure to the chemical being applied to and removed from the coated surface. Application and removal is a difficult process to accomplish without the worker coming in contact with the chemical. Training the worker to use the best work practices possible will help to alleviate some of these concerns. Examples of the types of work practices that are of concern include:

1. Close all containers, both storage and waste, when not in use. This will keep the chemical from adding to the vapor load in the area where the work is being conducted. 
2. Assure all PPE chosen is compatible with the chemical. An impervious apron (as recommended by the MSDS) is of no use if the material it is made of is incompatible with the chemical being used. Additional consideration needs to be given to the PPE used under the apron. If the chemical comes in contact with the garment under the apron and it is not compatible with the chemical, it is of no use.

3. All workers need to be trained in the specific hazards associated with the chemical and work practices should reflect avoidance of exposure or reducing the risk of exposure. For example, the organic solvent mixture is an eye irritant. Workers wearing goggles should never touch or remove the goggles while in the work area, nor should they touch or remove the goggles until their gloves that are contaminated with chemical are removed and their hands have been decontaminated. Additionally, touching the goggles with contaminated gloves increases the likelihood of getting the chemical on the face and head.

4. The chemical made the walking surface extremely slippery. Training workers to apply and remove the chemical to eliminate dripping and over spraying would reduce the risk of slipping and falling. Additionally, the waste containers should be placed in a location where workers do not have to walk on the slippery surface to get to them. This would also reduce the potential to have the chemical tracked onto "clean" areas. Workers should never move from the work area (exclusion zone) to the clean area (support zone) without proper decontamination.

PPE must be chosen that is compatible with the hazards and the job. Chemically impervious suits, aprons, gloves, and boots will be useless if the material they are made from is not compatible with the chemical. Consideration must also be given to special hazards that may be encountered. For example, normal chemical protective boots are inadequate during PCRS application and removal because of the extremely slippery surface conditions it creates. Special anti-slip soles need to be considered.

Due to the open outdoor environment in which the testing demonstration took place and therefore, the organic vapor monitoring, it is recommended that additional monitoring be conducted when the PCRS is applied and removed in an enclosed environment similar to environments in which it would be used at a hazardous waste clean-up site. Additionally, monitoring needs to be conducted, as appropriate, for the individual ingredients of the organic solvent mixture. 
The chemical had been applied to the wall/ceiling with a spraying application but there was not an opportunity to observe this. It was noted however, that there was a lot of over spray on adjoining surfaces. Workers spraying the chemical need to be aware of the potential for over spray and take the proper precautions. After the initial removal of the chemical, it was decided to do a second application of the chemical. When spraying was started, chemical began to ooze from ruptured areas of the hose line. The hose was replaced but the same situation occurred. Upon closer inspection of the hose, the hose had separated along several discolored areas. It appeared that the chemical which had been in the hose from the previous application had started to degrade the hose. It must always be assured that the material the hose is made of is compatible with the chemical being applied.

Since it was not possible to apply the chemical by spraying, it was applied using spatulas. Using spatulas caused a lot of dripping onto the walking surface. This increases the potential for workers to come into contact with the chemical and causes the walking surface to become extremely slippery. Workers need to be trained to use work practices to apply the chemical that cause the least amount of dripping and splashing, to clean up the walking surface as needed, and to avoid areas of the walking surface where dripping spills have occurred.

In addition, using spatulas and paint scrapers with short handles causes the chemical to come up over the tool and handle onto the workers gloves. This also increases the potential for exposure and would be eliminated by the use of longhandled tools.

There is concern with the ergonomic stressors placed on the worker during both application and removal of the chemical. The chemical was applied to the wall and ceiling using a spatula and removed using a paint scraper for the locations where the removal with the laminated paper was not complete. To reach the lower part of the wall personnel worked from ground level. To reach the upper portion of the wall, personnel worked from a ladder. There is the potential for sprain/strain to the back, shoulders, knees, and legs from the bending, kneeling, or stooping required to reach the lower section of the wall. When working from a ladder there is the potential for sprain/strain to the back, shoulders, and neck from reaching and from working with the arms extended above the head and the neck for long periods of time. Removal of the chemical with a paint scraper presents the same type of ergonomic stressors. Using ergonomically designed tools and long-handled tools would help to lessen and possibly eliminate many of the ergonomic stressors. In addition to other safety and health concerns, the use of scaffolding instead of a ladder to reach the upper wall and ceiling would help to alleviate some of the ergonomic stressors discussed above.

- There were several areas on the wall/ceiling where the laminated paper had fallen off and the chemical had become dry. When the dry chemical and coating 
were removed with a paint scrapper, dust was visible. Air sampling for total dust, respirable dust, and/or constituents of the coating and chemical needs to be conducted when dry chemical is removed.

- Reaching the upper portion of the wall and the ceiling requires a ladder or scaffolding. A ladder is not an appropriate method for reaching these areas unless the bucket containing the chemical is hoisted up to the worker on the ladder. The worker should never climb a ladder while carrying objects of any type in his/her hand(s). Additionally, the worker must be able to maintain threepoints of contact at all times while on the ladder and should never reach too far to the side or behind himself/herself to perform a task.

Scaffolding is recommended as a better alternative for reaching the upper wall and ceiling. Reaching the top portion of the wall requires the use of scaffolding. Proper precautions must be taken including compliance with the OSHA scaffold standard. No one should be permitted to work in the area of the scaffolding without a hard hat. 


\section{APPENDIX A \\ REFERENCES}

Occupational Safety and Health Standards for General Industry, 29 CFR Part 1910, Occupational Safety and Health Administration United States Department of Labor.

Occupational Safety and Health Standards for the Construction Industry, 29 CFR Part 1926, Occupational Safety and Health Administration United States Department of Labor.

Threshold Limit Values(TLV's) for Chemical Substances and Physical Agents and Biological Exposure Indices (BEl's), American Conference of Governmental Industrial Hygienists, 1995-1996.

ANSI 1986, Guide for the Measurement and Evaluation of Human Exposure to Vibration Transmitted to the Hand, New York, NY: American National Standards Institute, ANSI S3.34.

U.S. Department of Health and Human Services, Manual for the Revised NIOSH Lifting Equation, January 1994. 


\section{APPENDIX B ACRONYMS}

$\begin{array}{lll}\text { ACGIH } & - & \text { American Conference of Governmental Industrial Hygienists } \\ \text { ANSI } & - & \text { American National Standards Institute } \\ \text { CFR } & - & \text { Code of Federal Regulations } \\ \text { DOE } & - & \text { Department of Energy } \\ \text { FIU } & - & \text { Florida International University } \\ \text { HAZCOM } & - & \text { Hazard Communication } \\ \text { HAZWOPER - } & \text { Hazardous Waste Operations } \\ \text { MSA } & - & \text { Mine Safety Appliances } \\ \text { MSDS } & - & \text { Material Safety Data Sheet } \\ \text { NFPA } & - & \text { National Fire Protection Association } \\ \text { NIOSH } & - & \text { National Institute of Occupational Safety and Health } \\ \text { OSHA } & - & \text { Occupational Safety and Health Administration } \\ \text { PCRS } & - & \text { Pegasus Coating Removal System } \\ \text { PEL } & - & \text { permissible exposure limit } \\ \text { PID } & - & \text { photo ionization detector } \\ \text { PPE } & - & \text { personal protective equipment } \\ \text { PPM } & - & \text { parts per million } \\ \text { SOP's } & - & \text { standard operating procedures } \\ \text { TLV } & - & \text { threshold limit value }\end{array}$




\section{PEGASUS INTERNATIONAL, INC. COATING REMOVAL SYSTEM (PCRS) (METAL) TABLE OF CONTENTS}

ACKNOWLEDGEMENTS iii

EXECUTIVE SUMMARY iv

SECTION 1 - SUMMARY 1

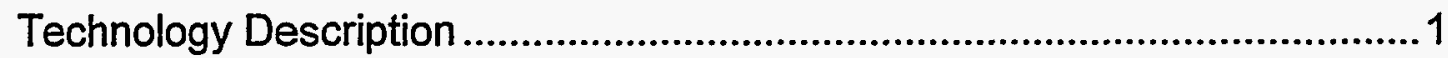

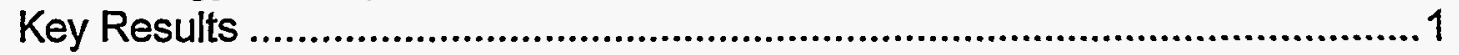

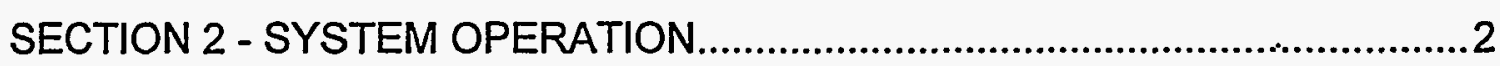

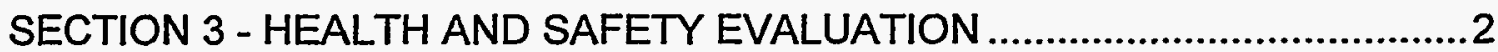

General Health and Safety Concerns.......................................................2

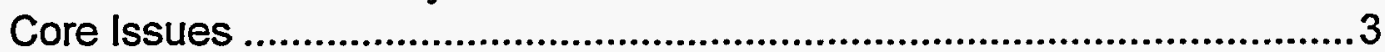

Best Management Practices......................................................................

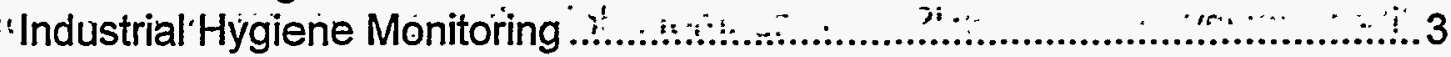

Human Factors Interface .....................................................................

Technology Applicability ..........................................................................

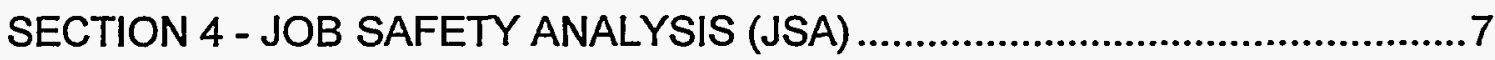

SECTION 5 - FAILURE MODES AND EFFECTS ANALYSIS (FMEA).............11

SECTION 6 - TECHNOLOGY SAFETY DATA SHEET (TSDS) …..................12

SECTION 7 - EMERGENCY RESPONSE/PREPAREDNESS ........................20

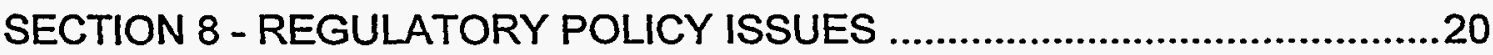

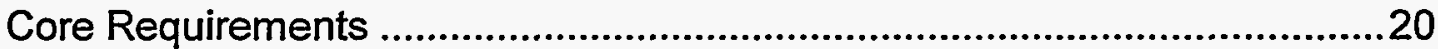

Technology Specific Requirements ...........................................................21

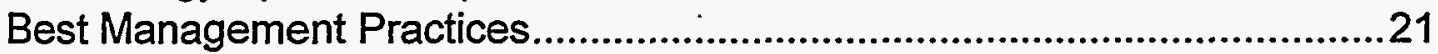

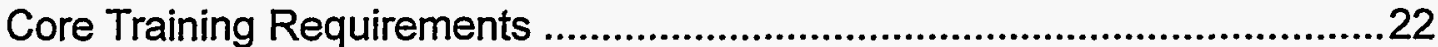

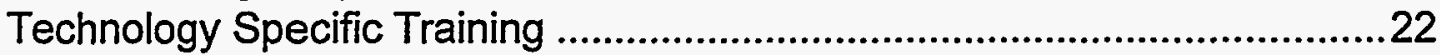

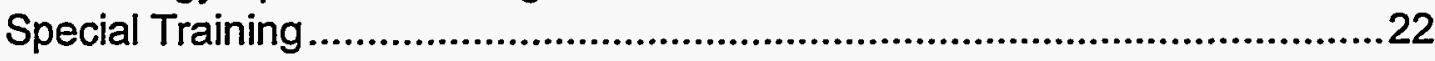

Best Management Practice Training …...................................................22 


\section{TABLE OF CONTENTS \\ (Continued)}

\section{SECTION 9 - OPERATIONAL CONSIDERATIONS AND}

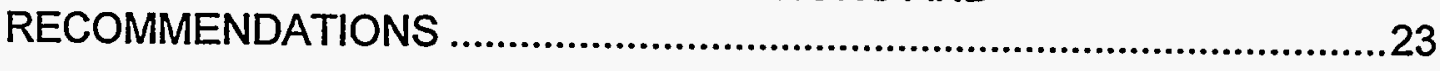

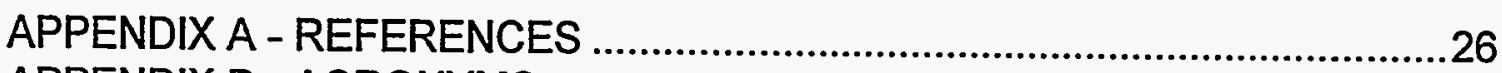

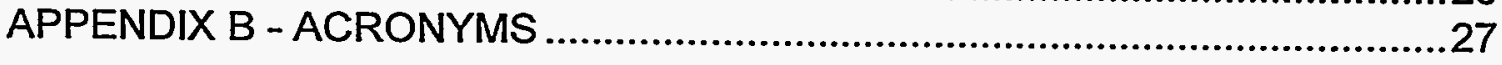




\section{ACKNOWLEDGEMENTS}

The human factors assessment of Pegasus International, Inc., Coating Removal System (Concrete Floor), was conducted under support of the U.S. Department of Energy's Federal Energy Technology Center, under cooperative agreement DE-FC2195MC32260 with the Operating Engineers National Hazmat Program. The Operating Engineers National Hazmat Program would like to thank the following people for their participation on the "research action team" and the professional expertise they provided for this assessment:

Barbara McCabe Ralph Pascarella

Daniel Timmerman
Operating Engineers National Hazmat Program Operating Engineers Local Union 30 Operating Engineers National Hazmat Program 


\section{EXECUTIVE SUMMARY}

The Pegasus Coating Removal System (PCRS) was demonstrated at Florida International University (FIU) where it was being evaluated for efficiency and cost. In conjunction with the FIU testing demonstration, a human factors assessment was conducted to assess the hazards and associated safety and health issues of concern for workers utilizing this technology.

The PCRS is a chemical paste that is applied to the surface using a brush, roller, or airless sprayer. Two types of PCRS are available. PCRS-5/7 is an organic solvent mixture primarily used for chemically resistant coatings and PCRS-ST1 and PCRS-1, which is an alkaline mixture of calcium hydroxide, magnesium hydroxide, and sodium hydroxide. PCRS-ST1 and PCRS-1 are primarily used for alkyd/latex coating removal. The type of PCRS used depends on the type and thickness of the coating and the type of substrate material. In order to determine the type of PCRS for the job, the required thickness of the paste, and the dwell time, a test area of approximately one square foot is used. Based on the performance of the chemical over this one square foot area, the operational parameters can be determined. Dwell time, which is the time required for the chemical to have its desired effect, can range from several hours to 24 hours. After the type of PCRS, thickness, and dwell time have been determined, a laminated backed material is placed on top of the chemical paste to slow down the drying process and to provide a mechanism to strip-off the chemical. After the dwell time is reached, the chemical substrate can be removed. Scrapers may be used to break-loose the layers as necessary or to break-loose the layers that are not removed when the laminated paper is picked up. Residue may also be cleaned off of the surface with a damp sponge with an agitating motion, absorbent sponges, or a vacuum, as needed. The paint and removal agent is then placed in drums for disposal at a later time.

During the human factors assessment of the PCRS, the PCRS-5/7 was used for the removal of the metal slab and I-beam coatings.

During the assessment sampling was conducted for organic vapors and general observational techniques were conducted for ergonomics. General observational techniques for ergonomics showed the potential for some ergonomic problems during application and removal of the chemical. The chemical was applied to the metal slabs and I-beams using spatulas. Using the spatula to apply the chemical requires workers to bend, kneel, or stoop to reach all sections of the metal plates and l-beams. This has the potential to cause strain/sprain to the back, knees, ankles, lower/upper legs, and back. Removal of the chemical presents the same types of ergonomic stressors because removal requires the use of a paint scraper. 
The organic vapor readings during application and removal of the PCRS ranged from 0.0 to $15.0 \mathrm{ppm}$, the higher readings being recorded in the enclosed work environment. These measurements indicate that organic vapors are present during application and removal of the PCRS. Monitoring for the specific ingredients needs to be considered on a job-by-job site-by-site basis. The low levels of organic vapor have the potential to cause headache, skin irritation, and respiratory tract irritation. Therefore, workers may need to utilize appropriate PPE when applying and removing the PCRS regardless of the ppm levels recorded.

Recommendations for improved worker safety and health during application and removal of the PCRS include: 1. work practices that reflect avoidance of exposure or reducing the risk of exposure; 2 . assuring all PPE and equipment are compatible with the chemicals being used; 3 . work practices that reduce the worker's need to walk on the slippery surface caused by the chemical or the use of special anti-slip soles; 4. careful control of overspray (if a spray application is used); and 5. the use of ergonomically designed long-handled tools and adjustable work stations to apply and remove the chemical (to alleviate some of the ergonomic concerns). 


\section{PEGASUS INTERNATIONAL, INC. COATING REMOVAL SYSTEM (PCRS) (METAL) \\ Human Factors Assessment}

\section{SECTION 1 - SUMMARY}

\section{TECHNOLOGY DESCRIPTION}

The Pegasus Coating Removal System (PCRS) technology was tested and is being evaluated at Florida International University (FIU) as a baseline technology. In conjunction with FIU's evaluation of efficiency and cost, this report covers the hazard analysis and safety evaluation. PCRS is a commercially available technology and has been used for various projects at locations throughout the country.

The PCRS is a chemical paste that is applied to the surface using a brush, roller, or airless sprayer. They type of PCRS used depends on the type and thickness of the coating, the age of the coating, and the type of substrate material. A laminated backed material is placed on top of the chemical paste to slow down the drying process and to provide a mechanișm to strip-off the material. In order to determine the type of PCRS, the required thickness of the paste, and the dwell time, a test area of approximately one square foot is used. Based on the performance of the chemical over this one square foot area, the operational parameters can be determined. Dwell time can range from several hours to 24 hours.

\section{KEY RESULTS}

The safety and health evaluation during the testing demonstration focused on two main areas: exposure to the organic chemicals and ergonomics. Air sampling with a photo ionization detector (PID) showed low exposure values but there is concern for skin exposures. Further testing for the individual ingredients of the organic based solvent is recommended. In addition, it is recommended that sampling be conducted in an enclosed environment. The outdoor environment where part of the testing demonstration took place may cause the results to be inapplicable to enclosed operating environments, where it is feasible that the exposure levels would be greater. Ergonomic stressors were potentially significant. Other safety and health issues found were heat stress, slipping/fall hazards, and environmental concerns from accidentally spreading the chemical to areas outside the immediate exclusion zone. 


\section{SECTION 2 - SYSTEM OPERATION}

The PCRS is a chemical paste that is applied to the surface using a brush, roller, or airless sprayer. Two types of PCRS are available. PCRS-5/7 is an organic solvent mixture primarily used for chemically resistant coatings and PCRS-ST1 and PCRS-1, which are alkaline mixtures of calcium hydroxide, magnesium hydroxide, and sodium hydroxide. PCRS-ST1 and PCRS-1 are primarily used for alkyd/latex coating removal. The type of PCRS used depends on the type and thickness of the coating and the type of substrate material. In order to determine the type of PCRS for the job, the required thickness of the paste, and the dwell time, a test area of approximately one square foot is used. Based on the performance of the chemical over this one square foot area, the operational parameters can be determined. Dwell time, which is the time required for the chemical to have its desired effect, can range from several hours to 24 hours. After the type of PCRS, thickness, and dwell time have been determined, a laminated backed material is placed on top of the chemical paste to slow down the drying process and to provide a mechanism to strip-off the material. After the dwell time is reached, the chemical substrate can be removed. Scrapers may be used to break-loose the layers as necessary or to break-loose the layers that are not removed when the laminated paper is picked up. Residue may also be cleaned off of the surface with a damp sponge with an agitating motion, absorbent sponges, or a vacuum, as needed. The paint and removal agent is then placed in drums for disposal at a later time. ......

During the human factors assessment of the PCRS, the PCRS- $5 / 7$ was used for the removal of the metal coating.

\section{SECTION 3 - HEALTH AND SAFETY EVALUATION}

\section{GENERAL SAFETY AND HEALTH CONCERNS}

Personnel where the PCRS is being used need to be concerned with safety and health issues. Issues that personnel need to be cognizant of may be divided into two categories. Core issues are those that are based on current safety and health regulatory requirements. Best management practices are related to issues that are not based on current safety and health regulations, but are key elements in preventing worker injury and illness on the job.

Safety and health issues of concern with PCRS included: 


\section{Core Issues:}

- Work Practices (housekeeping) - The process of applying the chemical is difficult to accomplish without the worker coming in contact with it. Training the workers to apply good work practices would assist in alleviating this concern. In addition, the need for stringent housekeeping must be addressed.

- Personal Protective Equipment (PPE) - The PPE utilized during the application of the PCRS needs to be compatible with the chemicals being used.

- Hazard Communication - The material safety data sheet (MSDS) for the . chemical being used must be available in accordance with 29 CFR 1910.1200. In addition, workers must be trained on its specific hazards.

- Exposure to Chemical - There is potential for the worker to be exposed to the chemical being used for coating removal. Exposure may occur during application and removal, from the chemical splashing during application, or by the worker coming in direct contact with the chemical. This will be discussed in greater detail in the Industrial Hygiene section of this report.

\section{Best Management Practices:}

- Ergonomics - There are ergonomic stressors that have the potential to cause stress/strain to the lower and upper back, shoulders, arms, and knees due to the bending, stooping, kneeling postures required for application and removal of the PCRS.

Slipping Hazards - The chemical applied to the metal made the work/walking surface extremely slippery.

- Heat Stress - Workers are subjected to an increase in heat stress due to the need to utilize chemical protective PPE during the application and removal of the PCRS. The user will need to develop a heat stress program for the environment in which the chemical removal system is being used, taking into consideration any PPE that may need to be utilized, ambient temperature, etc.

\section{INDUSTRIAL HYGIENE MONITORING}

During the testing demonstration with the PCRS, sampling was conducted for organic vapors. In addition, the wet-bulb globe temperature was monitored to evaluate heat stress. Observational evaluation was conducted for ergonomics. 
Through general observational techniques the potential for ergonomic problems was evaluated during the testing demonstration. The chemical was applied to the metal plates and I-beams using spatulas. Using the spatula to apply the chemical requires workers to bend, kneel, or stoop to reach all sections of the metal plates and I-beams. This has the potential to cause strain/sprain to the back, knees, ankles, lower/upper legs, and back. Removal of the chemical presents the same type of ergonomic stressors because removal was done using a paint scraper.

Heat stress parameters were monitored using a Quest QuestTemp 15 Heat Stress Monitor. The wet-bulb globe temperature was used to determine the work/rest regimen in accordance with the American Conference of Governmental Industrial

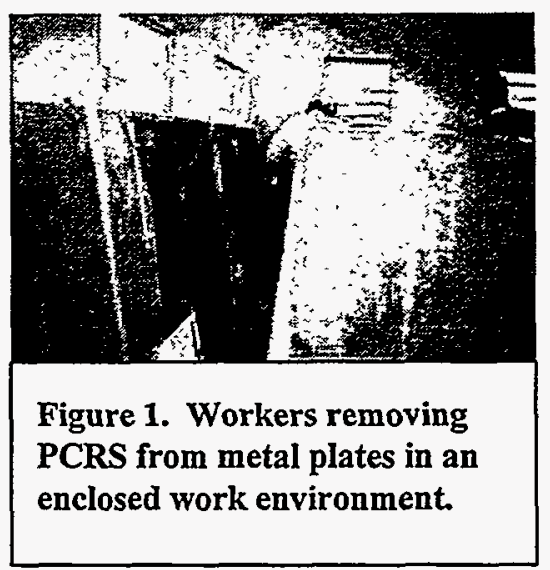
Hygienist (ACGIH) recommendations. In accordance with ACGIH guidelines, the wetbulb globe temperature was adjusted for the type of clothing, including PPE, that the worker was wearing. While heat stress will be increased when wearing PPE, the overall heat stress response will vary from worker to worker. Each situation in which the current technology is used will need to be evaluated for the heat stress potential, taking into consideration the wet-bulb globe temperature, PPE in use, physical condition of the worker, and amount of worker acclimatization.

The PCRS applied to the metal for coating removal was the PCRS- $5 / 7$, the organic solvent mixture. According to the MSDS supplied by Pegasus Inc., the mixture contains 10-25\% Dibasic Ether, 20-50\% N-Methyl-2-Pyrrolidone, 20-40\% Aluminum Silicate, 1$5 \%$ Nonylphenol Ethoxylate, and $10-30 \%$ Non-hazardous ingredients. The dibasic ether has a manufacturer's recommended exposure limit of $10 \mathrm{mg} / \mathrm{m}^{3}$ and the aluminum silicate has an Occupational Safety and Health Administration permissible exposure limit (PEL) of $15 \mathrm{mg} / \mathrm{m}^{3}$ and an ACGIH threshold limit value (TLV) of $10 \mathrm{mg} / \mathrm{m}^{3}$, as total dust. Dust was not a concern during the application and removal of the PCRS since it was a wet process. Therefore, organic vapor monitoring was conducted during application and removal. Monitoring was conducted using an MSA Passport Photo lonization Detector (PID). The Passport is a real-time monitor that measures organic vapors in parts per million (ppm). The PID does not identify the specific organic vapor but identifies the presence of any organic vapor.

The organic vapor readings during application and removal ranged from 0.0 to 15.0 $\mathrm{ppm}$, the higher readings being recorded in the enclosed work environment. Since it cannot be determined if these levels present the potential for overexposure, sampling for the individual ingredients in the PCRS-5/7 needs to be conducted. It does, however, 
indicate that organic vapors are present. Even at low levels, the organic vapor odor

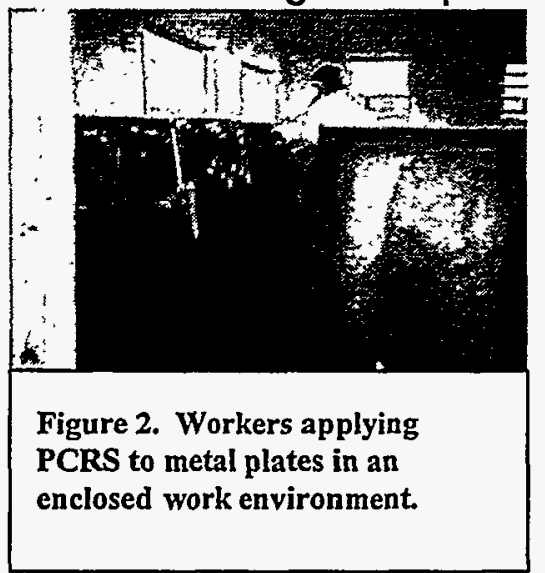
could be detected, especially when down wind of the testing area. These low levels have the potential to cause headache, skin irritation, and respiratory tract irritation. Therefore, workers may need to utilize the appropriate PPE when applying and removing the PCRS regardless of the ppm levels recorded.

Environmental conditions such as temperature, radiant heat load, and ventilation in the area can affect how rapidly the organic solvent mixture vaporizes and therefore, the exposure level at a given time. The exposure level (vapor build-up) will also be affected by the size or the area where it is being used. The PCRS was applied and removed in an open outdoor environment during part of the testing demonstration. As previously noted, the lower organic vapors were measured at that time. There is the potential for the organic vapor levels to be significantly higher in an enclosed environment. A monitoring plan will need to be developed for the specific site and job where the chemical is being used.

\section{HUMAN FACTORS INTERFACE}

The MSDS for PCRS-5/7 recommends the following PPE be used when applying or removing it: chemical goggles, butyl rubber gloves, impervious apron, and boots. It states that respiratory protection is not normally needed, but for spray applications or where exposures may be excessive, a National Institute of Occupational Safety and Health (NIOSH) approved organic vapor respirator may be used.

Depending on the application and removal methods used, a greater level of PPE may be required. (This was evident during the testing demonstration when the tyvek suit being worn under the impervious apron was soaked with the chemical.) This may include a chemically impervious suit instead of only an apron and a full face air purifying respirator. This has the potential to cause a decrease in visibility, mobility, and tactile sensation for the workers, as well as an increase in heat stress. Additionally, because of the extremely slippery walking surface condition, boots with special anti-slip soles need to be used.

\section{. TECHNOLOGY APPLICABILITY}

After the coating has been removed from the surface by the chemical, it will need to be assured that the surface is "clean" of both PCRS residue and whatever contaminant was originally present on the surface. 
Consideration will also need to be given to the wastes that are generated. Wastes may include different combinations: the PCRS itself and the PCRS combined with the surface coating being removed and its contaminants. 


\section{SECTION 4 - JOB SAFETY ANALYSIS}

\section{JOB SAFETY ANALYSIS PEGASUS INTERNATIONAL, INC. COATING REMOVAL SYSTEM (PCRS) (METAL)}

\begin{tabular}{|c|c|}
\hline \multicolumn{2}{|c|}{$\begin{array}{c}\text { HAZARD } \\
\text { UNLOADING EQUIPMENT/SETUP }\end{array}$} \\
\hline \multicolumn{2}{|c|}{ UNLOADING EQUIPMENT/SETUP } \\
\hline $\begin{array}{l}\text { * Back sprain/strain from lifting and } \\
\text { carrying buckets of chemical and tools }\end{array}$ & $\begin{array}{l}\text { * Use a fork lift to unload and lift the } \\
\text { buckets of chemical and the tools } \\
\text { * Ergonomic training to include proper } \\
\text { techniques for lifting and carrying loads }\end{array}$ \\
\hline $\begin{array}{l}\text { * Exposure to chemical when removing } \\
\text { lid from bucket }\end{array}$ & $\begin{array}{l}\text { *Wear respiratory protection, goggles, } \\
\text { and chemical protective personal } \\
\text { protective equipment (PPE), as } \\
\text { appropriate, when removing the lid from } \\
\text { the bucket } \\
\text { " Use a mechanical method for removing } \\
\text { the lid from the bucket } \\
\text { * Train worker to remove the lid from the } \\
\text { bucket with the least amount of direct } \\
\text { exposure to himself/herself }\end{array}$ \\
\hline *Mix chemical in bucket & $\begin{array}{l}\text { * Use a mechanical method for mixing } \\
\text { * Design a lid for the bucket where mixing } \\
\text { can occur with the lid on the bucket } \\
\text { * Train worker to mix with the least } \\
\text { amount of direct exposure to } \\
\text { himself/herself } \\
\text { * Wear respiratory protection, goggles, } \\
\text { and chemical protective PPE, as } \\
\text { appropriate, when mixing }\end{array}$ \\
\hline
\end{tabular}




\begin{tabular}{|l|l|}
\hline \multicolumn{2}{|c|}{ UNLOADING EQUIPMENT/SETUP } \\
\hline of test patches
\end{tabular}




\begin{tabular}{|c|c|}
\hline \multicolumn{2}{|c|}{ REMOVAL OF PCRS } \\
\hline $\begin{array}{l}\text { * Exposure to chemical during removal } \\
\text { (of chemical and laminated paper) }\end{array}$ & $\begin{array}{l}\text { * Wear respiratory protection, goggles, } \\
\text { and chemical protective PPE, as } \\
\text { appropriate, when removing the chemical } \\
{ }^{*} \text { Assure workers are trained in the } \\
\text { hazards associated with the chemicals in } \\
\text { accordance with Hazard Communication } \\
\text { (29 CFR } 1910.1200) \\
{ }^{*} \text { Assure the MSDS's for all chemicals } \\
\text { being used are available in accordance } \\
\text { with } 29 \text { CFR } 1910.1200\end{array}$ \\
\hline $\begin{array}{l}{ }^{*} \text { Ergonomic stressors during removal (of } \\
\text { the chemical and laminated paper) }\end{array}$ & $\begin{array}{l}{ }^{*} \text { Ergonomic training to include correct } \\
\text { techniques for lifting, bending, stooping, } \\
\text { and kneeling } \\
{ }^{*} \text { Use ergonomically designed tools that } \\
\text { allow removal with the minimum amount } \\
\text { of bending, kneeling, or twisting }\end{array}$ \\
\hline \multicolumn{2}{|c|}{$\begin{array}{l}\text { CLEANING UP OF THE SITE AND TOOLS USED FOR APPLICATION } \\
\text { AND REMOVAL OF THE CHEMICAL }\end{array}$} \\
\hline $\begin{array}{l}{ }^{*} \text { Exposure to chemical during clean up } \\
\text { of tools and area }\end{array}$ & 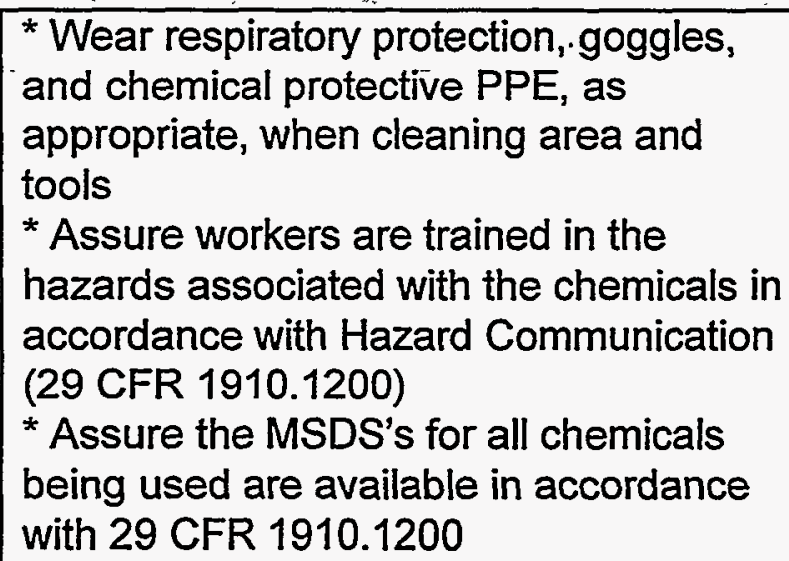 \\
\hline $\begin{array}{l}\text { * Back sprain/strain from lifting and } \\
\text { bending during clean up }\end{array}$ & $\begin{array}{l}\text { * Ergonomic training to include correct } \\
\text { techniques for lifting, bending, and } \\
\text { carrying }\end{array}$ \\
\hline
\end{tabular}




\begin{tabular}{|c|c|}
\hline $\begin{array}{l}\text { * Exposure to chemical from leaving } \\
\text { PCRS buckets open to dry }\end{array}$ & $\begin{array}{l}\text { *Wear respiratory protection, goggles, } \\
\text { and chemical protective PPE, as } \\
\text { appropriate, when entering area where } \\
\text { open buckets are drying } \\
\text { * Place open buckets in a remote area to } \\
\text { dry } \\
\text { * Dispose of buckets as waste instead of } \\
\text { allowing to dry to be reused } \\
\text { *Assure workers are trained in the } \\
\text { hazards associated with the chemicals in } \\
\text { accordance with Hazard Communication } \\
\text { (29 CFR } 1910.1200 \text { ) } \\
\text { *Assure the MSDS's for all chemicals } \\
\text { being used are available in accordance } \\
\text { with } 29 \text { CFR } 1910.1200\end{array}$ \\
\hline $\begin{array}{l}\text { * Back strain/sprain from lifting/carrying } \\
\text { waste containers for disposal }\end{array}$ & $\begin{array}{l}\text { * Ergonomic training to include correct } \\
\text { techniques for lifting, bending, and } \\
\text { carrying } \\
\text { * Use mechanical method such as fork lift } \\
\text { for lifting and moving waste to disposal } \\
\text { area }\end{array}$ \\
\hline \multicolumn{2}{|c|}{ LOADING/TEAR DOWN } \\
\hline $\begin{array}{l}{ }^{*} \text { Back sprain/strain from lifting and } \\
\text { carrying buckets of chemical and tools }\end{array}$ & $\begin{array}{l}\text { * Use a fork lift to load and lift the buckets } \\
\text { of chemical and the tools } \\
\text { * Ergonomics training to include proper } \\
\text { techniques for lifting and carrying loads }\end{array}$ \\
\hline
\end{tabular}




\section{SECTION 5 - FAILURE MODE AND EFFECTS ANALYSIS}

\section{FAILURE MODE AND EFFECTS ANALYSIS PEGASUS INTERNATIONAL, INC. COATING REMOVAL SYSTEM (PCRS) (METAL)}

\begin{tabular}{|l|l|}
\hline \multicolumn{1}{|c|}{ FAILURE MODE } & \multicolumn{1}{|c|}{ EFFECT } \\
\hline $\begin{array}{l}\text { * Lid on bucket containing chemical will } \\
\text { not come off/go back on }\end{array}$ & $\begin{array}{l}\text { * Bucket of chemical spills while worker } \\
\text { trying to get lid off/on and increases the } \\
\text { potential for the worker to be exposed to } \\
\text { the chemical } \\
\text { * Spill must be cleaned up which } \\
\text { increases the potential for the worker to } \\
\text { be exposed to the chemical }\end{array}$ \\
\hline $\begin{array}{l}\text { * The chemical does not remove the } \\
\text { surface coating as expected }\end{array}$ & $\begin{array}{l}\text { * Increase in ergonomic stressors on } \\
\text { worker from additional effort that must be } \\
\text { used to scrape chemical and coating } \\
\text { from surface }\end{array}$ \\
\hline
\end{tabular}




\section{SECTION 6 - TECHNOLOGY SAFETY DATA SHEET}

\section{TECHNOLOGY SAFETY DATA SHEET PEGASUS INTERNATIONAL INC. COATING REMOVAL SYSTEM (PCRS) (METAL)}

\begin{tabular}{|c|c|}
\hline \multicolumn{2}{|l|}{ SECTION 1: TECHNOLOGY IDENTITY } \\
\hline \multirow{3}{*}{$\begin{array}{l}\text { Manufacturer's Name and Address: } \\
\text { Pegasus International Inc. } \\
\text { 106 Railroad Street } \\
\text { Schenley, PA } 15682\end{array}$} & $\begin{array}{l}\text { Emergency Contact: } \\
\text { Tom Bodkin } \\
\text { (412) 295-0066 }\end{array}$ \\
\hline & $\begin{array}{l}\text { Information Contact: } \\
\text { Tom Bodkin } \\
\text { (412) 295-0066 }\end{array}$ \\
\hline & Date Prepared: \\
\hline $\begin{array}{l}\text { Other Names: } \\
\text { PCRS, PCRS-5/7., Organic solvent } \\
\text { mixture }\end{array}$ & $\begin{array}{l}\text { Signature of Preparer: } \\
\text { Operating Engineers National Hazmat } \\
\text { Program } \\
1293 \text { Airport Road, Beaver, WW } 25813 \text {, } \\
\text { phone 304-253-8674, fax 304-253-7758. } \\
\text { Under cooperative agreement DE-FC21- } \\
95 \text { MC } 32260\end{array}$ \\
\hline
\end{tabular}




\section{SECTION 2: PROCESS DESCRIPTION}

The PCRS is a chemical paste that is applied to the surface using a brush, roller, or airless sprayer. Two types of PCRS are available. PCRS-5/7 is an organic solvent mixture primarily used for chemically resistant coatings and PCRS-ST1 and PCRS-1 which is an alkaline mixture of calcium hydroxide, magnesium hydroxide, and sodium hydroxide. PCRS-ST1 and PCRS-1 are primarily used for alkyd/latex coating removal. The type of PCRS used depends on the type and thickness of the coating and the type of substrate material. In order to determine the type of PCRS for the job, the required thickness of the paste, and the dwell time, a test area of approximately one square foot is used. Based on the performance of the system over this one square foot area, the operational parameters can be determined. Dwell time, which is the time required for the chemical to have its desired effect, can range from several hours to 24 hours. After the type of PCRS, thickness, and dwell time have been determined, a laminated backed material is placed on top of the chemical paste to slow down the drying process and to provide a mechanism to strip-off the material. After the dwell time is reached, the chemical substrate can be removed. Scrapers may be used to break-loose the layers as necessary or to break-loose the layers that are not removed when the laminated paper is picked up. Residue may also be cleaned off of the surface with a damp sponge with an agitating motion, absorbent sponges, or a vacuum, as needed. The paint and removal agent is then

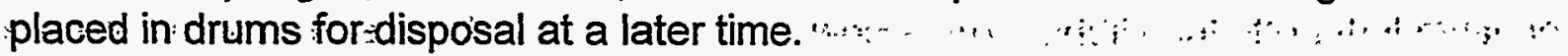

The PCRS $-5 / 7$ is referenced by this technology safety data sheet (TSDS). This TSDS does not include information for PCRS-ST1 and PCRS-1. 


\section{SECTION 3: PROCESS DIAGRAMS}

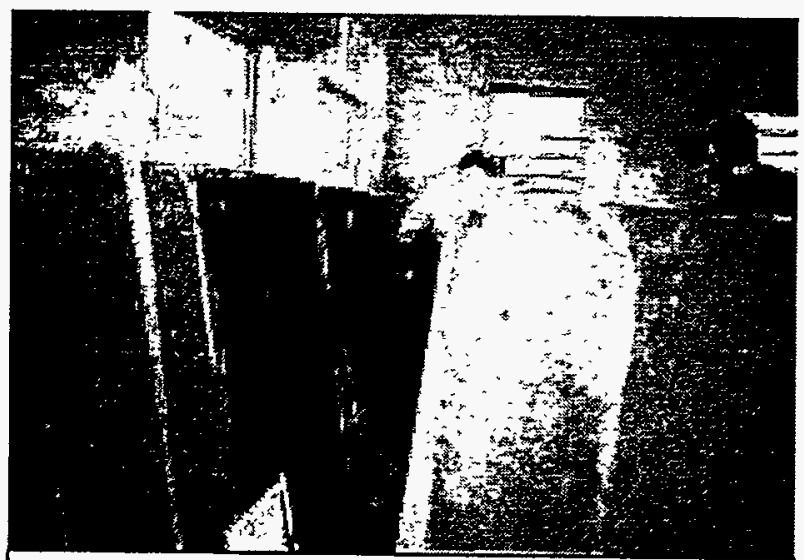

Figure 1. Workers removing PCRS from metal plate in an enclosed work environment.

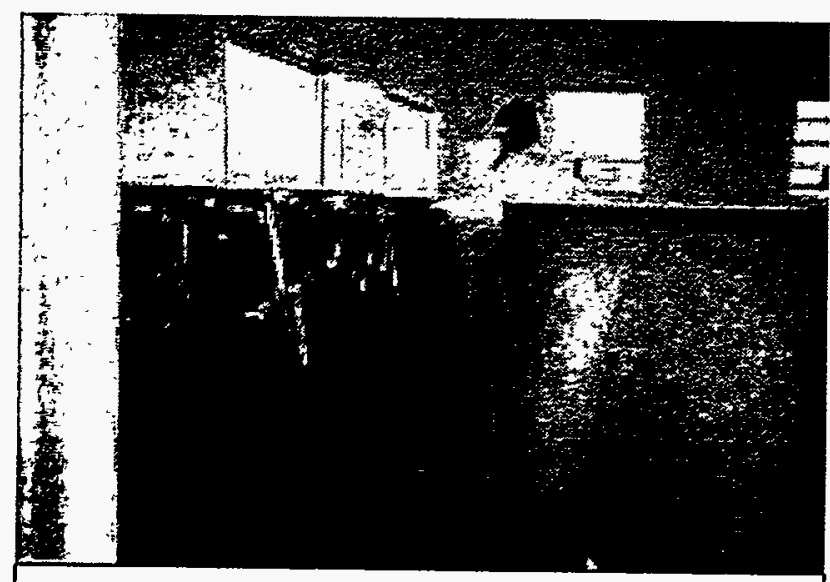

Figure 4. Workers removing chemical laminated paper and coating from Ibeams.

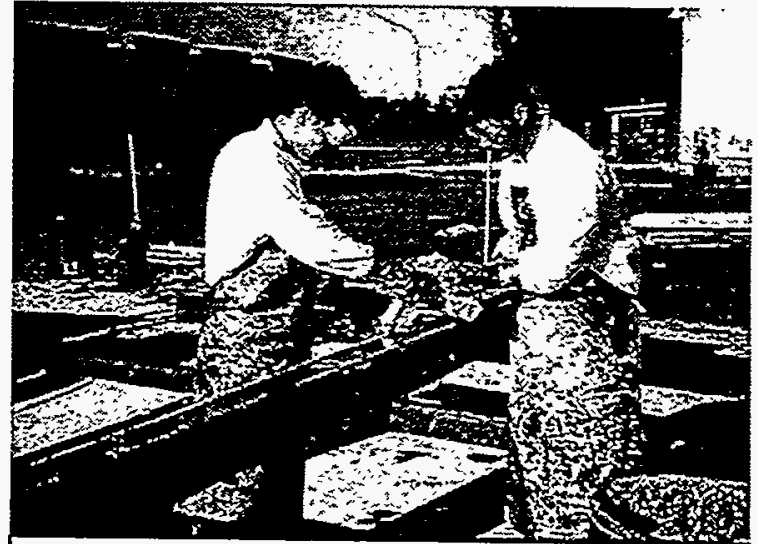

Figure 2. Workers applying PCRS to metal plates in an enclosed work environment.

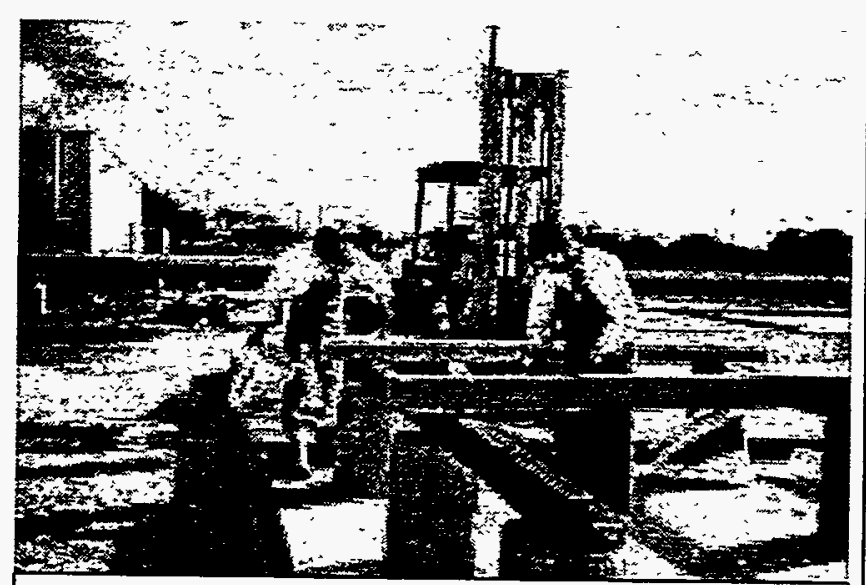

Figure 3. Workers applying PCRS to Ibeams. 


\section{SECTION 4: CONTAMINANTS AND MEDIA}

The PCRS- $5 / 7$ is an organic solvent mixture. According to the MSDS supplied by Pegasus Inc., the mixture contains 10-25\% Dibasic Ether, 20-50\% N-Methyl-2Pyrrolidone, $20-40 \%$ Aluminum Silicate, $1-5 \%$ Nonylphenol Ethoxylate, and $10-30 \%$ Non-hazardous ingredients. The dibasic ether has a manufacturer's recommended exposure limit of $10 \mathrm{mg} / \mathrm{m}^{3}$ and the aluminum silicate has an OSHA permissible exposure limit (PEL) of $15 \mathrm{mg} / \mathrm{m}^{3}$ and an ACGIH threshold limit vale (TLV) of 10 $\mathrm{mg} / \mathrm{m}^{3}$, as total dust. Dust should not be a concern during the application and removal of the PCRS since it is a wet process, but may become a concern if the chemical is allowed to dry before removal. Monitoring needs to be conducted for organic vapors and/or the individual ingredients of the mixture. A monitoring plan will need to be developed on a site-by-site job-by-job basis.

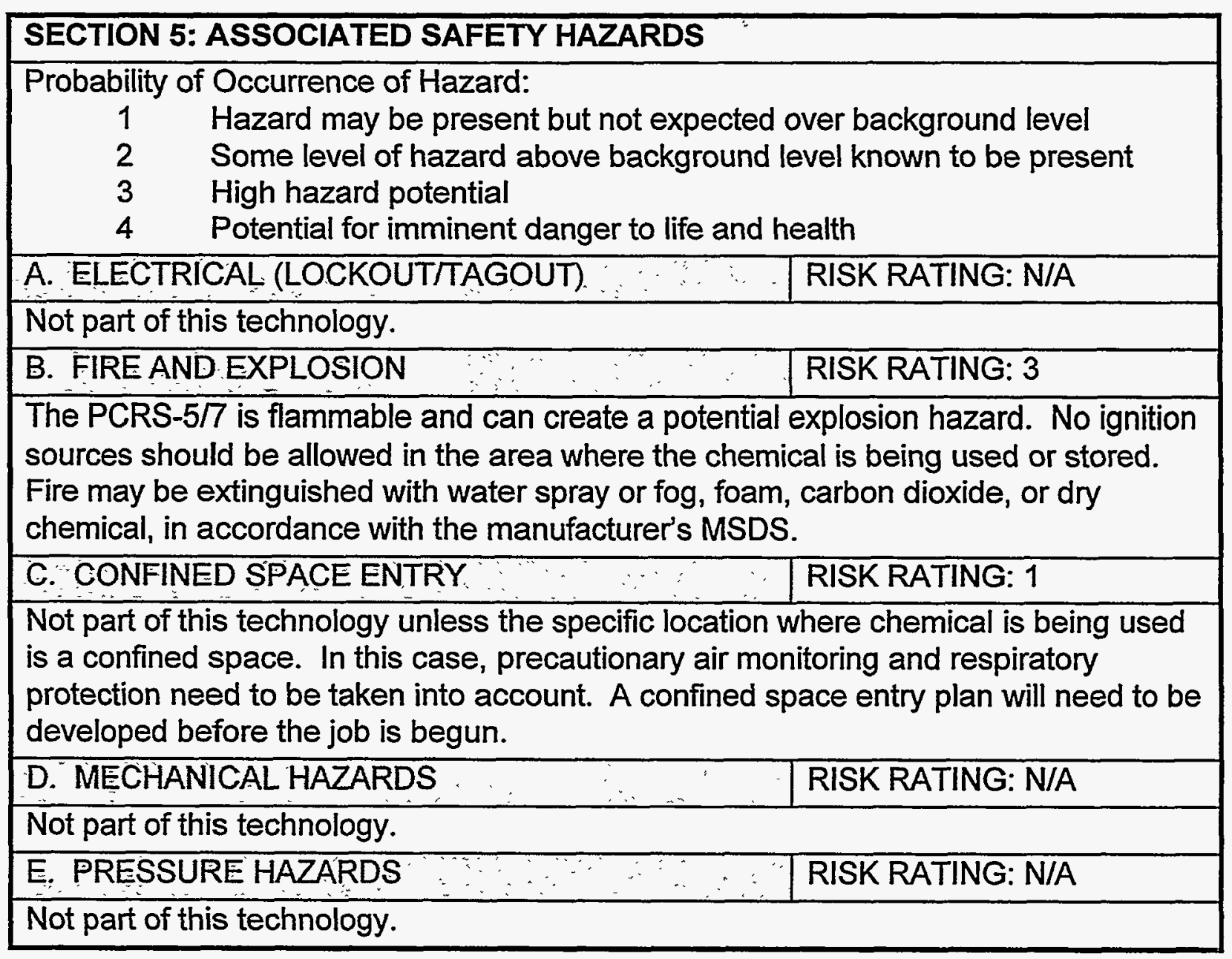


F. TRIPPING AND FALLING

RISK RATING: 4

There is an extreme slipping/fall hazard created by the chemical dripping on the walking surface. Walking on the surface after the chemical has been applied needs to be avoided. Special anti-slip soles on the chemical protective boots needs to be considered.
G. LADDERS AND PLATFORMS
RISK RATING: N/A

Not part of this technology.

H. MOVING VEHICLES RISK RATING: N/A

Not part of this technology.

I. BURIED UTILITIES, DRUMS, AND TANKS

RISK RATING: N/A

Not part of this technology.

J. PROTRUDING OBJECTS

RISK RATING: N/A

Not part of this technology.

K. GAS CYLINDERS

RISK RATING: N/A

Not part of this technology.

L. TRENCHING AND EXCAVATIONS

RISK RATING: N/A

Not part of this technology.

M. OVERHEAD LIFTS

RISK.RATING: N/A

Not part of this technology.

N. OVERHEAD HAZARDS

RISK RATING: N/A

Not part of this technology.

\section{SECTION 6: ASSOCIATED HEALTH HAZARDS}

\section{A. INHALATION HAZARD \\ RISK RATING: 3}

Organic vapors are produced during application and removal of the PCRS. Even at low levels these have the potential to cause headache, skin irritation, and respiratory tract irritation. The aluminum silicate does not present a concern as long as the chemical is wet.

B. SKIN ABSORPTION

RISK RATING: 3

The PCRS- $5 / 7$ is a concern for skin exposure. The chemical may be absorbed into the body through the skin and may cause skin irritation and prolonged exposure may cause burns, in accordance with the MSDS.

C. HEAT STRESS RISK RATING: 4

Ambient atmospheric conditions correlated with PPE levels must be considered. 


\begin{tabular}{|l|l|}
\hline D. NOISE & RISK RATING: N/A \\
\hline Not a concern with this technology. & RISK RATING: N/A \\
\hline E: NON-IONIZING RADIATION & RISK RATING: N/A \\
\hline Not part of this technology. & RISK RATING: 1 \\
\hline F. IONIZING RADIATION & RISK RATING: 3 \\
\hline Not part of this technology, but may be associated with the surface being treated. \\
\hline G. COLD STRESS \\
\hline $\begin{array}{l}\text { Technology does not produce a hazard, but ambient conditions need to be } \\
\text { considered. }\end{array}$ \\
\hline H. ERGONOMIC HAZARDS \\
\hline $\begin{array}{l}\text { Poses ergonomic hazards associated with lifting, bending, twisting, stooping and } \\
\text { kneeling. These may cause injury/strain to the back, knees, hips and/or legs. }\end{array}$ \\
\hline L. OTHER & RISK RATING: N/A \\
\hline None noted.
\end{tabular}

\section{SECTION 7: PHASE ANALYSIS}

A. CONSTRUCTION/START-UP

The set-up/start-up phase presents predominantly ergonomic hazards from lifting and carrying the buckets of PCRS to be applied to the surface. There is the potential for exposure to the chemical when the lids are removed from the buckets to mix and prepare the chemical for application.

B. OPERATION

The operational phase presents the potential for exposure to the chemical both during application and removal. There are also ergonomic stressors associated with bending, kneeling, and stooping during application and removal.

C. MAINTENANCE

There are no maintenance activities associated with this technology.

D. DECOMMISSIONING

After the coating has been removed from the surface by the chemical, it will need to be assured that the surface is "clean" of both PCRS residue and whatever contaminant was originally present on the surface. Precautions need to be taken to assure the chemical is not tracked from one area to another during clean-up and that all water runoff from cleaning up is contained and disposed of appropriately. 


\section{SECTION 8: HEALTH AND SAFETY PLAN REQUIRED ELEMENTS \\ A. AIR MONITORING}

Environmental conditions such as air temperature, radiant heat load, and ventilation in the area can affect how rapidly the organic solvent mixture vaporizes and therefore, the exposure level at a given time. The exposure level (vapor build-up) will also be affected by the size of the area where the PCRS is being used. A monitoring plan will need to be developed for the specific site and job where the chemical is being used. If circumstances are such that the chemical may dry before removal, aluminum silicate, as total dust, may also need to be monitored.

\section{B. WORKER TRAINING}

Training that would apply to the use of the PCRS may include but not be limited to: HAZWOPER (Hazardous Waste Operations and Emergency Response), HAZCOM (Hazard Communication), Respiratory Protection, Personal Protective Equipment, Ergonomics (proper lifting, bending, kneeling, stooping), Heat Stress, CPR/First Aid/Emergency Response/Bloodborne Pathogens, Construction Safety (OSHA 500) and/or General Industry Safety (OSHA 501), and job specific training for application and removal of the PCRS.

C. EMERGENCY RESPONSE

Emergency response planning for a site needs to assure adequate coverage for hazards described in the TSDS. Having at least one person per shift trained in CPR and first aid is recommended.

All precautions used when responding to an emergency situation at the site will apply. The PCRS- $5 / 7$ is flammable and is $85 \%$ volatile by volume. Its products of decomposition may include carbon dioxide, carbon monoxide, and oxides of nitrogen. In accordance with the MSDS, a fire involving the PCRS-5/7 should be extinguished with water spray or fog, foam, carbon dioxide, or dry chemical. This information needs to be conveyed to both on-site and off-site emergency response personnel before a situation occurs that involves the PCRS.

\section{MEDICAL SURVEILLANCE}

Evaluation of personnel's general health in accordance with 29 CFR 1910.120 with emphasis on the cardiovascular and respiratory system; back, knees, and legs; and central and peripheral nervous systems. In addition, any medical surveillance required by the OSHA standards needs to be provided.

E. INFORMATIONAL PROGRAM

Workers must be trained in specific application and removal of the PCRS.

Additionally, they must be trained in accordance with 29 CFR 1910.1200, Hazard

Communication. 


\section{SECTION 9: COMMENTS AND SPECIAL CONSIDERATIONS}

Only personnel who have been adequately trained in the application and removal, as well as the hazards associated with the PCRS, should be permitted to work with it.

Consideration needs to be given to the compatibility of PPE with the specific chemical being used. 


\section{SECTION 7 - EMERGENCY RESPONSE/PREPAREDNESS}

The use of the PCRS technology would not be applicable for use in an emergency response situation.

Emergency response/preparedness must be part of every hazardous waste site safety and health plan. In addition to credible site emergencies, site personnel must plan for credible emergencies in connection with the PCRS.

All precautions used when responding to an emergency situation at the site will apply. The PCRS $-5 / 7$ is flammable and is $85 \%$ volatile by volume. Its products of decomposition may include carbon dioxide, carbon monoxide, and oxides of nitrogen. In accordance with the MSDS a fire involving the PCRS-5/7 should be extinguished with water spray or fog, foam, carbon dioxide, or dry chemical. This information needs to be conveyed to both on-site and off-site emergency response personnel before a situation occurs that involves the PCRS.

\section{SECTION 8 - REGULATORYIPOLICY ISSUES}

The site safety and health personnel where the PCRS technology is being used need to be concerned with safety and health regulations applicable to the issues discussed above. Regulations that apply may be divided into four categories. Core requirements are those regulations that would apply to any hazardous waste work site, regardless of the type of job. Technology specific requirements are those regulations that apply due to the specific technology being used. Special requirements are standards and policies that are specific to the technology itself and are required by reference in a regulation. Best management practices are not required, but are recommended by organizations such as the American National Standards Institute (ANSI), NIOSH, Department of Energy (DOE), National Fire Protection Association (NFPA), etc. These regulations/standards may include but not be limited to the following:

\section{Core requirements:}

$\checkmark \quad$ OSHA 29 CFR 1926.25 Housekeeping

- OSHA 29 CFR 1910.141 Sanitation (1910.141(a)(3) covers housekeeping)

- OSHA 29 CFR 1926 Subpart Z Toxic and Hazardous Substances

- OSHA 29 CFR 1910 Subpart Z Toxic and Hazardous Substances

$\checkmark \quad$ OSHA 29 CFR 1926.59 Hazard Communication 
- OSHA 29 CFR 1910.1200 Hazard Communication

OSHA 29 CFR 1926.64 Process Safety Management of Highly Hazardous Chemicals

OSHA 29 CFR 1910.119 Process Safety Management of Highly Hazardous Chemicals

OSHA 29 CFR 1926.65 Hazardous Waste Operations and Emergency Response

- OSHA 29 CFR 1910.120 Hazardous Waste Operations and Emergency Response

Occupational Safety and Health Act 1970(5)(a)(1) General Duty Clause Technology Specific Requirements:

- OSHA 29 CFR 1926.103 Respiratory Protection

- OSHA 29 CFR 1910.134 Respiratory Protection

- OSHA 29 CFR 1926.102 Eye and Face Protection

- OSHA 29 CFR 1910.133 Eye and Face Protection

- OSHA 29 CFR 1926.28 Personal Protective Equipment

- OSHA 29 CFR 1910.132 General Requirements (Personal Protective Equipment)

- OSHA 29 CFR 1926.23 First Aid and Medical Attention

- OSHA 29 CFR 1910.151 Medical Services and First Aid

\section{Best Management Practices:}

- ACGIH Threshold Limit Values for Chemical Substances and Physical Agents and Biological Exposure Indices 
In addition to the above regulations and policies, it is imperative that all workers have appropriate and adequate training for the task and associated safety and health hazards. Training that would be required may be divided into four categories. Core training is that which is required for anyone entering a hazardous waste site to perform work, regardless of the type of job. Technology specific training is that training that is specific to the technology and required by safety and health standards. Special training is that which is specific to the technology to assure the worker is adequately trained for the task, but is not necessarily required by safety and health standards. Best management practices are trainings that while not mandated by health and safety standards, provide information and knowledge to the worker that will allow the worker to perform his/her job safely. Training to be applied for the centrifugal shot blast technology may include but not be limited to:

\section{Core Training Requirements:}

\section{$\checkmark$ HAZWOPER}

$\checkmark \quad$ HAZCOM

\section{Technology Specific Training:}

- Respiratory Protection

- Personal Protective Equipment

\section{Special Training:}

- Job specific training for chemical application and removal

\section{Best Management Practice Training:}

- Ergonomics (proper lifting, bending, stooping, kneeling, safe shoveling techniques)

- Heat stress (learning to recognize signs and symptoms)

- CPR/First Aid/Emergency Response/Blood-borne Pathogens

- Construction Safety (OSHA 500) and or General Industry Safety (OSHA 501) 


\section{SECTION 9 - \\ OPERATIONAL CONSIDERATIONS \& RECOMMENDATIONS}

Recommendations made here for improved worker safety and health take into consideration the use of the PCRS-5/7. Specific recommendations include:

- Work practices are of critical importance for worker exposure to the chemical being applied to and removed from the coated surface. Application and removal is a difficult process to accomplish without the worker coming in contact with the chemical. Training the worker to use the best work practices possible will help to alleviate some of these concerns. Examples of the types of work practices that are of concern include:

1. Close all containers, both storage and waste, when not in use. This will keep the chemical from adding to the vapor load in the area where the work is being conducted.

2. Assure all PPE chosen is compatible with the chemical. An impervious apron (as recommended by the MSDS) is of no use if the material it is made of is incompatible with the chemical being

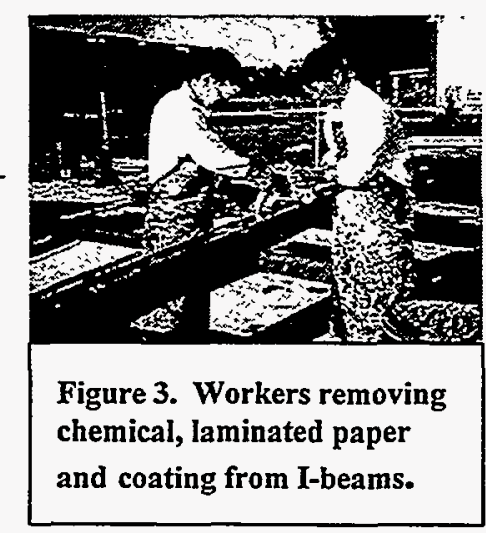
used. Additional consideration needs to be given to the PPE used under the apron. If the chemical comes in contact with the garment under the apron and it is not compatible with the chemical, it is of no use.

3. All workers need to be trained in the specific hazards associated with the chemical and work practices should reflect avoidance of exposure or reducing the risk of exposure. For example, the organic solvent mixture is an eye irritant. Workers wearing goggles should never touch or remove the goggles while in the work area, nor should they touch or remove the goggles until their gloves that are contaminated with chemical are removed and their hands have been decontaminated. Additionally, touching the goggles with contaminated gloves increases the likelihood of getting the chemical on the face and head. 
4. The chemical being applied to the metal plates and I-beams dripped onto the walking surface. This made the walking surface extremely slippery. Placing the plates and I-beams in a confined area or placing something under them, which could later be picked up, to catch the dripping would help keep the chemical off of the

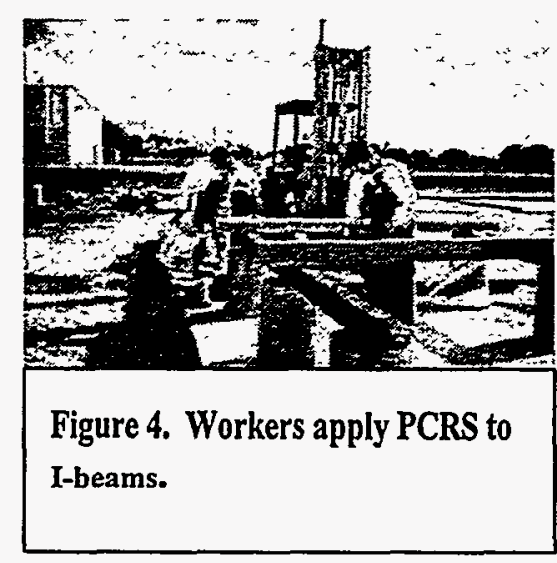
walking surface. Workers should also avoid walking where the chemical has dripped on the surface. This would also prevent the spread of the chemical to other areas of the work site.

- PPE must be chosen that is compatible with the hazards and the job.

Chemically impervious suits, aprons, gloves, and boots will be useless if the material they are made from is not compatible with the chemical. Consideration must also be given to special hazards that may be encountered. For example, normal chemical protective boots are inadequate during PCRS application and removal because of the extremely slippery walking surface conditions it creates. Special anti-slip soles need to be considered.

- Due to the open outdoor environment in which part of the testing demonstration took place and therefore, the organic vapor monitoring, it is recommended that additional monitoring be conducted when the PCRS is applied and removed in an enclosed environment similar to environments in which it would be used at a hazardous waste clean-up site. Additionally, monitoring needs to be conducted, as appropriate, for the individual ingredients of the organic solvent mixture.

- Using the spatulas and paint scrapers which had short handles cause the chemical to come up over the tool and handle onto the worker's gloves. This increases the potential for exposure and would be eliminated by the use of longhandled tools and appropriate work practices.

- Through general observational techniques the potential for ergonomic problems was evaluated during the testing demonstration. The chemical was applied to the metal plates and I-beams using spatulas. Using the spatula to apply the chemical requires the workers to bend, kneel, or stoop to reach all sections of the plates and I-beams. This has the potential to cause strain/sprain to the back, 
knees, ankles, and lower/upper legs. Removal of the chemical presents the same type of ergonomic stressors because removal was done using a paint scraper.

The use of long-handled applicators and tools for removal would allow the worker to reach all sections of the metal plates and I-beams without bending, kneeling, and stooping. Additionally, the metal pieces could be placed on an adjustable work surface that could be manipulated to the correct height and angle for the worker. 


\section{APPENDIX A REFERENCES}

Occupational Safety and Health Standards for General Industry, 29 CFR Part 1910, Occupational Safety and Health Administration United States Department of Labor

Occupational Safety and Health Standards for the Construction Industry, 29 CFR Part 1926, Occupational Safety and Health Administration United States Department of Labor

Threshold Limit Values (TLV's) for Chemical Substances and Physical Agents and Biological Exposure Indices (BEl's), American Conference of Governmental Industrial Hygienists, 1995-1996

ANSI 1986, Guide for the Measurement and Evaluation of Human Exposure to Vibration Transmitted to the Hand, New York, NY: American National Standards Institute, ANSI S3.34

U.S. Department of Health and Human Services, Manual for the Revised NIOSH Lifting Equation, January 1994 


\section{APPENDIX B ACRONYMS}

$\begin{array}{lcl}\text { ACGIH } & - & \text { American Conference of Governmental Industrial Hygienists } \\ \text { ANSI } & - & \text { American National Standards Institute } \\ \text { CFR } & - & \text { Code of Federal Regulations } \\ \text { DOE } & - & \text { Department of Energy } \\ \text { FIU } & - & \text { Florida International University } \\ \text { HAZCOM } & - & \text { Hazard Communication } \\ \text { HAZWOPER - } & \text { Hazardous Waste Operations } \\ \text { MSA } & - & \text { Mine Safety Appliances } \\ \text { MSDS } & - & \text { Material Safety Data Sheet } \\ \text { NFPA } & - & \text { National Fire Protection Association } \\ \text { NIOSH } & - & \text { National Institute of Occupational Safety and Health } \\ \text { OSHA } & - & \text { Occupational Safety and Health Administration } \\ \text { PCRS } & - & \text { Pegasus Coating Removal System } \\ \text { PEL } & - & \text { permissible exposure limit } \\ \text { PID } & - & \text { photo ionization detector } \\ \text { PPE } & - & \text { personal protective equipment } \\ \text { PPM } & - & \text { parts per million } \\ \text { SOP'S } & - & \text { standard operating procedures } \\ \text { TLV } & - & \text { threshold limit value }\end{array}$




\section{PEGASUS INTERNATIONAL, INC. COATING REMOVAL SYSTEM (PCRS) (CONCRETE FLOOR) TABLE OF CONTENTS}

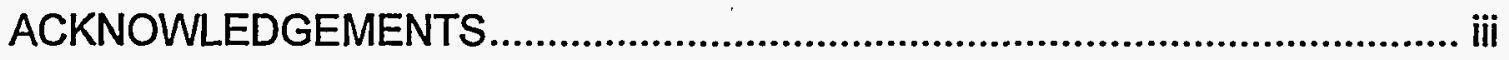

EXECUTIVE SUMMARY ................................................................................. iv

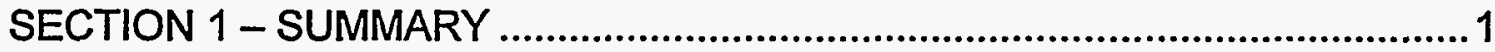

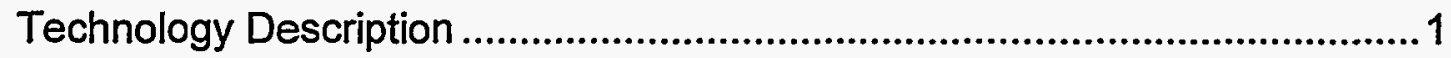

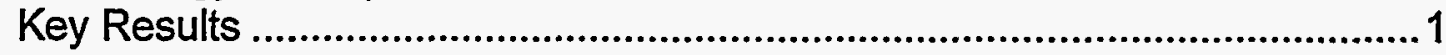

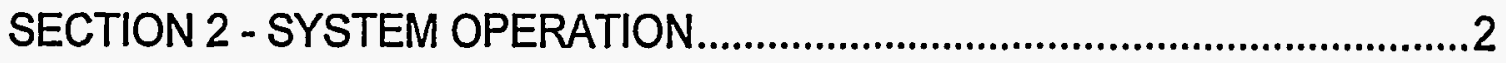

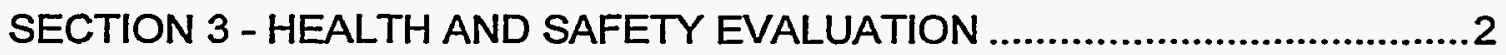

General Health and Safety Concerns .....................................................2

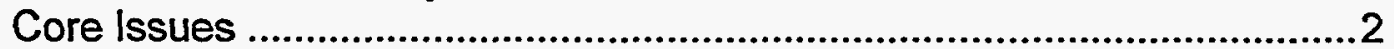

Best Management Practices.......................................................................... 3

Industrial Hygiene Monitoring ...............................................................

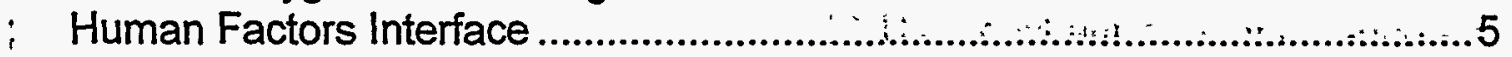

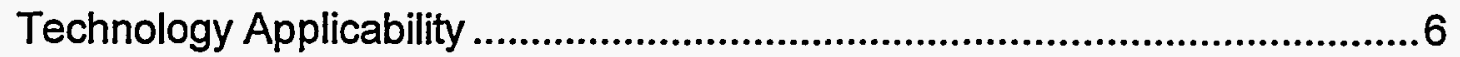

SECTION 4 - JOB`SAFETY ANALYSIS (JSA) ….........................................

SECTION 5 - FAILURE MODES AND EFFECTS ANALYSIS (FMEA).............11

SECTION 6 - TECHNOLOGY SAFETY DATA SHEET (TSDS) ......................12

SECTION 7 - EMERGENCY RESPONSE/PREPAREDNESS ........................20

SECTION 8 - REGULATORY POLICY ISSUES

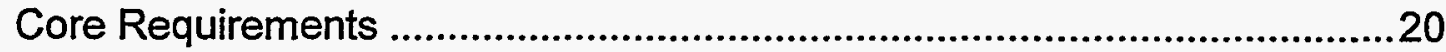

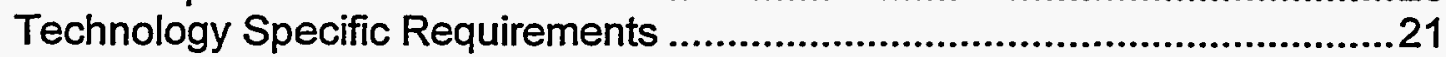

Best Management Practices ...................................................................21

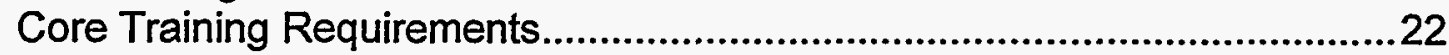

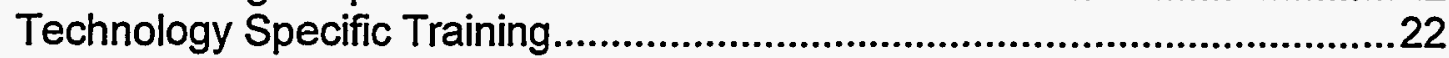

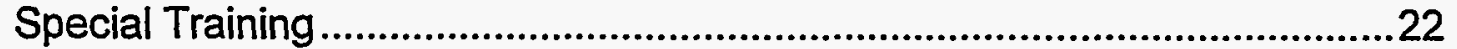

Best Management Practice Training ...............................................................22

SECTION 9 - OPERATIONAL CONSIDERATIONS AND

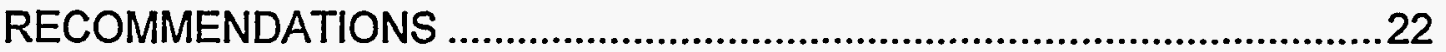




\section{TABLE OF CONTENTS}

(Continued)

APPENDIX A - REFERENCES

APPENDIX B - ACRONYMS

$5: 2 \%$

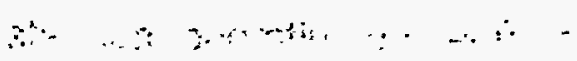




\section{ACKNOWLEDGEMENTS}

The human factors assessment of Pegasus International, Inc., Coating Removal System (Concrete Floor), was conducted under support of the U.S. Department of Energy's Federal Energy Technology Center, under cooperative agreement DE-FC2195MC32260 with the Operating Engineers National Hazmat Program. The Operating Engineers National Hazmat Program would like to thank the following people for their participation on the "research action team" and the professional expertise they provided for this assessment:

Barbara McCabe

Ralph Pascarella

Daniel Timmerman
Operating Engineers National Hazmat Program Operating Engineers Local Union 30 Operating Engineers National Hazmat Program 


\section{EXECUTIVE SUMMARY}

The Pegasus Coating Removal System (PCRS) was demonstrated at Florida International University (FIU) where it was being evaluated for efficiency and cost. In conjunction with the FIU testing demonstration, a human factors assessment was conducted to assess the hazards and associated safety and health issues of concern for workers utilizing this technology.

The PCRS is a chemical paste that is applied to the surface using a brush, roller, or airless sprayer. Two types of PCRS are available. PCRS- $5 / 7$ is an organic solvent mixture primarily used for chemically resistant coatings and PCRS-ST1 and PCRS-1, which is an alkaline mixture of calcium hydroxide, magnesium hydroxide, and sodium hydroxide. PCRS-ST1 and PCRS-1 are primarily used for alkyd/latex coating removal. The type of PCRS used depends on the type and thickness of the coating, and the type of substrate material. In order to determine the type of PCRS for the job, the required thickness of the paste, and the dwell time, a test area of approximately one square foot is used. Based on the performance of the system over this one square foot area, the operational parameters can be determined. Dwell time, which is the time required for the chemical to have its desired effect, can range from several hours to 24 hours. After the type of PCRS, thickness, and dwell time have been determined, a laminated backed material is placed on top of the chemical paste to slow down the drying process and to provide a mechanism to strip-off the chemical. After the dwell time is reached, the chemical substrate can be removed. Scrapers may be used to break-loose the layers as necessary or to break-loose the layers that are not removed when the laminated paper is picked up. Residue may also be cleaned off of the surface with a damp sponge with an agitating motion, absorbent sponges, or a vacuum, as needed. The paint and removal agent is then placed in drums for disposal at a later time.

During the human factors assessment of the PCRS, the PCRS-5/7 was used for the removal of the concrete slab coating.

During the assessment sampling was conducted for organic vapors and general observational techniques were conducted for ergonomics. General observational techniques for ergonomics showed the potential for some ergonomic problems during application and removal of the chemical. The chemical was applied to the concrete slab by two methods: (1) long-handled squeegee-type applicators and (2) spatulas. Using the long-handled applicator required both workers to constantly bend over because the handles were straight and slightly short for them. This constant bending, although slight, has the potential to cause lower back sprain/strain. An adjustable ergonomically designed handle would help alleviate this stress on the back. Using the spatula to apply the chemical requires the worker to either kneel or stoop. This has the potential to cause strain/sprain to the knees, ankles, lower/upper legs, and back. Removal of the 
chemical presents the same types of ergonomic stressors because removal requires the use of either a shovel and/or a paint scraper.

The organic vapor readings during application and removal of the PCRS ranged from 0.0 to $6.0 \mathrm{ppm}$. These measurements indicate that organic vapors are present during application and removal of the PCRS. Monitoring for the specific ingredients needs to be considered on a job-by-job site-by-site basis. The low levels of organic vapor have the potential to cause headache, skin irritation, and respiratory tract irritation. Therefore, workers may need to utilize appropriate PPE when applying and removing the PCRS regardless of the ppm levels recorded.

Recommendations for improved worker safety and health during application and removal of the PCRS include: 1. work practices that reflect avoidance of exposure or reducing the risk of exposure; 2 . assuring all PPE and equipment are compatible with the chemicals being used; 3 . work practices that reduce the worker's need to walk on the slippery surface caused by the chemical or the use of special anti-slip soles; 4. careful control of overspray (if a spray application is used); and 5. the use of ergonomically designed long-handled tools to apply and remove the chemical (to alleviate some of the ergonomic concerns). 


\section{PEGASUS INTERNATIONAL, INC. COATING REMOVAL SYSTEM (PCRS) (CONCRETE FLOOR) Human Factors Assessment}

\section{SECTION 1 - SUMMARY}

\section{TECHNOLOGY DESCRIPTION}

The Pegasus Coating Removal System (PCRS) technology was tested and is being evaluated at Florida International University (FIU) as a baseline technology. In conjunction with FIU's evaluation of efficiency and cost, this report covers the hazard analysis and safety evaluation. PCRS is a commercially available technology and has been used for various projects at locations throughout the country.

The PCRS is a chemical paste that is applied to the surface using a brush, roller, or airless sprayer. The type of PCRS used depends on the type and thickness of the coating, the age of the coating, and the type of substrate material. A laminated backed material is placed on top of the chemical paste to slow down the drying process and to provide a mechanism to strip-off the material. In order to determine the type of PCRS, the required thickness of the paste, and the dwell time, a test area of approximately one square foot is used. Based on the performance of the chemical over this one square foot area, the operational parameters can be determined. Dwell time can range from several hours to 24 hours.

\section{KEY RESULTS}

The safety and health evaluation during the testing demonstration focused on two main areas: exposure to the organic chemicals and ergonomics. Air sampling with a photo ionization detector (PID) showed low exposure values but there is concern for skin exposures. Further testing for the individual ingredients of the organic based solvent is recommended. In addition, it is recommended that sampling be conducted in an enclosed environment. The outdoor environment where the testing demonstration took place may cause the results to be inapplicable to enclosed operating environments, where it is feasible that the exposure levels would be greater. Ergonomic stressors are potentially significant. Other safety and health issues found were heat stress, slipping/fall hazards, and environmental concerns from accidentally spreading the chemical to areas outside the immediate exclusion zone. 


\section{SECTION 2 - SYSTEM OPERATION}

The PCRS is a chemical paste that is applied to the surface using a brush, roller, or airless sprayer. Two types of PCRS are available. PCRS- $5 / 7$ is an organic solvent mixture primarily used for chemically resistant coatings and PCRS-ST1 and PCRS-1, which are alkaline mixtures of calcium hydroxide, magnesium hydroxide, and sodium hydroxide. PCRS-ST1 and PCRS-1 are primarily used for alkyd/latex coating removal. The type of PCRS used depends on the type and thickness of the coating and the type of substrate material. In order to determine the type of PCRS for the job, the required thickness of the paste, and the dwell time, a test area of approximately one square foot is used. Based on the performance of the chemical over this one square foot area, the operational parameters can be determined. Dwell time, which is the time required for the chemical to have its desired effect, can range from several hours to 24 hours. After the type of PCRS, thickness, and dwell time have been determined, a laminated backed material is placed on top of the chemical paste to slow down the drying process and to provide a mechanism to strip-off the material. After the dwell time is reached, the chemical substrate can be removed. Scrapers may be used to break-loose the layers as necessary or to break-loose the layers that are not removed when the laminated paper is picked up. Residue may also be cleaned off of the surface with a damp sponge with an agitating motion, absorbent sponges, or a vacuum, as needed. The paint and removal agent is then placed in drums for disposal at a later time.

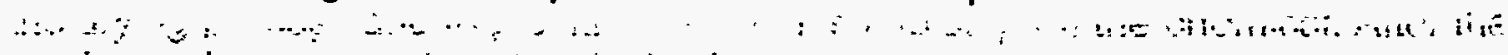
During the human factors assessment of the PCRS, the PCRS- $5 / 7$ was used for the removal of the concrete floor coating.

\section{SECTION 3 - HEALTH AND SAFETY EVALUATION}

\section{GENERAL SAFETY AND HEALTH CONCERNS}

Personnel where the PCRS is being used need to be concerned with safety and health issues. Issues that personnel need to be cognizant of may be divided into two categories. Core issues are those that are based on current safety and health regulatory requirements. Best management practices are related to issues that are not based on current safety and health regulations, but are key elements in preventing worker injury and illness on the job.

Safety and health issues of concern with PCRS included:

\section{Core Issues:}

Work Practices (housekeeping) - The process of applying the chemical is difficult to accomplish without the worker coming in contact with it. Training workers to 
apply good work practices would assist in alleviating this concern. In addition, the need for stringent housekeeping must be addressed.

- Personal Protective Equipment (PPE) - The PPE utilized during the application of the PCRS needs to be compatible with the chemicals being used.

Hazard Communication - The material safety data sheet (MSDS) for the chemical being used must be available in accordance with 29 CFR 1910.1200. In addition, workers must be trained on its specific hazards.

Exposure to Chemical - There is potential for the worker to be exposed to the chemical being used for coating removal. Exposure may occur during application and removal, from the chemical splashing during application, or by the worker coming in direct contact with the chemical. This will be discussed in greater detail in the Industrial Hygiene section of this report.

\section{Best management practices:}

- Ergonomics - There are ergonomic stressors that have the potential to cause stress/strain to the lower and upper back, shoulders, arms, and knees due to the bending, stooping, kneeling.postures required for application and removal of the PCRS:

- Slipping Hazards - The chemical applied to the concrete pad made the surface extremely slippery. The workers almost fell several times during both application and removal of the chemical.

- Heat Stress - Workers are subjected to an increase in heat stress due to the need to utilize chemical protective PPE during the application and removal of the PCRS. The user will need to develop a heat stress program for the environment in which the chemical removal system is being used, taking into consideration any PPE that may need to be utilized, ambient temperatures, etc.

\section{INDUSTRIAL HYGIENE MONITORING}

During the testing demonstration with the PCRS, sampling was conducted for organic vapors. In addition, the wet-bulb globe temperature was monitored to evaluate heat stress. Observational evaluation was conducted for ergonomics.

Through general observational techniques the potential for ergonomic problems was evaluated during the testing demonstration. The chemical was applied to the concrete 
slab by two methods: (1) long-handled squeegee-type applicators and (2) spatulas. Using the long-handled applicator required both workers to constantly bend over

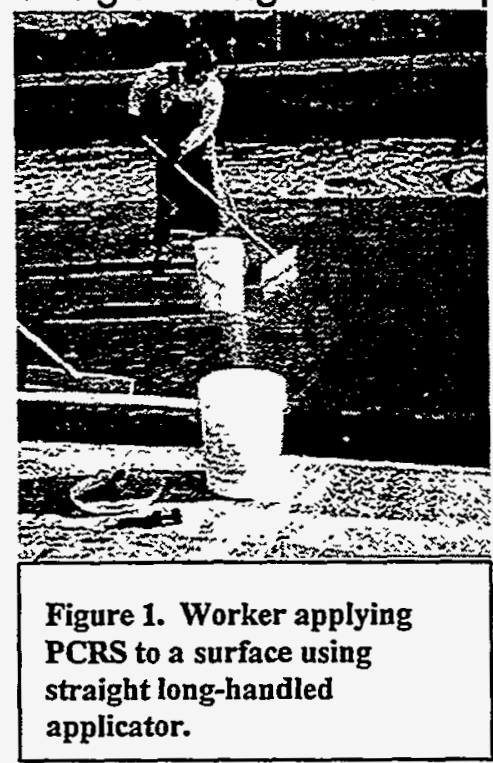

because the handles were straight and slightly short for them. This constant bending, although slight, has the potential to cause lower back sprain/strain. An adjustable ergonomically designed handle would help alleviate this stress on the back. Using the spatula to apply the chemical requires the worker to either kneel or stoop. This has the potential to cause strain/sprain to the knees, ankles, lower/upper legs, and

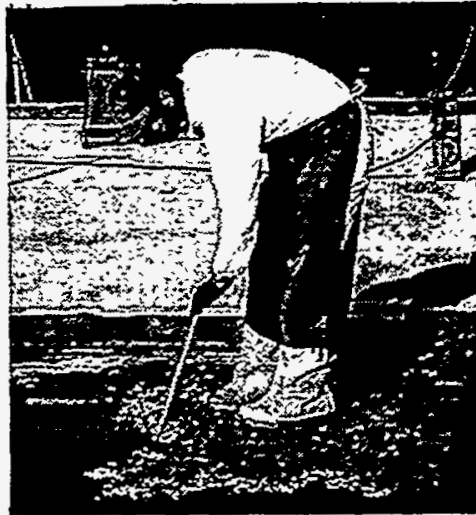

Figure 2. Worker using a long-handled paint scraper to remove chemical and surface coating.

back. Removal of the chemical presents the same types of ergonomic stressors because removal requires the use of either a shovel and/or a paint scraper.

Heat stress parameters were monitored using a Quest QuestTemp 15 Heat Stress Monitor. The wet-bulb globe temperature was used to determine the work/rest regimen in accordance with the American Conference of Governmental Industrial Hygienist (ACGIH) recommendations. In accordance with ACGIH guidelines, the wet-bulb globe temperature was adjusted for the type of clothing, including PPE, that the worker was wearing. While heat stress will be increased when wearing PPE, the overall heat stress response will vary from worker to worker. Each situation in which the current technology is used will need to be evaluated for the heat stress potential, taking into consideration the wet-bulb globe temperature, PPE in use, physical condition of the worker, and amount of worker acclimatization.

The PCRS applied to the concrete slab for coating removal was the PCRS-5/7, the organic solvent mixture. According to the MSDS supplied by Pegasus Inc., the mixture contains 10-25\% Dibasic Ether, 20-50\% N-Methyl-2-Pyrrolidone, 20-40\% Aluminum Silicate, $1-5 \%$ Nonylphenol Ethoxylate, and $10-30 \%$ Non-hazardous ingredients. The dibasic ether has a manufacturer's recommended exposure limit of $10 \mathrm{mg} / \mathrm{m}^{3}$ and the aluminum silicate has an OSHA permissible exposure limit (PEL) of $15 \mathrm{mg} / \mathrm{m}^{3}$ and an ACGIH threshold limit value (TLV) of $10 \mathrm{mg} / \mathrm{m}^{3}$, as total dust. Dust was not a concern during the application and removal of the PCRS since it was a wet process. Therefore, organic vapor monitoring was conducted during application and removal. Monitoring was conducted using an MSA Passport Photo lonization Detector (PID). The Passport is a real-time monitor that measures organic vapors in parts per million (ppm). The PID 
does not identify the specific organic vapor but identifies the presence of any organic vapor.

The organic vapor readings during application and removal of the PCRS ranged from 0.0 to $6.0 \mathrm{ppm}$. Since it cannot be determined if these levels present the potential for overexposure, sampling for the individual ingredients in the PCRS-5/7 needs to be conducted. It does, however, indicate that organic vapors are present. Even at low levels, the organic vapor odor could be detected, especially when down wind of the concrete pad. These low levels have the potential to cause headache, skin irritation, and respiratory tract irritation. Therefore, workers may need to utilize the appropriate PPE when applying and removing the PCRS regardless of the ppm levels recorded.

Environmental conditions such as temperature, radiant heat load, and ventilation in the area can affect how rapidly the organic solvent mixture vaporizes and therefore, the exposure level at a given time. The exposure level (vapor build-up) will also be affected by the size of the area where it is being used. The PCRS was applied and removed in an open outdoor environment during the testing demonstration. There is the potential for the organic vapor levels to be significantly higher in an enclosed environment. A monitoring plan will need to be developed for the specific site and job where the chemical is being used.

\section{HUMAN FACTORS INTERFACE}

The MSDS for PCRS-5/7 recommends the following PPE be used when applying or removing it: chemical goggles, butyl rubber gloves, impervious apron, and boots. It states that respiratory protection is not normally needed, but for spray applications or where exposures may be excessive, a National Institute of Occupational Safety and Health (NIOSH) approved organic vapor respirator may be used.

Depending on the application and removal methods used, a greater level of PPE may be required. (This was evident during the testing demonstration when the tyvek suit being worn under the impervious apron was soaked with the chemical.) This may include a chemically impervious suit instead of only an apron and a full face air purifying respirator. This has the potential to cause a decrease in visibility, mobility, and tactile sensation for the workers, as well as an increase in heat stress. Additionally, because of the extremely slippery surface condition, boots with special anti-slip soles need to be used. 


\section{TECHNOLOGY APPLICABILITY}

After the coating has been removed from the surface by the chemical, it will need to be assured that the surface is "clean" of both PCRS residue and whatever contaminant was originally present on the surface.

Consideration will also need to be given to the wastes that are generated. Wastes may include different combinations: the PCRS itself and the PCRS combined with the surface coating being removed and its contaminants. 


\section{SECTION 4 - JOB SAFETY ANALYSIS}

\section{JOB SAFETY ANALYSIS PEGASUS INTERNATIONAL, INC. COATING REMOVAL SYSTEM (PCRS) (CONCRETE FLOOR)}

\begin{tabular}{|l|l|}
\hline \multicolumn{2}{|c|}{ HAZARD } \\
\hline \multicolumn{2}{|c|}{ UNLOADING EQUIPMENT/SETUP } \\
\hline $\begin{array}{l}\text { * Back sprain/strain from lifting and } \\
\text { carrying buckets of chemical and tools }\end{array}$ & $\begin{array}{l}\text { * Use a fork lift to unload and lift the } \\
\text { buckets of chemical and the tools } \\
\text { * Ergonomic training to include proper } \\
\text { techniques for lifting and carrying loads }\end{array}$ \\
\hline $\begin{array}{l}\text { * Back sprain/strain from sweeping debris } \\
\text { from surface where chemical is to be } \\
\text { applied }\end{array}$ & $\begin{array}{l}\text { * Use vacuum cleaner instead of hand } \\
\text { sweeping } \\
\text { *Use industrial type brooms that the } \\
\text { worker pushes instead of standard } \\
\text { brooms that the worker must use with a } \\
\text { back and forth motion }\end{array}$ \\
\hline lid from bucket & $\begin{array}{l}\text { * Wear respiratory protection, goggles, } \\
\text { and chemical protective personal } \\
\text { protective equipment (PPE), as } \\
\text { appropriate, when removing a lid from a } \\
\text { bucket } \\
\text { *Use a mechanical method to remove } \\
\text { the lid from the bucket } \\
\text { * Train worker to remove the lid from the } \\
\text { bucket with the least amount of direct } \\
\text { exposure to himself/herself }\end{array}$ \\
\hline
\end{tabular}




\begin{tabular}{|c|c|}
\hline \multicolumn{2}{|c|}{ UNLOADING EQUIPMENTISETUP $\quad$} \\
\hline${ }^{*}$ Mix chemical in bucket & $\begin{array}{l}\text { * Use a mechanical method for mixing } \\
\text { * Design a lid for the bucket where mixing } \\
\text { can occur with the lid on the bucket } \\
\text { " Train worker to mix with the least } \\
\text { amount of direct exposure to } \\
\text { himself/herself } \\
\text { "Wear respiratory protection, goggles, } \\
\text { and chemical protective PPE, as } \\
\text { appropriate, when mixing }\end{array}$ \\
\hline $\begin{array}{l}\text { * Exposure to chemical during application } \\
\text { of test patches }\end{array}$ & $\begin{array}{l}\text { *Wear respiratory protection, goggles, } \\
\text { and chemical protective PPE, as } \\
\text { appropriate, when applying test patches } \\
\text { " Assure workers are trained in the } \\
\text { hazards associated with the chemicals in } \\
\text { accordance with Hazard Communication } \\
\text { (29 CFR } 1910.1200) \\
\text { *Assure the Material Safety Data Sheets } \\
\text { (MSDS's) for all chemicals being used } \\
\text { are available in accordance with } 29 \text { CFR } \\
1910.1200\end{array}$ \\
\hline \multicolumn{2}{|c|}{ APPLICATION OF.PCRS } \\
\hline $\begin{array}{l}\text { * Exposure to chemical during application } \\
\text { (of chemical and laminated paper) }\end{array}$ & $\begin{array}{l}\text { * Wear respiratory protection, goggles, } \\
\text { and chemical protective PPE, as } \\
\text { appropriate, when applying the chemical } \\
\text { * Assure workers are trained in the } \\
\text { hazards associated with the chemicals in } \\
\text { accordance with Hazard Communication } \\
\text { (29 CFR } 1910.1200) \\
\text { *Assure the MSDS's for all chemicals } \\
\text { being used are available in accordance } \\
\text { with } 29 \text { CFR } 1910.1200\end{array}$ \\
\hline $\begin{array}{l}\text { "Ergonomic stressors during application } \\
\text { (of chemical and laminated paper) }\end{array}$ & $\begin{array}{l}{ }^{*} \text { Ergonomic training to include } \\
\text { techniques for lifting, bending, stooping, } \\
\text { and kneeling } \\
{ }^{*} \text { For application, use only long-handled } \\
\text { tools that are ergonomically designed }\end{array}$ \\
\hline
\end{tabular}




\begin{tabular}{|c|c|}
\hline \multicolumn{2}{|c|}{ REMOVAL OF PCRS } \\
\hline $\begin{array}{l}\text { * Exposure to chemical during removal of } \\
\text { chemical and the laminated paper }\end{array}$ & $\begin{array}{l}\text { "Wear respiratory protection, goggles, } \\
\text { and chemical protective PPE, as } \\
\text { appropriate, when removing the chemical } \\
\text { or laminated paper } \\
\text { " Assure workers are trained in the } \\
\text { hazards associated with the chemicals in } \\
\text { accordance with Hazard Communication } \\
\text { ( } 29 \text { CFR } 1910.1200) \\
\text { "Assure the MSDS's for all chemicals } \\
\text { being used are available in accordance } \\
\text { with } 29 \text { CFR } 1910.1200\end{array}$ \\
\hline $\begin{array}{l}\text { * Ergonomic stressors during removal (of } \\
\text { chemical and laminated paper) }\end{array}$ & $\begin{array}{l}\text { *Ergonomic training to include correct } \\
\text { techniques for lifting, bending, stooping } \\
\text { and kneeling } \\
{ }^{*} \text { For application, use only long-handled } \\
\text { tools that are ergonomically designed }\end{array}$ \\
\hline \multicolumn{2}{|c|}{$\begin{array}{l}\text { CLEAN-UP OF THE SITE AND TOOLS USED FOR APPLICATION } \\
\text { AND REMOVAL OF THE CHEMICAL }\end{array}$} \\
\hline $\begin{array}{l}\text { Exposure to chemical during clean up } \\
\text { of tools and area }\end{array}$ & $\begin{array}{l}\text { *Wear respiratory protection, goggles, } \\
\text { and chemical protective PPE, as } \\
\text { appropriate, when cleaning area and } \\
\text { tools } \\
\text { *Assure workers are trained in the } \\
\text { hazards associated with the chemicals in } \\
\text { accordance with Hazard Communication } \\
\text { ( } 29 \text { CFR } 1910.1200) \\
\text { "Assure the MSDS's for all chemicals } \\
\text { being used are available in accordance } \\
\text { with } 29 \text { CFR } 1910.1200\end{array}$ \\
\hline $\begin{array}{l}\text { * Back sprain/strain from lifting and } \\
\text { bending during clean up }\end{array}$ & $\begin{array}{l}\text { * Ergonomic training to include correct } \\
\text { techniques for lifting, bending, and } \\
\text { carrying }\end{array}$ \\
\hline
\end{tabular}




\begin{tabular}{|c|c|}
\hline \multicolumn{2}{|c|}{$\begin{array}{l}\text { CLEAN-UP OF THE SITE AND TOOLS USED FOR APPLICATION } \\
\text { AND REMOVAL OF THE CHEMICAL }\end{array}$} \\
\hline $\begin{array}{l}\text { * Exposure to chemical from leaving } \\
\text { PCRS buckets open to dry }\end{array}$ & $\begin{array}{l}\text { * Wear respiratory protection, goggles, } \\
\text { and chemical protective PPE, as } \\
\text { appropriate, when entering area where } \\
\text { open buckets are drying } \\
\text { * Place open buckets in a remote area to } \\
\text { dry } \\
\text { * Dispose of buckets as waste instead of } \\
\text { allowing to dry to be reused } \\
\text { * Assure workers are trained in the } \\
\text { hazards associated with the chemicals in } \\
\text { accordance with Hazard Communication } \\
\text { (29 CFR } 1910.1200) \\
\text { *Assure the MSDS's for all chemicals } \\
\text { being used are available in accordance } \\
\text { with } 29 \text { CFR } 1910.1200\end{array}$ \\
\hline 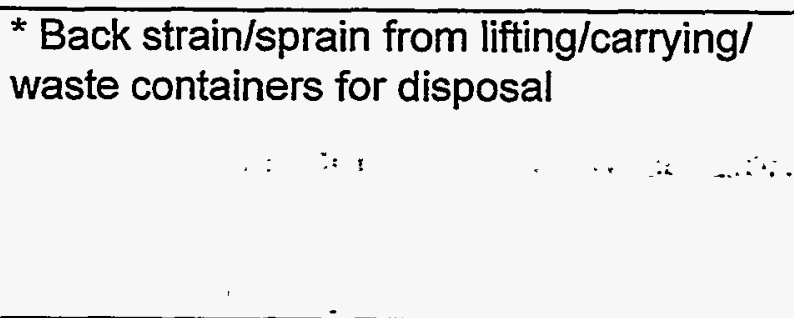 & $\begin{array}{l}\text { * Ergonomics training to include correct } \\
\text { techniques for lifting, bending, and } \\
\text { carrying } \\
\text { * Use mechanical method such as forklift } \\
\text { for lifting and moving waste to disposal } \\
\text { area }\end{array}$ \\
\hline \multicolumn{2}{|c|}{ UNLOADING/TEARING DOWN } \\
\hline $\begin{array}{l}\text { * Back sprain/strain from lifting and } \\
\text { carrying buckets of chemical and tools }\end{array}$ & $\begin{array}{l}\text { * Use a forklift to load and lift the buckets } \\
\text { of chemical and the tools } \\
\text { "Ergonomics training to include proper } \\
\text { techniques for lifting and carrying loads }\end{array}$ \\
\hline $\begin{array}{l}\text { *Back sprain/strain from sweeping debris } \\
\text { from surface where chemical had been } \\
\text { applied }\end{array}$ & $\begin{array}{l}\text { * Use vacuum cleaner instead of hand } \\
\text { sweeping } \\
\text { * Use industrial type brooms that the } \\
\text { worker pushes instead of standard } \\
\text { brooms that the worker must use with a } \\
\text { back and forth motion }\end{array}$ \\
\hline
\end{tabular}




\section{SECTION 5 - FAILURE MODE AND EFFECTS ANALYSIS}

\section{FAILURE MODE AND EFFECTS ANALYSIS PEGASUS INTERNATIONAL, INC. COATING REMOVAL SYSTEM (PCRS) (CONCRETE FLOOR)}

\begin{tabular}{|l|l|}
\hline \multicolumn{1}{|c|}{ FAILURE MODE } & \multicolumn{1}{|c|}{ EFFECT } \\
\hline $\begin{array}{l}\text { * Lid on bucket containing chemical will } \\
\text { not come off/go back on }\end{array}$ & $\begin{array}{l}\text { " } \text { Bucket of chemical spills while worker } \\
\text { trying to get lid off/on and increases the } \\
\text { potential or the worker to be exposed to } \\
\text { the chemical } \\
\text { * Spill must be cleaned up which } \\
\text { increases the potential for the worker to } \\
\text { be exposed to the chemical }\end{array}$ \\
\hline $\begin{array}{l}{ }^{*} \text { The chemical does not remove the } \\
\text { surface coating as expected }\end{array}$ & $\begin{array}{l}\text { * Increase in ergonomic stressors on } \\
\text { worker from additional effort that must be } \\
\text { used to scrape chemical and coating } \\
\text { from surface }\end{array}$ \\
\hline
\end{tabular}




\section{TECHNOLOGY SAFETY DATA SHEET PEGASUS INTERNATIONAL INC. COATING REMOVAL SYSTEM (PCRS) (CONCRETE FLOOR)}

\begin{tabular}{|c|c|}
\hline \multicolumn{2}{|l|}{ SECTION 1: TECHNOLOGY IDENTITY } \\
\hline \multirow{3}{*}{$\begin{array}{l}\text { Manufacturer's Name and Address: } \\
\text { Pegasus International Inc. } \\
\text { 106 Railroad Street } \\
\text { Schenley, PA } 15682\end{array}$} & $\begin{array}{l}\text { Emergency Contact: } \\
\text { Tom Bodkin } \\
\text { (412) 295-0066 }\end{array}$ \\
\hline & $\begin{array}{l}\text { Information Contact: } \\
\text { Tom Bodkin } \\
\text { (412) 295-0066 }\end{array}$ \\
\hline & Date Prepared: \\
\hline Other Names: & Signature of Preparer: \\
\hline $\begin{array}{l}\text { PCRS, PCRS- } 5 / 7 \text {, Organic solvent } \\
\text { mixture }\end{array}$ & $\begin{array}{l}\text { Operating Engineers National Hazmat } \\
\text { Program } \\
1293 \text { Airport Road } \\
\text { Beaver, WW } 25813 \\
\text { phone } 304-253-8674 \text { fax } 253-7758 \\
\text { Under cooperative agreement DE-FC21- } \\
95 \text { MC } 32260\end{array}$ \\
\hline
\end{tabular}




\section{SECTION 2: PROCESS DESCRIPTION}

The PCRS is a chemical paste that is applied to the surface using a brush, roller, or airless sprayer. Two types of PCRS are available. PCRS- $5 / 7$ is an organic solvent mixture primarily used for chemically resistant coatings and PCRS-ST1 and PCRS-1, alkaline mixtures of calcium hydroxide, magnesium hydroxide, and sodium hydroxide. PCRS-ST1 and PCRS-1 are primarily used for alkyd/latex coating removal. The type of PCRS used depends on the type and thickness of the coating and the type of substrate material. In order to determine the type of PCRS for the job, the required thickness of the paste, and the dwell time, a test area of approximately one square foot is used. Based on the performance of the system over this one square foot area, the operational parameters can be determined. Dwell time, which is the time required for the chemical to have its desired effect, can range from several hours to 24 hours. After the type of PCRS, thickness, and dwell time have been determined, a laminated backed material is placed on top of the chemical paste to slow down the drying process and to provide a mechanism to strip-off the material. After the dwell time is reached, the chemical substrate can be removed. Scrapers may be used to break-loose the layers as necessary or to break-loose the layers that are not removed when the laminated paper is picked up. Residue may also be cleaned off of the surface with a damp sponge with an agitating motion, absorbent sponges, or a vacuum, as needed. The paint and removal agent is then placed in drums for disposal at a later time.

The PCRS- $5 / 7$ is referenced by this technology safety data sheet (TSDS). The TSDS does not include information for PCRS-ST1 and PCRS-1. 


\section{SECTION 3: PROCESS DIAGRAMS}
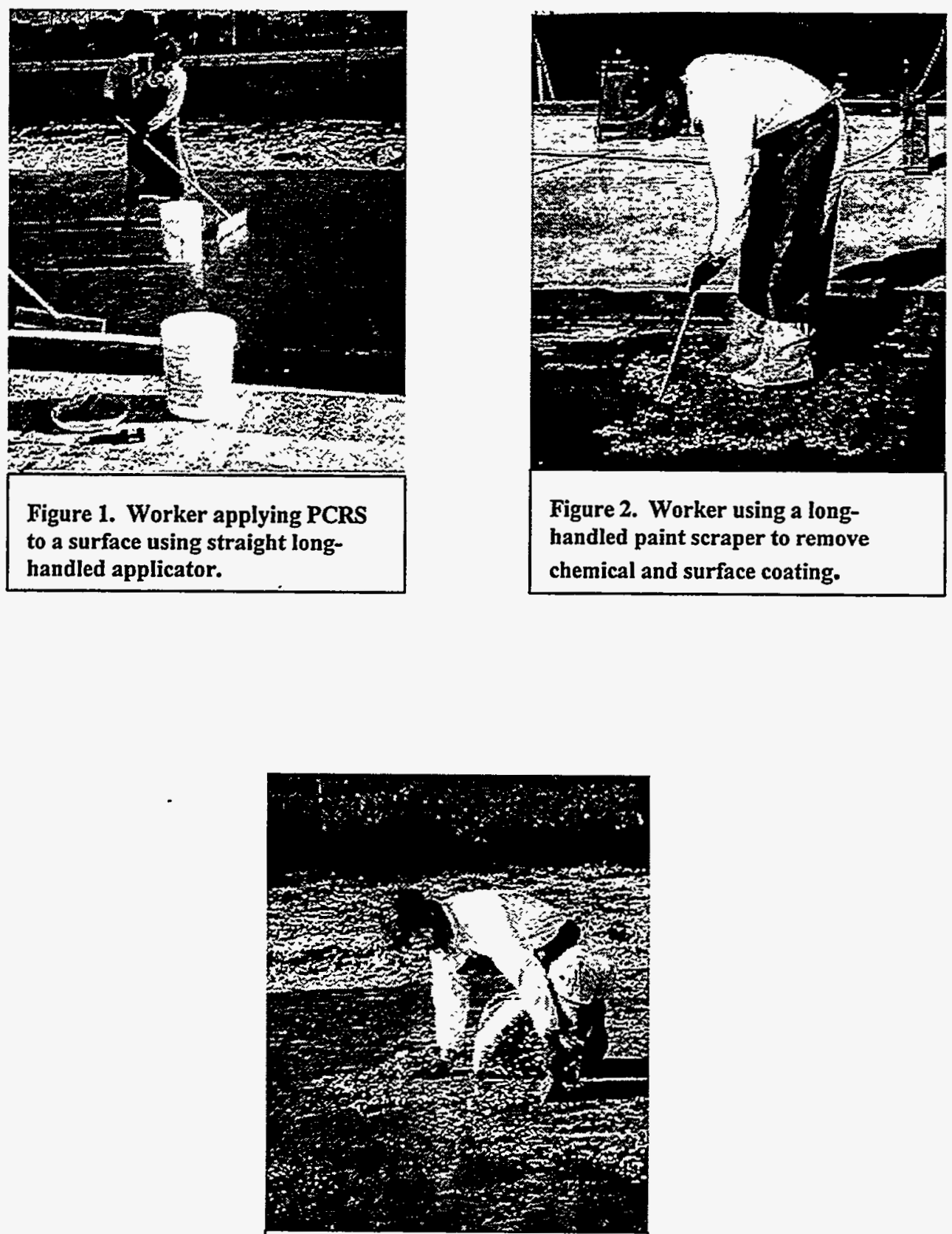

Figure 3. Worker kneeling on surface using a short-handled paint scraper to remove chemical and surface coating. 


\section{SECTION 4: CONTAMINANTS AND MEDIA}

The PCRS- $5 / 7$ is an organic solvent mixture. According to the MSDS supplied by Pegasus Inc., the mixture contains 10-25\% Dibasic Ether, 20-50\% N-Methyl-2-

Pyrrolidone, $20-40 \%$ Aluminum Silicate, $1-5 \%$ Nonylphenol Ethoxylate, and $10-30 \%$ Non-hazardous ingredients. The dibasic ether has a manufacturer's recommended exposure limit of $10 \mathrm{mg} / \mathrm{m}^{3}$ and the aluminum silicate has an Occupational Safety and Health Administration (OSHA) permissible exposure limit (PEL) of $15 \mathrm{mg} / \mathrm{m}^{3}$ and an ACGIH threshold limit vale (TLV) of $10 \mathrm{mg} / \mathrm{m}^{3}$, as total dust. Dust should not be a concern during the application and removal of the PCRS since it is a wet process but may be of some concern if the chemical is allowed to dry before removal. Monitoring needs to be conducted for organic vapors and/or the individual ingredients of the mixture. A monitoring plan will need to be developed on a site-by-site job-by-job basis.

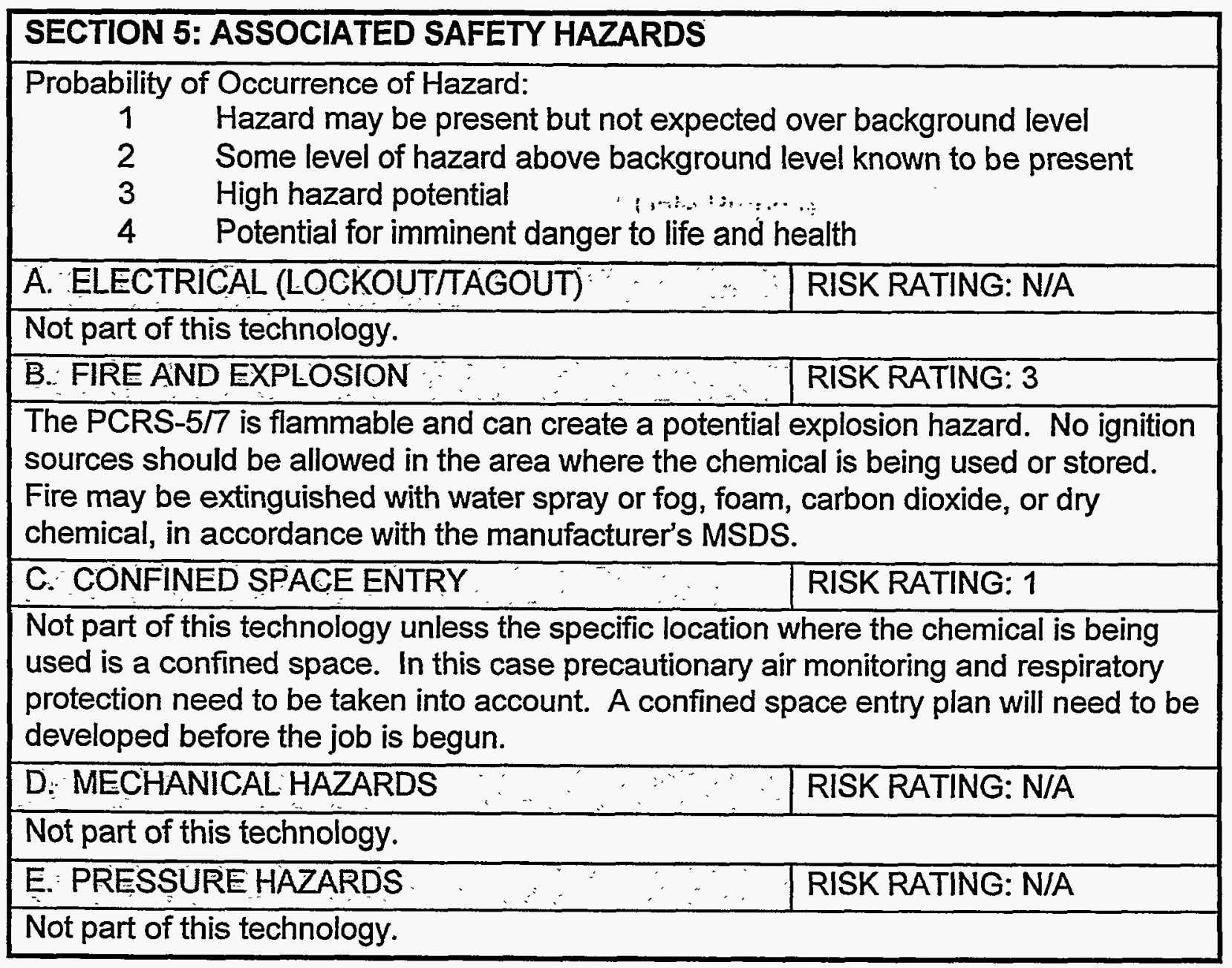




\section{SECTION 5: ASSOCIATED SAFETY HAZARDS}

\section{\begin{tabular}{|l|l|}
\hline F. TRIPPING AND FALLING & RISK RATING: 4
\end{tabular}}

There is an extreme slipping/fall hazard created by the chemical being applied to the walking surface. Walking on the surface after the chemical has been applied needs to be avoided. Special anti-slip soles on the chemical protective boots needs to be considered.
G. LADDERS AND PLATFORMS
RISK RATING: N/A

Not part of this technology.

H. MOVING VEHICLE RISK RATING: N/A

Not part of this technology.

\begin{tabular}{|l|l|}
\hline I. BURIED UTILITIES, DRUMS, AND TANKS : - - & RISK RATING: N/A
\end{tabular}

Not part of this technology.

\begin{tabular}{ll|l}
\hline J. PROTRUDING OBJECTS & RISK RATING: N/A
\end{tabular}

Not part of this technology.

\begin{tabular}{|l|l|}
\hline K. GAS CYLINDERS & RISK RATING: N/A \\
\hline
\end{tabular}

Not part of this technology.

\begin{tabular}{ll|l}
\hline L. TRENCHING AND EXCAVATIONS $\vdots \ldots$ & RISK RATING: N/A
\end{tabular}

Not part of this technology.

M. OVERHEAD LIFTS

RISK RATING: N/A

Not part of this technology.

N. OVERHEAD HAZARDS

RISK RATING: N/A

Not part of this technology. 


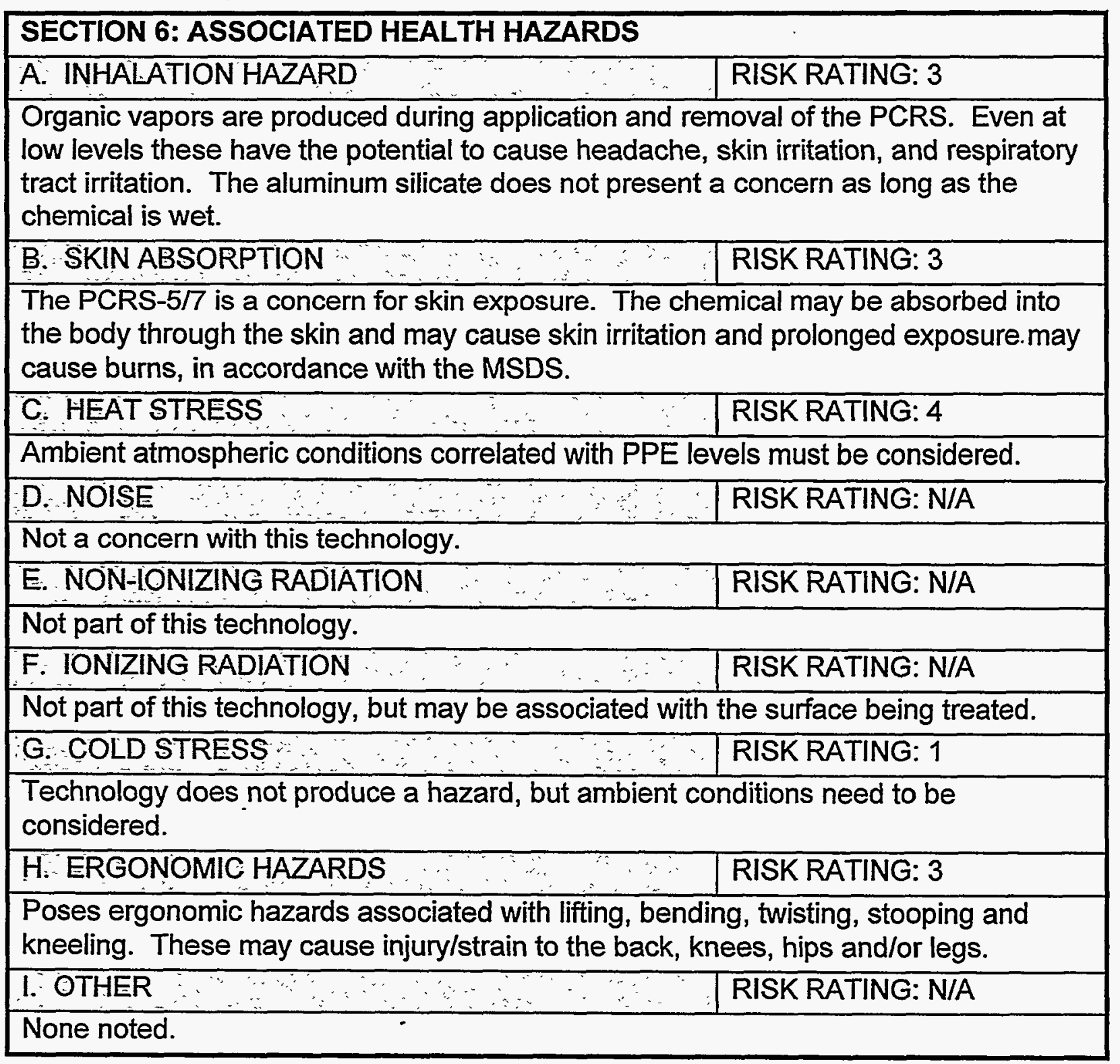




\begin{tabular}{|c|c|}
\hline \multicolumn{2}{|l|}{ SECTION 7: PHASE ANALYSIS } \\
\hline A. CONSTRUCTION/START-UP & \\
\hline \multicolumn{2}{|c|}{$\begin{array}{l}\text { The set-up/start-up phase presents predominantly ergonomic hazards from lifting and } \\
\text { carrying the buckets of PCRS to be applied to the surface. There is the potential for } \\
\text { exposure to the chemical when the lids are removed from the buckets to mix and } \\
\text { prepare the chemical for application. }\end{array}$} \\
\hline B. OPERATION & $\therefore \quad \cdots$ \\
\hline \multicolumn{2}{|c|}{$\begin{array}{l}\text { The operational phase presents the potential for exposure to the chemical both } \\
\text { during application and removal. There are also ergonomic stressors associated with } \\
\text { bending, kneeling, and stooping during application and removal. }\end{array}$} \\
\hline \multicolumn{2}{|l|}{ C. MAINTENANCE } \\
\hline \multicolumn{2}{|c|}{ There are no maintenance activities associated with this technology. } \\
\hline D. DECOMMISSIONING & \\
\hline $\begin{array}{l}\text { After the coating has been remove } \\
\text { be assured that the surface is "clea } \\
\text { contaminant was originally present } \\
\text { assure the chemical is not tracked } \\
\text { all water runoff from clean up is cor }\end{array}$ & $\begin{array}{l}\text { mical, it will need to } \\
\text { whatever } \\
\text { need to be taken to } \\
\text { ing clean-up and that } \\
\text { opriately. }\end{array}$ \\
\hline
\end{tabular}

\section{SECTION 8: HEALTH AND SAFETY PLAN REQUIRED ELEMENTS}

\begin{tabular}{l} 
A. AIR MONITORING \\
Environmental conditions such as air temperature, radiant heat load, and ventilation \\
in the area can affect how rapidly the organic solvent mixture vaporizes and \\
therefore, the exposure level at any given time. The exposure level (vapor build-up) \\
will also be affected by size of the area where the PCRS is being used. A monitoring \\
plan will need to be developed for the specific site and job where the chemical is \\
being used. If circumstances are such that the chemical may dry before removal, \\
aluminum silicate, as total dust, may also need to be monitored. \\
\hline B. WORKER TRAINING \\
Training that would apply to the use of the PCRS may include but not be limited to: \\
Hazardous Waste Operations and Emergency Response (HAZWOPER), Hazard \\
Communication (HAZCOM), Respiratory Protection, Personal Protective Equipment, \\
Ergonomics (proper lifting, bending, kneeling, stooping), Heat Stress, CPR/First \\
Aid/Bloodborne Pathogens, Construction Safety (OSHA 500) and/or General Industry \\
Safety (OSHA 501), and job specific training for application and removal of the \\
PCRS.
\end{tabular}




\section{EMERGENCY RESPONSE}

Emergency response planning for a site needs to assure adequate coverage for hazards described in the TSDS. Having at least one person per shift trained in CPR and first aid is recommended.

All precautions used when responding to an emergency situation at the site will apply. The PCRS $-5 / 7$ is flammable and is $85 \%$ volatile by volume. Its products of decomposition may include carbon dioxide, carbon monoxide, and oxides of nitrogen. In accordance with the MSDS a fire involving the PCRS-5/7 should be extinguished with water spray or fog, foam, carbon dioxide, or dry chemical. This information needs to be conveyed to both on-site and off-site emergency response personnel before a situation occurs that involves the PCRS.

\section{MEDICAL SURVEILLANCE}

Evaluation of personnel's general health in accordance with 29 CFR 1910.120 with emphasis on cardiovascular and respiratory system; back, knees, and legs; and central and peripheral nervous systems. In addition, any medical surveillance required by the OSHA standards needs to be provided.

E: INFORMATIONAL PROGRAM

Workers must be trained in specific application and removal of the PCRS. Additionally they-must be trained in accordance with 29 CFR 1910.1200, Hazard Communication.

\section{SECTION 9: COMMENTS AND SPECIAL CONSIDERATIONS}

Only personnel who have been adequately trained in the application and removal, as well as the hazards associated with the PCRS, should be permitted to work with it.

Consideration needs to be given to the compatibility of PPE with the specific chemical being used. 


\section{SECTION 7 - EMERGENCY RESPONSE/PREPAREDNESS}

The use of the PCRS technology would not be applicable for use in an emergency response situation.

Emergency response/preparedness must be part of every hazardous waste site safety and health plan. In addition to credible site emergencies, site personnel must plan for credible emergencies in connection with the PCRS.

All precautions used when responding to an emergency situation at the site will apply. The PCRS $-5 / 7$ is flammable and is $85 \%$ volatile by volume. Its products of decomposition may include carbon dioxide, carbon monoxide, and oxides of nitrogen. In accordance with the MSDS a fire involving the PCRS-5/7 should be extinguished with water spray or fog, foam, carbon dioxide, or dry chemical. This information needs to be conveyed to both on-site and off-site emergency response personnel before a situation occurs that involves the PCRS.

\section{SECTION 8 - REGULATORYIPOLICY ISSUES}

The site safety and health personnel where the PCRS technology is being used need to be concerned with safety and health regulations applicable to the issues discussed above. Regulations that apply may be divided into four categories. Core requirements are those regulations that would apply to any hazardous waste work site, regardless of the type of job. Technology specific requirements are those regulations that apply due to the specific technology being used. Special requirements are standards and policies that are specific to the technology itself and are required by reference in a regulation. Best management practices are not required, but are recommended by organizations such as the American National Standards Institute (ANSI), NIOSH, Department of Energy (DOE), National Fire Protection Association (NFPA), etc. These regulations/standards may include but not be limited to the following:

\section{Core requirements:}

- OSHA 29 CFR 1926.25 Housekeeping

- OSHA 29 CFR 1910.141 Sanitation (1910.141(a)(3) covers housekeeping)

- OSHA 29 CFR 1926 Subpart Z Toxic and Hazardous Substances

- OSHA 29 CFR 1910 Subpart Z Toxic and Hazardous Substances

- OSHA 29 CFR 1926.59 Hazard Communication 
- OSHA 29 CFR 1910.1200 Hazard Communication

OSHA 29 CFR 1926.64 Process Safety Management of Highly Hazardous Chemicals

- OSHA 29 CFR 1910.119 Process Safety Management of Highly Hazardous Chemicals

OSHA 29 CFR 1926.65 Hazardous Waste Operations and Emergency Response

OSHA 29 CFR 1910.120 Hazardous Waste Operations and Emergency Response

- Occupational Safety and Health Act 1970(5)(a)(1) General Duty Clause Technology Specific Requirements:

$\checkmark \quad$ OSHA 29 CFR 1926.103 Respiratory Protection

- OSHA 29 CFR 1910.134 Respiratory Protection

- OSHA 29 CFR 1926.102 Eye and Face Protection

OSHA 29 CFR 1910.133 Eye and Face Protection

OSHA 29 CFR 1926.28 Personal Protective Equipment

- OSHA 29 CFR 1910.132 General Requirements (Personal Protective Equipment)

OSHA 29 CFR 1926.23 First Aid and Medical Attention

OSHA 29 CFR 1910.151 Medical Services and First Aid

\section{Best Management Practices:}

- ACGIH Threshold Limit Values for Chemical Substances and Physical Agents and Biological Exposure Indices

In addition to the above regulations and policies, it is imperative that all workers have 
appropriate and adequate training for the task and associated safety and health hazards. Training that would be required may be divided into four categories. Core training is that which is required for anyone entering a hazardous waste site to perform work, regardless of the type of job. Technology specific training is that training which is specific to the technology and required by safety and health standards. Special training is that which is specific to the technology to assure the worker is adequately trained for the task, but is not necessarily required by safety and health standards. Best management practices are trainings that while not mandated by health and safety standards, provide information and knowledge to the worker that will allow the worker to perform his/her job safely. Training to be applied may include but not be limited to:

\section{Core Training Requirements:}

$\checkmark \quad$ HAZWOPER

$\checkmark \quad$ HAZCOM

Technology Specific Training:

$\checkmark \quad$ Respiratory Protection

- Personal Protective Equipment.

Special training:

- Job specific training for chemical application and removal

Best Management Practice training:

- Ergonomics (proper lifting, bending, stooping, kneeling, safe shoveling techniques)

- Heat stress (learning to recognize signs and symptoms)

- CPR/First Aid/Emergency Response/Blood-borne Pathogens

- Construction Safety (OSHA 500) and or General Industry Safety (OSHA 501)

\section{SECTION 9 - OPERATIONAL CONSIDERATIONS \& RECOMMENDATIONS}

Recommendations made here for improved worker safety and health take into 
consideration the use of the PCRS-5/7. Specific recommendations include:

Work practices are of critical importance for worker exposure to the chemical being applied to and removed from the coated surface. Application and removal is a difficult process to accomplish without the worker coming in contact with the chemical. Training the worker to use the best work practices possible will help to alleviate some of these concerns. Examples of the types of work practices that are of concern include:

1. Close all containers, both storage and waste, when not in use. This will keep the chemical from adding to the vapor load in the area where the work is being conducted.

2. Assure all PPE chosen is compatible with the chemical. An impervious apron (as recommended by the MSDS) is of no use if the material it is made of is incompatible with the chemical being used. Additional consideration needs to be given to the PPE used under the apron. If the chemical comes in contact with the garment under the apron and it is not compatible with the chemical, it is of no use.

3. All workers need to be trained in the specific hazards associated with the chemical and work practices should reflect avoidance of exposure or reducing the risk of exposure. For example, the organic solvent mixture is an eye irritant. Workers wearing goggles should never touch or remove the goggles while in the work area, nor should they touch or remove the goggles until their gloves that are contaminated with chemical are removed and their hands have been decontaminated. Additionally, touching the goggles with contaminated gloves increases the likelihood of getting the chemical on the face and head.

4. The chemical made the surface extremely slippery. Training workers to apply and remove the chemical to eliminate the need to walk on the area where chemical has been applied would reduce the risk of slipping and falling. Additionally, the waste containers should be placed in a location where workers do not have to walk on the slippery surface to get to them. This would also reduce the potential to have the chemical tracked onto "clean" areas. Workers should never move from the work area (exclusion zone) to the clean area (support zone) without proper decontamination of the worker taking place. 
- PPE must be chosen that is compatible with the hazards and the job.

Chemically impervious suits, aprons, gloves, and boots will be useless if the material they are made from is not compatible with the chemical. Consideration must also be given to special hazards that may be encountered. For example, normal chemical protective boots are inadequate during PCRS application and removal because of the extremely slippery surface conditions it creates. Special anti-slip soles need to be considered.

- Due to the open outdoor environment in which the testing demonstration took place and therefore, the organic vapor monitoring, it is recommended that additional monitoring be conducted when the PCRS is applied and removed in an enclosed environment similar to environments in which it would be used at a hazardous waste clean-up site. Additionally, monitoring needs to be conducted, as appropriate, for the individual ingredients of the organic solvent mixture.

- Using the spatulas to apply and paint scrapers to remove the chemical caused

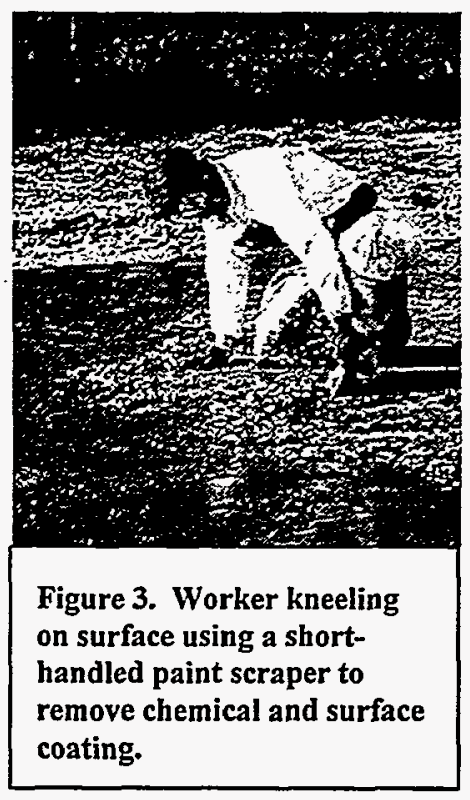
the workers to come into direct contact with the chemical that was on the surface either by kneeling on the surface or by stooping and balancing with a hand on the surface. This increases the workers potential for exposure as well as increases the ergonomic stressors placed on the worker. It is recommended. that application and removal only be done with longhandled (ergonomically designed) tools and standard operating procedures (SOP's) be developed that do not permit the worker to come into direct contact with the surface where the chemical has been applied.

In addition, using the spatulas and paint scrapers which had short handles cause the chemical to come up over the tool and handle onto the worker's gloves. This increases the potential for exposure and would be eliminated by the use of long-handled tools.

There is concern with the ergonomic stressors placed on the worker during both application and removal of the chemical. The chemical was applied to the concrete slab by two methods: (1) long-handled squeegee-type applicators; and (2) spatulas. Using the long-handled applicator required both workers to constantly bend over because the handles were straight and slightly short for them. This constant bending, although slight, has the potential to cause lower back sprain/strain. Using the spatula to apply the chemical requires the worker to either kneel or stoop. This has the potential to cause strain/sprain to the 
knees, ankles, and lower/upper legs. Removal of the chemical presents the same types of ergonomic stressors because removal requires the use of a shovel and/or a paint scraper. Using only long-handled ergonomically designed tools would help alleviate these stressors. 


\section{APPENDIX A \\ REFERENCES}

Occupational Safety and Health Standards for General Industry, 29 CFR Part 1910, Occupational Safety and Health Administration United States Department of Labor.

Occupational Safety and Health Standards for the Construction Industry, 29 CFR Part 1926, Occupational Safety and Health Administration United States Department of Labor.

Threshold Limit Values(TLV's) for Chemical Substances and Physical Agents and Biological Exposure Indices (BEl's), American Conference of Governmental Industrial Hygienists, 1995-1996.

ANSI 1986, Guide for the Measurement and Evaluation of Human Exposure to Vibration Transmitted to the Hand, New York, NY: American National Standards Institute, ANSI S3.34.

U.S. Department of Health and Human Services, Manual for the Revised NIOSH Lifting Equation, January 1994. 


\section{APPENDIX B ACRONYMS}

$\begin{array}{lll}\text { ACGIH } & - & \text { American Conference of Governmental Industrial Hygienists } \\ \text { ANSI } & - & \text { American National Standards Institute } \\ \text { CFR } & - & \text { Code of Federal Regulations } \\ \text { DOE } & - & \text { Department of Energy } \\ \text { FIU } & - & \text { Florida International University } \\ \text { HAZCOM } & - & \text { Hazard Communication } \\ \text { HAZWOPER - } & \text { Hazardous Waste Operations } \\ \text { MSA } & - & \text { Mine Safety Appliances } \\ \text { MSDS } & - & \text { Material Safety Data Sheet } \\ \text { NFPA } & - & \text { National Fire Protection Association } \\ \text { NIOSH } & - & \text { National Institute of Occupational Safety and Health } \\ \text { OSHA } & - & \text { Occupational Safety and Health Administration } \\ \text { PCRS } & - & \text { Pegasus Chemical Removal System } \\ \text { PEL } & - & \text { permissible exposure limit } \\ \text { PID } & - & \text { photo ionization detector } \\ \text { PPE } & - & \text { personal protective equipment } \\ \text { PPM } & - & \text { parts per million } \\ \text { SOP's } & - & \text { standard operating procedures } \\ \text { TLV } & - & \text { threshold limit value }\end{array}$




\section{PEGASUS INTERNATIONAL, INC. COATING REMOVAL SYSTEM (PCRS) (WALL/CEILING) TABLE OF CONTENTS}

ACKNOWLEDGEMENTS. iii

EXECUTIVE SUMMARY iv

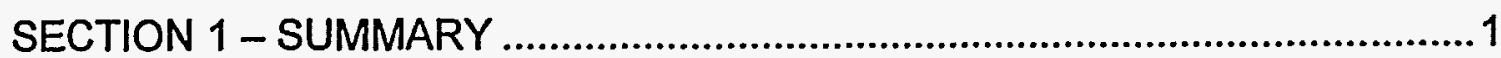

Technology Description ............................................................................

Key Results .........................................................................................

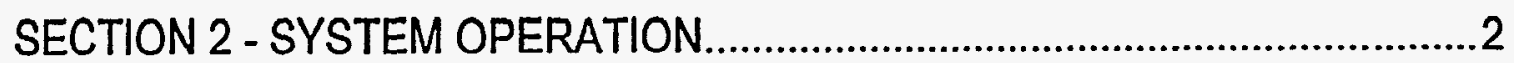

SECTION 3 - HEALTH AND SAFETY EVALUATION .....................................

General Health and Safety Concerns .........................................................2

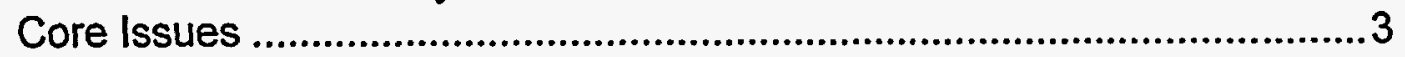

Best Management Practices.......................................................................

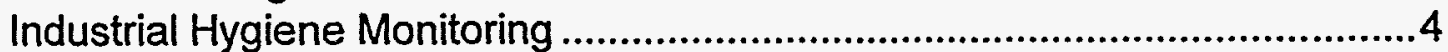

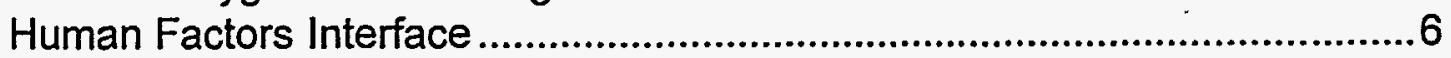

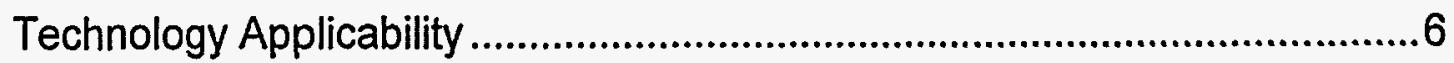

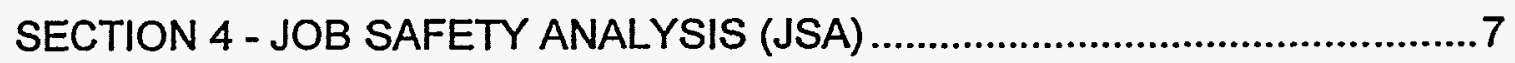

SECTION 5 - FAILURE MODES AND EFFECTS ANALYSIS (FMEA).............11

SECTION 6 - TECHNOLOGY SAFETY DATA SHEET (TSDS) .....................12

SECTION 7 - EMERGENCY RESPONSE/PREPAREDNESS .......................19

SECTION 8 - REGULATORY POLICY ISSUES …........................................19

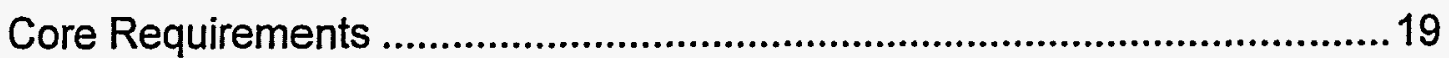

Technology Specific Requirements .........................................................20

Best Management Practices..........................................................................21

Core Training Requirements ...................................................................21

Technology Specific Training .................................................................21

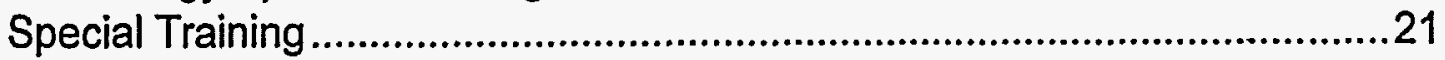

Best Management Practice Training ….......................................................22 


\section{TABLE OF CONTENTS (Continued)}

SECTION 9 - OPERATIONAL CONSIDERATIONS AND

RECOMMENDATIONS ………………………………….....................22

APPENDIX A - REFERENCES ............................................................26

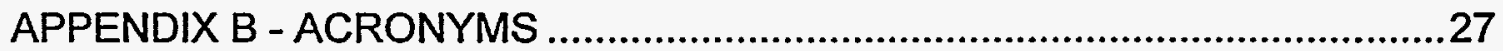




\section{ACKNOWLEDGEMENTS}

The human factors assessment of Pegasus International, Inc., Coating Removal System (Concrete Floor), was conducted under support of the U.S. Department of Energy's Federal Energy Technology Center, under cooperative agreement DE-FC2195MC32260 with the Operating Engineers National Hazmat Program. The Operating Engineers National Hazmat Program would like to thank the following people for their participation on the "research action team" and the professional expertise they provided for this assessment:

Barbara McCabe John Mason

Bill Nelson
Operating Engineers National Hazmat Program Operating Engineers Local Union 66 Operating Engineers Local Union 324 


\section{EXECUTIVE SUMMARY}

The Pegasus Coating Removal System (PCRS) was demonstrated at Florida International University (FIU) where it was being evaluated for efficiency and cost. In conjunction with the FIU testing demonstration, a human factors assessment was conducted to assess the hazards and associated safety and health issues of concern for workers utilizing this technology.

The PCRS is a chemical paste that is applied to the surface using a brush, roller, or airless sprayer. Two types of PCRS are available. PCRS-5/7 is an organic solvent mixture primarily used for chemically resistant coatings and PCRS-ST1 and PCRS-1, which is an alkaline mixture of calcium hydroxide, magnesium hydroxide, and sodium hydroxide. PCRS-ST1 and PCRS-1 are primarily used for alkyd/latex coating removal. The type of PCRS used depends on the type and thickness of the coating, and the type of substrate material. In order to determine the type of PCRS for the job, the required thickness of the paste, and the dwell time, a test area of approximately one square foot is used. Based on the performance of the system over this one square foot area, the operational parameters can be determined. Dwell time, which is the time required for the chemical to have its desired effect, can range from several hours to 24 hours. After the type of PCRS, thickness, and dwell time have been determined, a laminated backed material is placed on top of the chemical paste to slow down the drying process and to provide a mechanism to strip-off the chemical. After the dwell time is reached, the chemical substrate can be removed. Scrapers may be used to break-loose the layers as necessary or to break-loose the layers that are not removed when the laminated paper is picked up. Residue may also be cleaned off of the surface with a damp sponge with an agitating motion, absorbent sponges, or a vacuum, as needed. The paint and removal agent is then placed in drums for disposal at a later time.

During the human factors assessment of the PCRS, the PCRS- $5 / 7$ was used for the removal of the wall/ceiling coating.

During the assessment sampling was conducted for organic vapors and general observational techniques were conducted for ergonomics. General observational techniques for ergonomics showed the potential for some ergonomic problems during application and removal of the chemical. The chemical was applied to the wall and ceiling using a spatula and removed using a paint scraper for the locations where the removal with the laminated paper was not complete. To reach the lower portion of the wall personnel worked from ground level. To reach the upper portion of the wall, personnel worked from a ladder. There is the potential for sprain/strain to the back, shoulders, knees, and legs from the bending, kneeling, or stooping required to reach the lower section of the wall. When working from a ladder there is the potential for sprain/strain to the back, shoulders, and neck from reaching and from working with the arms extended above the head and neck for long periods of time. Removal of the 
chemical with a paint scraper presents the same type of ergonomic stressors as application using a spatula.

During removal of the chemical, the organic vapor readings ranged from 0.0 to 1.5 parts per million (ppm). During application with the paint sprayer (this was only done for approximately 5-10 minutes due to equipment malfunction), the readings ranged from 0.0 to $2.0 \mathrm{ppm}$ and during application using a spatula the readings ranged from 0.0 to $5.0 \mathrm{ppm}$. These measurements indicate that organic vapors are present during application and removal of the PCRS. Monitoring for the specific ingredients needs to be considered on a job-by-job site-by-site basis. The low levels of organic vapor have the potential to cause headache, skin irritation, and respiratory tract irritation.

Therefore, workers may need to utilize appropriate PPE when applying and removing the PCRS regardless of the ppm levels recorded.

Recommendations for improved worker safety and health during application and removal of the PCRS include: 1. work practices that reflect avoidance of exposure or reducing the risk of exposure; 2 . assuring all PPE and equipment are compatible with the chemicals being used; 3 . work practices that reduce the worker's need to walk on the slippery surface caused by the chemical or the use of special anti-slip soles; 4 . careful control of overspray (if a spray application is used); 5 . the use of ergonomically designed long-handled tools to apply and remove the chemical (to alleviate some of the ergonomic concerns); and 6 . the use of scaffolding instead of a ladder to reach the upper portion of the wall and the ceiling for application and removal of the chemical. 


\section{PEGASUS INTERNATIONAL, INC. COATING REMOVAL SYSTEM (PCRS) \\ (WALL/CEILING) \\ Human Factors Assessment}

\section{SECTION 1 - SUMMARY}

\section{TECHNOLOGY DESCRIPTION}

The Pegasus Coating Removal System (PCRS) technology was tested and is being evaluated at Florida International University (FIU) as a baseline technology. In conjunction with FIU's evaluation of efficiency and cost, this report covers the hazard analysis and safety evaluation. PCRS is a commercially available technology and has been used for various projects at locations throughout the country.

The PCRS is a chemical paste that is applied to the surface using a brush, roller, or airless sprayer. The type of PCRS used depends on the type and thickness of the coating, the age of the coating, and the type of substrate material. A laminated backed material is placed on top of the chemical paste to slow down the drying process and to provide a mechanism to strip-off the material. In order to determine the type of PCRS, the required thickness of the paste, and the dwell time, a test area of approximately one square foot is used. Based on the performance of the chemical over this one square foot area, the operational parameters can be determined. Dwell time can range from several hours to 24 hours.

\section{KEY RESULTS}

The safety and health evaluation during the testing demonstration focused on two main areas: exposure to the organic chemicals and ergonomics. Air sampling with a photo ionization detector (PID) showed low exposure values but there is concern for skin exposures. Further testing for the individual ingredients of the organic based solvent is recommended. In addition, it is recommended that sampling be conducted in an enclosed environment. The outdoor environment where the testing demonstration took place may cause the results to be inapplicable to enclosed operating environments, where it is feasible that the exposure levels would be greater. Ergonomic stressors were potentially significant. Other safety and health issues found were heat stress, slipping/fall hazards, and environmental concerns from accidentally spreading the chemical to areas outside of the immediate exclusion zone. 


\section{SECTION 2 - SYSTEM OPERATION}

The PCRS is a chemical paste that is applied to the surface using a brush, roller, or airless sprayer. Two types of PCRS are available. PCRS-5/7 is an organic solvent mixture primarily used for chemically resistant coatings and PCRS-ST1 and PCRS-1, which are alkaline mixtures of calcium hydroxide, magnesium hydroxide, and sodium hydroxide. PCRS-ST1 and PCRS-1 are primarily used for alkyd/latex coating removal. The type of PCRS used depends on the type and thickness of the coating, and the type of substrate material. In order to determine the type of PCRS for the job, the required thickness of the paste, and the dwell time, a test area of approximately one square foot is used. Based on the performance of the system over this one square foot area, the operational parameters can be determined. Dwell time, which is the time required for the chemical to have its desired effect, can range from several hours to 24 hours. After the type of PCRS, thickness, and dwell time have been determined, a laminated

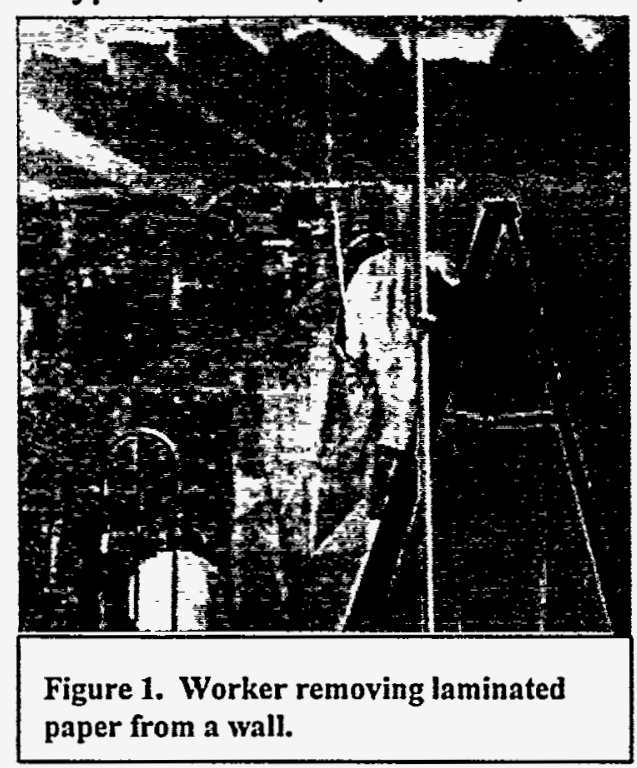

backed material is placed on top of the chemical paste to slow down the drying process and to provide a mechanism to strip-off the material. After the dwell time is reached, the chemical substrate can be removed. Scrapers may be used to breakloose the layers as necessary or to break-loose the layers that are not removed when the laminated paper is picked up. Residue may also be cleaned off of the surface with a damp sponge with an agitating motion, absorbent sponges, or a vacuum, as needed. The paint and removal agent is then placed in drums for disposal at a later time.

During the human factors assessment of the PCRS, the PCRS-5/7 was used for the removal of the wall/ceiling coating.

\section{SECTION 3 - HEALTH AND SAFETY EVALUATION}

\section{GENERAL SAFETY AND HEALTH CONCERNS}

Personnel where the Pegasus Coating Removal System is being used need to be concerned with safety and health issues. Issues that personnel need to be cognizant of may be divided into two categories. Core issues are those that are based on current safety and health regulatory requirements. Best management practices are related to 
issues that are not based on current safety and health regulations, but are key

elements in preventing worker injury and illness on the job.

Safety and health issues of concern with the PCRS included:

\section{Core Issues:}

- Work Practices (housekeeping) - The process of applying the chemical is difficult to accomplish without the worker coming in contact with it. Training the workers to apply good work practices would assist in alleviating this concern. In addition, the need for stringent housekeeping must be addressed.

- Personal Protective Equipment - The personal protective equipment (PPE) utilized during the application of the PCRS needs to be compatible with the chemicals being used.

- Hazard Communication - The material safety data sheet (MSDS) for the chemical being used must be available in accordance with 29 CFR 1910.1200. In addition, workers must be trained on its specific hazards.

- Exposure to Chemical - There is potential for the worker to be exposed to the chemical being used for coating removal. Exposure may occur during application and removal, from the chemical splashing during application, or by the worker coming in direct contact with the chemical. This will be discussed in greater detail in the Industrial Hygiene section of this report.

\section{Best Management Practices:}

- Ergonomics - There are ergonomic stressors that have the potential to cause stress/strain to the lower and upper back, shoulders, arms, and knees due to the bending, stooping, kneeling postures required for application and removal of the PCRS.

- Slipping Hazards - The chemical applied to the wall/ceiling made the walking surface extremely slippery. The workers almost fell several times during both application and removal of the chemical.

- Heat Stress - Workers are subjected to an increase in heat stress due to the need to utilize chemical protective PPE during the application and removal of the PCRS. The user will need to develop a heat stress program for the environment in which the chemical removal system is being used, taking into consideration any PPE that may need to be utilized, ambient air temperatures, etc. 


\section{INDUSTRIAL HYGIENE MONITORING}

During the testing demonstration with the PCRS, sampling was conducted for organic vapors. In addition, the wet-bulb globe temperature was monitored to evaluate heat stress. Observational evaluation was conducted for ergonomics.

Through general observational techniques the potential for ergonomic problems was evaluated during the testing demonstration. The chemical was applied to the wall and ceiling using a spatula and removed using a paint scraper for the locations where the removal with the laminated paper was not complete. To reach the lower portion of the wall personnel worked from ground level. To reach the upper portion of the wall, personnel worked from a ladder. There is the potential for sprain/strain to the back, shoulders, knees, and legs from the bending, kneeling, or stooping required to reach the lower section of the wall. When working from a ladder there is the potential for sprain/strain to the back, shoulders, and neck from reaching and from working with the arms extended above the head and neck for long periods of time. Removal of the chemical with a paint scraper presents the same type of ergonomic stressors as application using a spatula.

Applying the chemical by spraying it onto the wall and ceiling had been accomplished previously but was not observed. The ergonomic stressors associated with this method of application needs

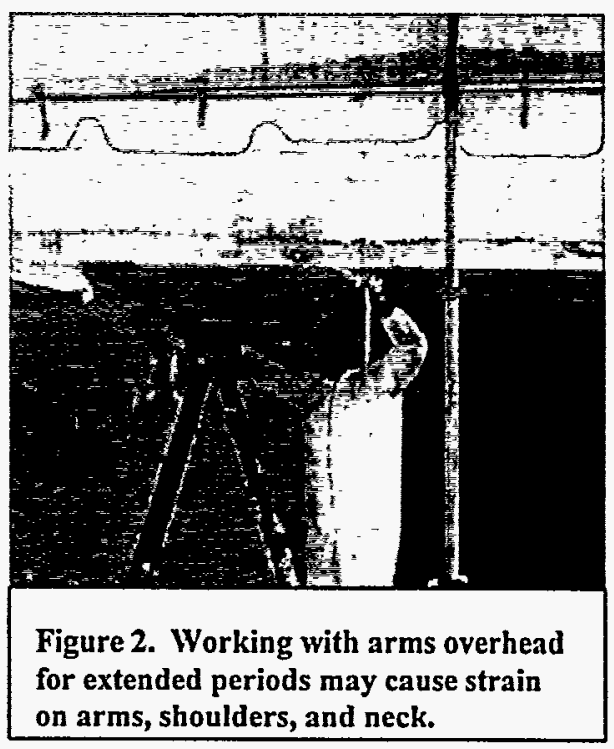
to be assessed.

There are additional safety and health concerns with the use of a ladder for this type of job and these will be discussed in greater detail in a later section of this report.

Heat stress parameters were monitored using a Quest QuestTemp 15 Heat Stress Monitor. The wet-bulb globe temperature was used to determine the work/rest regimen in accordance with the American Conference of Governmental Industrial Hygienist (ACGIH) recommendations. In accordance with ACGIH guidelines, the wet-bulb globe temperature was adjusted for the type of clothing, including PPE, that the worker was wearing. While heat stress will be increased when wearing PPE, the overall heat stress response will vary from worker to worker. Each situation in which the current technology is used will need to be evaluated for the heat stress potential, taking into 
consideration the wet-bulb globe temperature, PPE in use, physical condition of the worker, and amount of worker acclimatization.

The PCRS applied to the wall/ceiling for coating removal was the PCRS-5/7, the organic solvent mixture. According to the MSDS supplied by Pegasus Inc., the mixture contains 10-25\% Dibasic Ether, 20-50\% N-Methyl-2-Pyrrolidone, 20-40\% Aluminum Silicate, $1-5 \%$ Nonylphenol Ethoxylate, and $10-30 \%$ Non-hazardous ingredients. The dibasic ether has a manufacturer's recommended exposure limit of $10 \mathrm{mg} / \mathrm{m}^{3}$ and the aluminum silicate has an Occupational Safety and Health Administration (OSHA) permissible exposure limit (PEL) of $15 \mathrm{mg} / \mathrm{m}^{3}$ and an ACGIH threshold limit value (TLV) of $10 \mathrm{mg} / \mathrm{m}^{3}$, as total dust. Dust is not a concern during the application and removal of the PCRS when the chemical remains wet, however, dust may become an exposure hazard if the chemical is allowed to dry before removal. This will need to be taken into consideration for each job where the PCRS is being used.

During the testing demonstration, organic vapor monitoring was conducted during application and removal. Monitoring was conducted using an MSA Passport Photo lonization Detector (PID). The Passport is a real-time monitor that measures organic vapors in parts per million (ppm). The PID does not identify the specific organic vapor but identifies the presence of any organic vapor.

During removal of the chemical, organic vapor readings ranged from 0.0 to $1.5 \mathrm{ppm}$. During application with the paint sprayer (this was only done for approximately 5-10 minutes due to equipment malfunction), the readings ranged from 0.0 to $2.0 \mathrm{ppm}$ and during application using a spatula the readings ranged from 0.0 to $5.0 \mathrm{ppm}$. Since it cannot be determined if these levels present the potential for overexposure, sampling for the individual ingredients in the PCRS-5/7 needs to be conducted. It does, however, indicate that organic vapors are present. Even at low levels, the organic vapor odor could be detected, especially when down wind of the work area. These low levels have the potential to cause headache, skin irritation, and respiratory tract irritation. Therefore, workers may need to utilize the appropriate PPE when applying and removing the PCRS regardless of the ppm levels recorded.

After the first application of the chemical (when it had been sprayed on), sections of the chemical had dried before removal. During removal in these areas (using a paint scraper), there was visible dust falling from the wall and ceiling. This creates a potential dust exposure and the potential for exposure to the constituents (as a dust) of the chemical and the coating that is being removed. Appropriate air sampling needs to be conducted under these conditions.

Environmental conditions such as temperature, radiant heat load, and ventilation in the area can affect how rapidly the organic solvent mixture vaporizes and therefore, the exposure level at a given time. The exposure level (vapor build-up) will also be affected 
by the size of the area where it is being used. The PCRS was applied and removed in an open outdoor environment during the testing demonstration. There is the potential for the organic vapor levels to be significantly higher in an enclosed environment. A monitoring plan will need to be developed for the specific site and job where the chemical is being used.

\section{HUMAN FACTORS INTERFACE}

The MSDS for PCRS-5/7 recommends the following PPE be used when applying or removing it: chemical goggles, butyl rubber gloves, impervious apron, and boots. It states that respiratory protection is not normally needed, but for spray applications or where exposures may be excessive, a National Institute of Occupational Safety and Health (NIOSH) approved organic vapor respirator may be used.

Depending on the application and removal methods used, a greater level of PPE may be required. (This was evident during the testing demonstration when the tyvek suits being worn under the impervious apron were soaked with the chemical.) This may include a chemically impervious suit instead of only an apron, and a full face air purifying respirator. This has the potential to cause a decrease in visibility, mobility, and tactile sensation for the workers, as well as an increase in heat stress. Additionally, because of the extremely slippery work/walking surface condition, boots with special anti-slip soles need to be used.

\section{TECHNOLOGY APPLICABILITY}

After the coating has been removed from the surface by the chemical, it will need to be assured that the surface is "clean" of both PCRS residue and whatever contaminant was originally present on the surface.

Consideration will also need to be given to the wastes that are generated. Wastes may include different combinations: the PCRS itself and the PCRS combined with the surface coating being removed and its contaminants. 


\section{SECTION 4 - JOB SAFETY ANALYSIS}

\section{JOB SAFETY ANALYSIS PEGASUS INTERNATIONAL, INC. COATING REMOVAL SYSTEM (PCRS) (WALL/CEILING)}

\begin{tabular}{|c|c|}
\hline HAZARD & CORRECTIVE ACTION \\
\hline \multicolumn{2}{|c|}{ UNLOADING EQUIPMENT/SETUP } \\
\hline $\begin{array}{l}\text { * Back sprain/strain from lifting and } \\
\text { carrying buckets of chemical and tools }\end{array}$ & $\begin{array}{l}\text { * Use a fork lift to unload and lift the } \\
\text { buckets of chemical and the tools } \\
\text { * Ergonomic training to include proper } \\
\text { techniques for lifting and carrying loads }\end{array}$ \\
\hline $\begin{array}{l}\text { " Exposure to chemical when removed } \\
\text { from bucket }\end{array}$ & $\begin{array}{l}\text { Wear respiratory protection, goggles, } \\
\text { and chemical protective personal } \\
\text { protective equipment (PPE), as } \\
\text { appropriate, when removing the lid from } \\
\text { a bucket } \\
\text { * Use a mechanical method to remove } \\
\text { the lid from the bucket } \\
\text { * Train worker to remove the lid from the } \\
\text { bucket with the least amount of direct } \\
\text { exposure to himself/herself }\end{array}$ \\
\hline${ }^{\star}$ Mix chemical in bucket & $\begin{array}{l}\text { * Use a mechanical method for mixing } \\
\text { * Design a lid for the bucket where mixing } \\
\text { can occur with the lid on the bucket } \\
\text { * Train worker to mix with the least } \\
\text { amount of direct exposure to } \\
\text { himself/herself } \\
\text { * Wear respiratory protection, goggles, } \\
\text { and chemical protective PPE when } \\
\text { mixing }\end{array}$ \\
\hline
\end{tabular}




\begin{tabular}{|c|c|}
\hline \multicolumn{2}{|c|}{ UNLOADING EQUIPMENT/SETUP } \\
\hline $\begin{array}{l}\text { *xposure to chemical during application } \\
\text { of test patches }\end{array}$ & $\begin{array}{l}\text { *Wear respiratory protection, goggles, } \\
\text { and chemical protective PPE, as } \\
\text { appropriate, when applying test patches } \\
\text { *Assure workers are trained in hazards } \\
\text { associated with the chemicals in } \\
\text { accordance with Hazard Communication } \\
\text { (29 CFR } 1910.1200 \text { ) } \\
\text { *Assure the Material Safety Data Sheets } \\
\text { (MSDS's) for all chemicals being used } \\
\text { are available in accordance with } 29 \text { CFR } \\
1910.1200\end{array}$ \\
\hline \multicolumn{2}{|c|}{ APPLICATION OF PCRS } \\
\hline $\begin{array}{l}\text { *Exposure to chemical during application } \\
\text { (of chemical and laminated paper) }\end{array}$ & $\begin{array}{l}\text { *Wear respiratory protection, goggles, } \\
\text { and chemical protective PPE when } \\
\text { applying chemical or laminated paper, as } \\
\text { appropriate } \\
\text { *Assure workers are trained in the } \\
\text { hazards associated with the chemicals in } \\
\text { accordance with Hazard Communication } \\
(29 \text { CFR } 1910.1200) \\
\text { *Assure the MSDS's for all chemicals } \\
\text { being used are available in accordance } \\
\text { with } 29 \text { CFR } 1910.1200\end{array}$ \\
\hline $\begin{array}{l}\text { * Ergonomic stressors during application } \\
\text { (of chemical and laminated paper) }\end{array}$ & $\begin{array}{l}\text { Ergonomic training to include correct } \\
\text { techniques for lifting, bending, stooping, } \\
\text { and kneeling }\end{array}$ \\
\hline \multicolumn{2}{|c|}{ REMOVAL OF PCRS } \\
\hline $\begin{array}{l}\text { * Exposure to chemical during removal } \\
\text { (of chemical and laminated paper) }\end{array}$ & $\begin{array}{l}\text { *Wear respiratory protection, goggles, } \\
\text { and chemical protective PPE, as } \\
\text { appropriate, when removing chemical or } \\
\text { laminated paper } \\
\text { *Assure workers are trained in the } \\
\text { hazards associated with the chemicals in } \\
\text { accordance with Hazard Communication } \\
\text { ( } 29 \text { CFR } 1910.1200 \text { ) } \\
\text { *Assure the MSDS's for all chemicals } \\
\text { being used are available in accordance } \\
\text { with } 29 \text { CFR } 1910.1200\end{array}$ \\
\hline
\end{tabular}




\begin{tabular}{|l|l|}
\hline \multicolumn{2}{|c|}{ REMOVAL OF PCRS } \\
\hline $\begin{array}{l}\text { * Ergonomic stressors during removal (of } \\
\text { chemical and laminated paper) }\end{array}$ & $\begin{array}{l}\text { * Ergonomic training to include correct } \\
\text { techniques for lifting, bending, stooping, } \\
\text { and kneeling }\end{array}$ \\
\hline \multicolumn{2}{|c|}{ CLEAN UP OF THE SITE AND TOOLS USED FOR APPLICATION } \\
AND REMOVAL OF THE CHEMICAL
\end{tabular}




\begin{tabular}{|c|c|}
\hline \multicolumn{2}{|c|}{$\begin{array}{c}\text { CLEAN UP OF THE SITE AND TOOLS USED FOR APPLICATION } \\
\text { AND REMOVAL OF THE CHEMICAL }\end{array}$} \\
\hline $\begin{array}{l}\text { *Back strain/sprain from lifting/carrying } \\
\text { waste containers for disposal }\end{array}$ & $\begin{array}{l}\text { * Ergonomic training to include correct } \\
\text { techniques for lifting, bending, and } \\
\text { carrying } \\
\text { * Use mechanical method such as fork lift } \\
\text { for lifting and moving waste to disposal } \\
\text { area }\end{array}$ \\
\hline \multicolumn{2}{|c|}{ LOADING/TEAR DOWN } \\
\hline $\begin{array}{l}{ }^{*} \text { Back sprain/strain from lifting and } \\
\text { carrying buckets of chemical and tools }\end{array}$ & $\begin{array}{l}{ }^{*} \text { Use a fork lift to load and lift the buckets } \\
\text { of chemical and the tools } \\
{ }^{*} \text { Ergonomics training to include proper } \\
\text { techniques for lifting and carrying loads }\end{array}$ \\
\hline
\end{tabular}




\section{SECTION 5 - FAILURE MODE AND EFFECTS ANALYSIS}

\section{FAILURE MODE AND EFFECTS ANALYSIS PEGASUS INTERNATIONAL, INC. COATING REMOVAL SYSTEM (PCRS) WALL/CEILING}

\begin{tabular}{|l|l|}
\hline \multicolumn{1}{|c|}{ FAILURE MODE } & \multicolumn{1}{|c|}{ EFFECT } \\
\hline $\begin{array}{l}\text { * Lid on bucket containing chemical will } \\
\text { not come off/go back on }\end{array}$ & $\begin{array}{l}\text { * Bucket of chemical spills while worker } \\
\text { trying to get lid off/on and increases the } \\
\text { potential for the worker to be exposed to } \\
\text { the chemical }\end{array}$ \\
& $\begin{array}{l}\text { * Spill must be cleaned up which } \\
\text { increases the potential for the worker to } \\
\text { be exposed to the chemical }\end{array}$ \\
\hline $\begin{array}{l}{ }^{*} \text { The chemical does not remove the } \\
\text { surface coating as expected }\end{array}$ & $\begin{array}{l}\text { * Increase in ergonomic stressors on } \\
\text { worker from additional effort that must be } \\
\text { used to scrape chemical and coating } \\
\text { from surface }\end{array}$ \\
\hline
\end{tabular}




\section{SECTION 6 - TECHNOLOGY SAFETY DATA SHEET}

\section{TECHNOLOGY SAFETY DATA SHEET PEGASUS INTERNATIONAL INC. COATING REMOVAL SYSTEM (PCRS) (WALL/CEILING)}

\begin{tabular}{|l|l|}
\hline SECTION 1: TECHNOLOGY IDENTITY \\
\hline Manufacturer's Name and Address: \\
$\begin{array}{l}\text { Pegasus International Inc. } \\
\text { 106 Railroad Street } \\
\text { Schenley, PA 15682 }\end{array}$ & $\begin{array}{l}\text { Emergency Contact: } \\
\text { Tom Bodkin } \\
(412) 295-0066\end{array}$ \\
\cline { 2 - 2 } & $\begin{array}{l}\text { Information Contact: } \\
\text { Tom Bodkin } \\
(412) 295-0066\end{array}$ \\
\cline { 2 - 2 } & Date Prepared: \\
\hline $\begin{array}{l}\text { Other Names: } \begin{array}{l}\text { PCRS, PCRS-5/7, Organic solvent } \\
\text { mixture }\end{array} \\
\text { Signature of Preparer: } \\
\text { Operating Engineers National Hazmat } \\
\text { Program } \\
\text { 1293 Airport Road, Beaver, WV 25813, } \\
\text { phone 304-253-8674, fax 304-253-7758. } \\
\text { Under cooperative agreement DE-FC21- } \\
95 \text { MC 32260 }\end{array}$ \\
\hline
\end{tabular}




\section{PROCESS DESCRIPTION:}

The PCRS is a chemical paste that is applied to the surface using a brush, roller, or airless sprayer. Two types of PCRS are available. PCRS-5/7 is an organic solvent mixture primarily used for chemically resistant coatings and PCRS-ST1 and PCRS-1, alkaline mixtures of calcium hydroxide, magnesium hydroxide, and sodium hydroxide. PCRS-ST1 and PCRS-1 are primarily used for alkyd/latex coating removal. The type of PCRS used depends on the type and thickness of the coating, and the type of substrate material. In order to determine the type of PCRS for the job, the required thickness of the paste, and the dwell time, a test area of approximately one square foot is used. Based on the performance of the chemical over this one square foot area, the operational parameters can be determined. Dwell time, which is the time required for the chemical to have its desired effect, can range from several hours to 24 hours. After the type of PCRS, thickness, and dwell time have been determined, a laminated backed material is placed on top of the chemical paste to slow down the drying process and to provide a mechanism to strip-off the material. After the dwell time is reached, the chemical substrate can be removed. Scrapers may be used to break-loose the layers as necessary or to break-loose the layers that are not removed when the laminated paper is picked up. Residue may also be cleaned off of the surface with a damp sponge with an agitating motion, absorbent sponges, or a vacuum, as needed. The paint and removal agent is then placed in drums for disposal at a later time.

The PCRS- $5 / 7$ is referenced by this technology safety data sheet. The TSDS does not include information for PCRS-ST1 and PCRS-1. 


\section{SECTION 3: PROCESS DIAGRAMS}

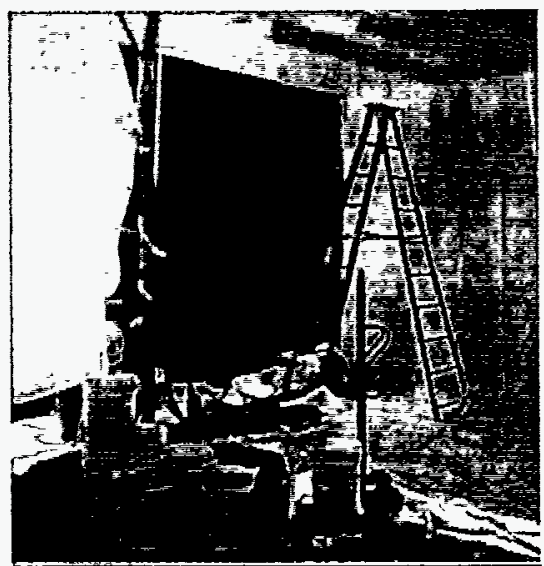

Figure 1. Baskets of PCRS assembled at the worksite.
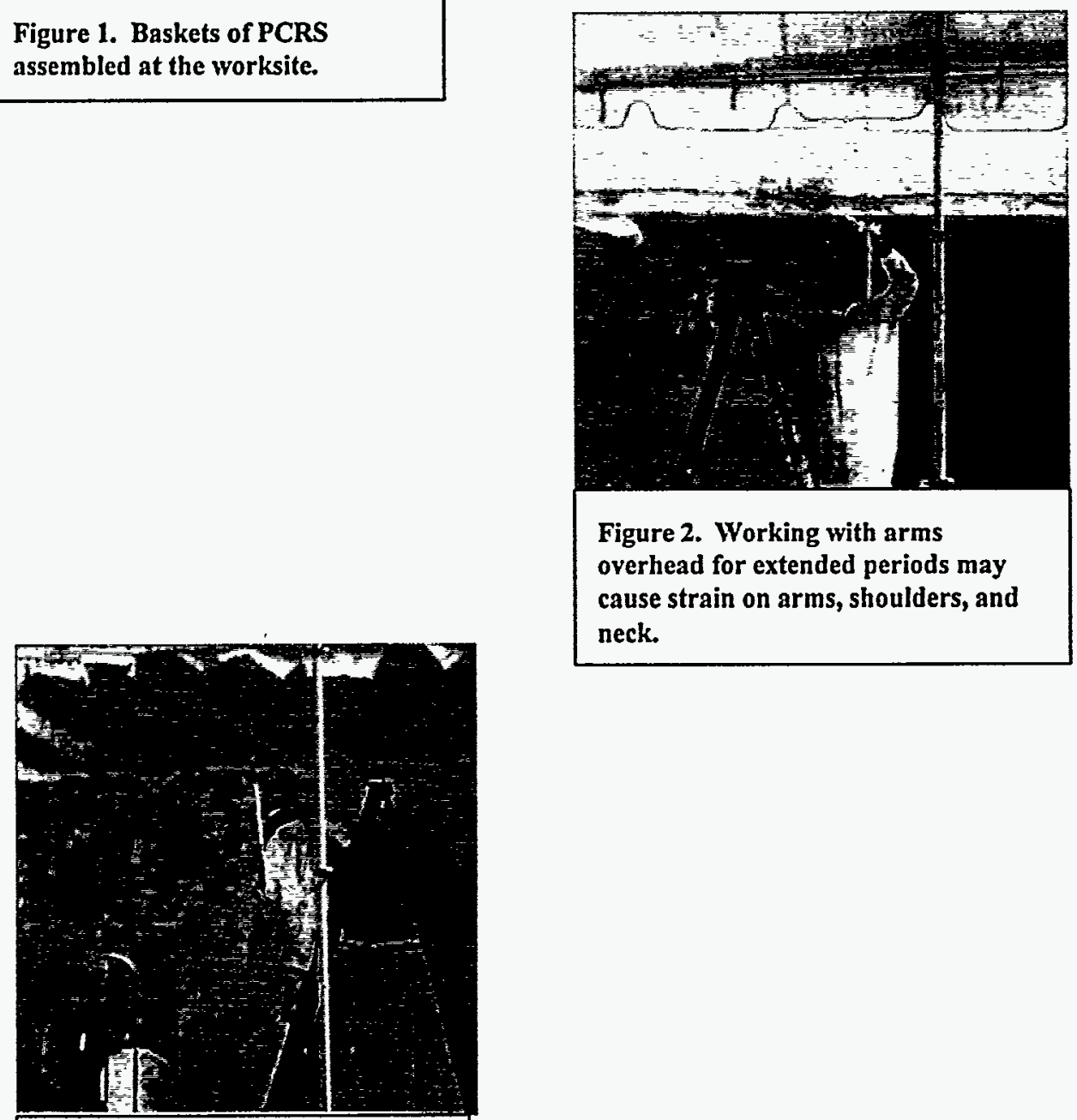

Figure 2. Working with arms overhead for extended periods may cause strain on arms, shoulders, and neck.

Figure 3. Worker removing laminated paper from wall. 


\section{SECTION 4: CONTAMINANTS AND MEDIA}

The PCRS- $5 / 7$, the organic solvent is an organic mixture. According to the MSDS supplied by Pegasus Inc., the mixture contains $10-25 \%$ Dibasic Ether, $20-50 \% \mathrm{~N}$ Methyl-2-Pyrrolidone, 20-40\% Aluminum Silicate, 1-5\% Nonylphenol Ethoxylate, and $10-30 \%$ Non-hazardous ingredients. The dibasic ether has a manufacturer's recommended exposure limit of $10 \mathrm{mg} / \mathrm{m}^{3}$ and the aluminum silicate has an OSHA PEL of $15 \mathrm{mg} / \mathrm{m}^{3}$ and an ACGIH TLV of $10 \mathrm{mg} / \mathrm{m}^{3}$, as total dust. Dust should not be a concern during the application and removal of the PCRS since it is a wet process, but may be of concern if the chemical is allowed to dry before removal. Monitoring needs to be conducted for organic vapors and/or the individual ingredients of the mixture. A monitoring plan will need to be developed on a site-by-site job-by-job basis.

\section{SECTION 5: ASSOCIATED SAFETY HAZARDS \\ Probability of Occurrence of Hazard: \\ 1 Hazard may be present but not expected over background level \\ 2 Some level of hazard above background level known to be present \\ 3 High hazard potential \\ $4 \quad$ Potential for imminent danger to life and health}

\begin{tabular}{|l|l|}
\hline A. ELECTRICAL (LOCKOUT/TAGOUT) & RISK RATING: N/A \\
\hline Not Part of
\end{tabular}

Not part of this technology.

B. FIRE AND EXPLOSION RISK RATING: 3

The PCRS- $5 / 7$ is flammable and can create a potential explosion hazard. No ignition sources should be allowed in the area where the chemical is being used or stored. Fire may be extinguished with water spray or fog, foam, carbon dioxide, or dry chemical, in accordance with the manufacturer's MSDS.

\begin{tabular}{l|l}
\hline C. CONFINED SPACE ENTRY & RISK RATING: 1
\end{tabular}

Not part of this technology unless the specific location where chemical is being used is a confined space. In this case, precautionary air monitoring and respiratory protection need to be taken into account. A confined space entry plan will need to be developed before the job is begun.
D. MECHANICAL HAZARDS
RISK RATING: N/A

Not part of this technology.

E. PRESSURE HAZARDS RISK RATING: N/A

Not part of this technology. 


\begin{tabular}{|c|c|}
\hline F. TRIPPING AND FALLING & RISK RATING: 4 \\
\hline \multicolumn{2}{|c|}{$\begin{array}{l}\text { There is an extreme slipping/fall hazard created by the chemical dripping or splashing } \\
\text { on the walking surface. Walking on the surface after the chemical has dripped or } \\
\text { spilled needs to be avoided. Special anti-slip soles on the chemical protective boots } \\
\text { need to be considered. }\end{array}$} \\
\hline G. LADDERS AND PLATFORMS & RISK RATING: N/A \\
\hline \multicolumn{2}{|l|}{ Not part of this technology. } \\
\hline H. MOVING VEHICLES & RISK RATING: N/A \\
\hline \multicolumn{2}{|l|}{ Not part of this technology. } \\
\hline 1. BURIED UTILITIES, DRUMS, AND TANKS & RISK RATING: N/A \\
\hline \multicolumn{2}{|l|}{ Not part of this technology. } \\
\hline J. PROTRUDING OBJECTS & RISK RATING: N/A \\
\hline \multicolumn{2}{|l|}{ Not part of this technology. } \\
\hline K. GAS CYLINDERS & RISK RATING: N/A \\
\hline \multicolumn{2}{|l|}{ Not part of this technology. } \\
\hline L. TRENCHING AND EXCAVATIONS & RISK RATING: N/A \\
\hline \multicolumn{2}{|l|}{ Not part of this technology. } \\
\hline M. OVERHEAD LIFTS & RISK RATING: N/A \\
\hline \multicolumn{2}{|l|}{ Not part of this technology. } \\
\hline N. OVERHEAD HAZARDS & RISK RATING: N/A \\
\hline
\end{tabular}




\section{SECTION 6: ASSOCIATED HEALTH HAZARDS}

\begin{tabular}{|l|l|}
\hline A. INHALATION HAZARD & RISK RATING: 3 \\
\hline
\end{tabular}

Organic vapors are produced during application and removal of the PCRS. Even at low levels, these have the potential to cause headache, skin irritation, and respiratory tract irritation. The aluminum silicate may present a concern when the chemical is allowed to dry.

B. SKIN ABSORPTION RISK RATING: 3

The PCRS-5/7 is a concern for skin exposure. The chemical may be absorbed into the body through the skin and may cause skin irritation and prolonged exposure may cause burns, in accordance with the manufacturer's MSDS.

\begin{tabular}{l|l}
\hline C. HEAT STRESS & RISK RATING: 4 \\
\hline Atmospenic
\end{tabular}

Atmospheric conditions, work rate, PPE levels, etc. must be considered.

D. NOISE RISK RATING: N/A

Not a part of this technology.

\begin{tabular}{l|l}
\hline E. NON-IONIZING RADIATION & RISK RATING: N/A
\end{tabular}

Not part of this technology.

\begin{tabular}{l|l}
\hline F. IONIZING RADIATION & RISK RATING: N/A
\end{tabular}

Not part of this technology, but may be associated with the surface being treated.

\begin{tabular}{l|l}
\hline G. COLD STRESS & RISK RATING: 1 \\
\hline
\end{tabular}

Technology does not produce a hazard, but ambient conditions need to be considered.

\begin{tabular}{|l|l}
\hline H. ERGONOMIC HAZARDS & RISK RATING: 3 \\
\hline
\end{tabular}

Poses ergonomic hazards associated with lifting, bending, twisting, stooping and kneeling. These may cause injury/strain to the back, knees, hips and/or legs.

I. OTHER

RISK RATING: N/A

None noted.

\begin{tabular}{l}
\hline SECTION 7: PHASE ANALYSIS \\
\hline A. CONSTRUCTION/START-UP \\
\hline The set-up/start-up phase presents predominantly ergonomic hazards from lifting and \\
carrying the buckets of PCRS to be applied to the surface. There is the potential for \\
exposure to the chemical when the lids are removed from the buckets to mix and \\
prepare the chemical for application.
\end{tabular}




\begin{tabular}{|l|}
\hline B. OPERATION \\
\hline $\begin{array}{l}\text { The operational phase presents the potential for exposure to the chemical both } \\
\text { during application and removal. There are also ergonomic stressors associated with } \\
\text { bending, kneeling, and stopping during application and removal. }\end{array}$ \\
\hline C. MAINTENANCE \\
\hline There are no maintenance activities associated with this technology. \\
\hline D. DECOMMISSIONING \\
\hline $\begin{array}{l}\text { After the coating has been removed from the surface by the chemical, it will need to } \\
\text { be assured that the surface is "clean" of both PCRS residue and whatever } \\
\text { contaminant was originally present on the surface. Precautions need to be taken to } \\
\text { assure the chemical is not tracked from one area to another during clean-up and that } \\
\text { all water runoff from clean up is contained and disposed of appropriately. }\end{array}$ \\
\hline
\end{tabular}

\begin{tabular}{|l|}
\hline SECTION 8: HEALTH AND SAFETY PLAN REQUIRED ELEMENTS \\
\hline A. AIR MONITORING \\
\hline Environmental conditions such as air temperature, radiant heat load, and ventilation \\
in the area can affect how rapidly the organic solvent mixture vaporizes and \\
therefore, the exposure level at any given time. The exposure level (vapor build-up) \\
will also be affected by the size of area where the PCRS is being used. A monitoring \\
plan will need to be developed for the specific site and job where the chemical is \\
being used. If circumstances are such that the chemical may dry before removal, \\
aluminum silicate, as total dust, may need to be monitored for also. \\
\hline B. WORKER TRAINING \\
\hline Training that would apply to the use of the PCRS may include but not be limited to: \\
Hazardous Waste Operations and Emergency Response (HAZWOPER), Hazard \\
Communication (HAZCOM), Respiratory Protection, Personal Protective Equipment, \\
Ergonomics (proper lifting, bending, kneeling, stooping), Heat Stress, CPR/First \\
Aid/Emergency Response/Bloodborne Pathogens, Construction Safety (OSHA 500) \\
and/or General Industry Safety (OSHA 501), and job specific training for application \\
and removal of the PCRS. Scaffolding safety training will be required, as needed. \\
\hline
\end{tabular}




\section{EMERGENCY RESPONSE}

Emergency response planning for a site needs to assure adequate coverage for hazards described in the TSDS. Having at least one person per shift trained in CPR and first aid is recommended.

All precautions used when responding to an emergency situation at the site will apply. The PCRS- $5 / 7$ is flammable and is $85 \%$ volatile by volume. Its products of decomposition may include carbon dioxide, carbon monoxide, and oxides of nitrogen. In accordance with the MSDS a fire involving the PCRS-5/7 should be extinguished with water spray or fog, foam, carbon dioxide, or dry chemical. This information needs to be conveyed to both on-site and off-site emergency response personnel before a situation occurs that involves the PCRS.

D. MEDICAL SURVEILLANCE

Evaluation of personnel's general health in accordance with 29 CFR 1910.120, with emphasis on the cardiovascular and respiratory system; back, knees and legs; and central and peripheral nervous systems. In addition, any medical surveillance required by the OSHA standards must be provided.

E. INFORMATIONAL PROGRAM

Workers must be trained in specific application and removal of the PCRS.

Additionally, they must be trained in accordance with 29 CFR 1910.1200, Hazard Communication.

\section{SECTION 9: COMMENTS AND SPECIAL CONSIDERATIONS}

Only personnel who have been adequately trained in the application and removal, as well as the hazards associated with the PCRS, should be permitted to work with it.

Consideration needs to be given to the compatibility of PPE with the specific chemical being used. 


\section{SECTION 7 - EMERGENCY RESPONSE/PREPAREDNESS}

The use of the PCRS technology would not be applicable for use in an emergency response situation.

Emergency response/preparedness must be part of every hazardous waste site safety and health plan. In addition to credible site emergencies, site personnel must plan for credible emergencies in connection with the PCRS.

All precautions used when responding to an emergency situation at the site will apply. The PCRS- $5 / 7$ is flammable and is $85 \%$ volatile by volume. Its products of decomposition may include carbon dioxide, carbon monoxide, and oxides of nitrogen. In accordance with the MSDS, a fire involving the PCRS-5/7 should be extinguished with water spray or fog, foam, carbon dioxide, or dry chemical. This information needs to be conveyed to both on-site and off-site emergency response personnel before a situation occurs that involves the PCRS.

\section{SECTION 8 - REGULATORYIPOLICY ISSUES}

The site safety and health personnel where the PCRS technology is being used need to be concerned with safety and health regulations applicable to the issues discussed above. Regulations that apply may be divided into four categories. Core requirements are those regulations that would apply to any hazardous waste work site, regardless of the type of job. Technology specific requirements are those regulations that apply due to the specific technology being used. Special requirements are standards and policies that are specific to the technology itself and are required by reference in a regulation. Best management practices are not required, but are recommended by organizations such as the American National Standards Institute (ANSI), NIOSH, Department of Energy (DOE), National Fire Protection Association (NFPA), etc. These regulations/standards may include but not be limited to the following:

\section{Core requirements:}

$\checkmark \quad$ OSHA 29 CFR 1926.25 Housekeeping

- OSHA 29 CFR 1910.141 Sanitation (1910.141(a)(3) covers housekeeping)

- OSHA 29 CFR 1926 Subpart Z Toxic and Hazardous Substances

OSHA 29 CFR 1910 Subpart Z Toxic and Hazardous Substances

OSHA 29 CFR 1926.59 Hazard Communication 
- OSHA 29 CFR 1910.1200 Hazard Communication OSHA 29 CFR 1926.64 Process Safety Management of Highly Hazardous Chemicals

OSHA 29 CFR 1910.119 Process Safety Management of Highly Hazardous Chemicals

OSHA 29 CFR 1926.65 Hazardous Waste Operations and Emergency Response

- OSHA 29 CFR 1910.120 Hazardous Waste Operations and Emergency Response

- Occupational Safety and Health Act 1970(5)(a)(1) General Duty Clause Technology Specific Requirements:

- OSHA 29 CFR 1926 Subpart L Scaffolding

- OSHA 29 CFR 1910.28 Safety Requirements for Scaffolding

- OSHA 29 CFR 1926 Subpart X Ladders

- OSHA 29 CFR 1910 Subpart D Ladders

- OSHA 29 CFR 1926.103 Respiratory Protection

- OSHA 29 CFR 1910.134 Respiratory Protection

$\checkmark \quad$ OSHA 29 CFR 1926.102 Eye and Face Protection

- OSHA 29 CFR 1910.133 Eye and Face Protection

OSHA 29 CFR 1926.28 Personal Protective Equipment

$\checkmark \quad$ OSHA 29 CFR 1910.132 General Requirements (Personal Protective Equipment)

- OSHA 29 CFR 1926.23 First Aid and Medical Attention 


\section{$\checkmark \quad$ OSHA 29 CFR 1910.151 Medical Services and First Aid}

\section{Best Management Practices:}

ACGIH Threshold Limit Values for Chemical Substances and Physical Agents and Biological Exposure Indices

In addition to the above regulations and policies, it is imperative that all workers have appropriate and adequate training for the task and associated safety and health hazards. Training that would be required may be divided into four categories. Core training is that which is required for anyone entering a hazardous waste site to perform work, regardless of the type of job. Technology specific training is that training that is specific to the technology and required by safety and health standards. Special training is that which is specific to the technology to assure the worker is adequately trained for the task, but is not necessarily required by safety and health standards. Best management practices are trainings that while not mandated by health and safety standards, provide information and knowledge to the worker that will allow the worker to perform his/her job safely. Training to be applied for the centrifugal shot blast technology may include but not be limited to:

\section{Core Training Requirements:}

\section{$\checkmark \quad$ HAZWOPER \\ $\checkmark \quad$ HAZCOM}

\section{Technology Specific Training:}

$\checkmark \quad$ Ladder Safety

$\checkmark \quad$ Scaffolding Safety

- Respiratory Protection

- Personal Protective Equipment

Special training:

- Job specific training for chemical application and removal 


\section{Best Management Practice training:}

- Ergonomics (proper lifting, bending, stooping, kneeling, safe shoveling techniques)

- Heat stress (learning to recognize signs and symptoms)

- CPR/First Aid/Emergency Response/Blood-borne Pathogens

- Construction Safety (OSHA 500) and or General Industry Safety (OSHA 501)

\section{SECTION 9 - \\ OPERATIONAL CONSIDERATIONS \& RECOMMENDATIONS}

Recommendations made here for improved worker safety and health take into consideration the use of the PCRS-5/7. Specific recommendations include:

- Work practices are of critical importance for worker exposure to the chemical being applied to and removed from the coated surface. Application and removal is a difficult process to accomplish without the worker coming in contact with the chemical. Training the worker to use the best work practices possible will help to alleviate some of these concerns. Examples of the types of work practices that are of concern include:

1. Close all containers, both storage and waste, when not in use. This will keep the chemical from adding to the vapor load in the area where the work is being conducted.

2. Assure all PPE chosen is compatible with the chemical. An impervious apron (as recommended by the MSDS) is of no use if the material it is made of is incompatible with the chemical being used. Additional consideration needs to be given to the PPE used under the apron. If the chemical comes in contact with the garment under the apron and it is not compatible with the chemical, it is of no use.

3. All workers need to be trained in the specific hazards associated with the chemical and work practices should reflect avoidance of exposure or reducing the risk of exposure. For example, the organic solvent mixture is an eye irritant. Workers wearing goggles should never touch or remove the goggles while in the work area, 
nor should they touch or remove the goggles until their gloves that are contaminated with chemical are removed and their hands have been decontaminated. Additionally, touching the goggles with contaminated gloves increases the likelihood of getting the chemical on the face and head.

4. The chemical made the walking surface extremely slippery. Training workers to apply and remove the chemical to eliminate dripping and over spraying would reduce the risk of slipping and falling. Additionally, the waste containers should be placed in a location where workers do not have to walk on the slippery surface to get to them. This would also reduce the potential to have the chemical tracked onto "clean" areas. Workers should never move from the work area (exclusion zone) to the clean area (support zone) without proper decontamination.

- PPE must be chosen that is compatible with the hazards and the job.

Chemically impervious suits, aprons, gloves, and boots will be useless if the material they are made from is not compatible with the chemical. Consideration must also be given to special hazards that may be encountered. For example, normal chemical protective boots are inadequate during PCRS application and removal because of the extremely slippery surface conditions it creates. Special anti-slip soles need to be considered.

- Due to the open outdoor environment in which the testing demonstration took place and therefore, the organic vapor monitoring, it is recommended that additional monitoring be conducted when the PCRS is applied and removed in an enclosed environment similar to environments in which it would be used at a hazardous waste clean-up site. Additionally, monitoring needs to be conducted, as appropriate, for the individual ingredients of the organic solvent mixture.

- The chemical had been applied to the wall/ceiling with a spraying application but there was not an opportunity to observe this. It was noted however, that there was a lot of over spray on adjoining surfaces. Workers spraying the chemical need to be aware of the potential for over spray and take the proper precautions. After the initial removal of the chemical, it was decided to do a second application of the chemical. When spraying was started, chemical began to ooze from ruptured areas of the hose line. The hose was replaced but the same situation occurred. Upon closer inspection of the hose, the hose had separated along several discolored areas. It appeared that the chemical which had been in the hose from the previous application had started to degrade the hose. It must always be assured that the material the hose is made of is compatible with the chemical being applied. 
Since it was not possible to apply the chemical by spraying, it was applied using spatulas. Using spatulas caused a lot of dripping onto the walking surface. This increases the potential for workers to come into contact with the chemical and causes the walking surface to become extremely slippery. Workers need to be trained to use work practices to apply the chemical that cause the least amount of dripping and splashing, to clean up the walking surface as needed, and to avoid areas of the walking surface where dripping spills have occurred.

In addition, using spatulas and paint scrapers with short handles causes the chemical to come up over the tool and handle onto the workers gloves. This also increases the potential for exposure and would be eliminated by the use of longhandled tools.

There is concern with the ergonomic stressors placed on the worker during both application and removal of the chemical. The chemical was applied to the wall and ceiling using a spatula and removed using a paint scraper for the locations where the removal with the laminated paper was not complete. To reach the lower part of the wall personnel worked from ground level. To reach the upper portion of the wall, personnel worked from a ladder. There is the potential for sprain/strain to the back, shoulders, knees, and legs from the bending, kneeling, or stooping required to reach the lower section of the wall. When working from a ladder there is the potential for sprain/strain to the back, shoulders, and neck from reaching and from working with the arms extended above the head and the neck for long periods of time. Removal of the chemical with a paint scraper presents the same type of ergonomic stressors. Using ergonomically designed tools and long-handled tools would help to lessen and possibly eliminate many of the ergonomic stressors. In addition to other safety and health concerns, the use of scaffolding instead of a ladder to reach the upper wall and ceiling would help to alleviate some of the ergonomic stressors discussed above.

- There were several areas on the wall/ceiling where the laminated paper had fallen off and the chemical had become dry. When the dry chemical and coating were removed with a paint scrapper, dust was visible. Air sampling for total dust, respirable dust, and/or constituents of the coating and chemical needs to be conducted when dry chemical is removed.

- Reaching the upper portion of the wall and the ceiling requires a ladder or scaffolding. A ladder is not an appropriate method for reaching these areas unless the bucket containing the chemical is hoisted up to the worker on the ladder. The worker should never climb a ladder while carrying objects of any type in his/her hand(s). Additionally, the worker must be able to maintain three- 
points of contact at all times while on the ladder and should never reach too far to the side or behind himself/herself to perform a task.

Scaffolding is recommended as a better alternative for reaching the upper wall and ceiling. Reaching the top portion of the wall requires the use of scaffolding. Proper precautions must be taken including compliance with the OSHA scaffold standard. No one should be permitted to work in the area of the scaffolding without a hard hat. 


\section{APPENDIX A \\ REFERENCES}

Occupational Safety and Health Standards for General Industry, 29 CFR Part 1910, Occupational Safety and Health Administration United States Department of Labor

Occupational Safety and Health Standards for the Construction Industry, 29 CFR Part 1926, Occupational Safety and Health Administration United States Department of Labor

Threshold Limit Values(TLV's) for Chemical Substances and Physical Agents and Biological Exposure Indices (BEl's), American Conference of Governmental Industrial Hygienists, 1995-1996

ANSI 1986, Guide for the Measurement and Evaluation of Human Exposure to Vibration Transmitted to the Hand, New York, NY: American National Standards Institute, ANSI S3.34

U.S. Department of Health and Human Services, Manual for the Revised NIOSH Lifting Equation, January 1994 